UNIVERSIDADE DE BRASÍLIA

FACULDADE DE TECNOLOGIA

DEPARTAMENTO DE ENGENHARIA MECÂNICA

PROJETO DE PLATAFORMA DE ANÁLISE DE CONVERSÃO DE TRAÇÃO DE VEÍCULOS COM MOTOR A COMBUSTÃO INTERNA PARA TRAÇÃO ELÉTRICA

MARCOS DE OLIVEIRA COSTA

ORIENTADOR: RUDI HENRI van ELS COORIENTADOR: CARLOS HUMBERTO LLANOS QUINTERO

\author{
DISSERTAÇÃO DE MESTRADO \\ EM SISTEMAS MECATRÔNICOS
}

PUBLICAÇÃO: ENM.DM - 081/2015 
BRASILIA/DF: FEVEREIRO - 2015

UNIVERSIDADE DE BRASÍLIA

FACULDADE DE TECNOLOGIA

DEPARTAMENTO DE ENGENHARIA MECÂNICA

PROJETO DE PLATAFORMA DE ANÁLISE DE CONVERSÃO DE TRAÇÃO DE VEÍCULOS COM MOTOR A COMBUSTÃo INTERNA PARA TRAÇÃO ELÉTRICA

MARCOS DE OLIVEIRA COSTA

DISSERTAÇÃO SUBMETIDA AO DEPARTAMENTO DE ENGENHARIA MECÂNICA DA FACULDADE DE TECNOLOGIA DA UNIVERSIDADE DE BRASÍlIA-UNB, COMO PARTE DOS REQUISITOS NECESSÁRIOS PARA OBTENÇÃO DO GRAU DE MESTRE EM SISTEMAS MECATRÔNICOS.

APROVADA POR:

Prof. Dr. Rudi Henri van Els, UnB (Orientador)

Prof. Dr Daniel Mauricio Muñoz Arboleda, UnB (Examinador Interno)

Prof. Dr. Henrique Gomes de Moura, UnB (Examinador Externo)

BRASÍLIA/DF, 12 DE FEVEREIRO DE 2015. 
FICHA CATALOGRÁFICA

\section{COSTA,, MARCOS DE OLIVEIRA}

Projeto de plataforma de análise de conversão de tração de veículos com motor a combustão interna para tração elétrica. [Distrito Federal] 2015.

xvii, 96p., 210 x 297 mm (ENM/FT/UnB, Mestre, Sistemas Mecatrônicos, 2015).

Dissertação de Mestrado - Universidade de Brasília, Faculdade de Tecnologia.

Departamento de Engenharia Mecânica.

1. Veículo elétrico

3. Tração elétrica

I. ENM/FT/UnB
2. Conversão

4. Plataforma de análise

II. Título (série)

\section{REFERÊNCIA BIBLIOGRÁFICA}

COSTA, M. DE O. (2015). Projeto de plataforma de análise de conversão de tração de veículos com motor a combustão interna para tração elétrica. Dissertação de Mestrado em Sistemas Mecatrônicos, Publicação ENM.DM - 081/15, Departamento de Engenharia Mecânica, Universidade de Brasília, Brasília, DF, 96p.

\section{CESSÃO DE DIREITOS}

AUTOR: Marcos de Oliveira Costa

TÍTULO: Projeto de plataforma de análise de conversão de tração de veículos com motor a combustão interna para tração elétrica.

GRAU: Mestre

ANO: 2015

É concedida à Universidade de Brasília permissão para reproduzir cópias desta dissertação de mestrado e para emprestar ou vender tais cópias somente para propósitos acadêmicos e científicos. $\mathrm{O}$ autor reserva outros direitos de publicação e nenhuma parte dessa dissertação de mestrado pode ser reproduzida sem autorização por escrito do autor.

Marcos de Oliveira Costa

QE 19 Conj. E Guará-II

CEP 71050-053 Distrito Federal 
Dedico este trabalho a minha esposa Cida e aos meus filhos Arthur e Daniel, pela paciência, apoio e compreensão durante toda a minha jornada. 


\section{Agradecimentos}

Ao meu orientador, professor Dr. Rudi van Els, agradeço pelo apoio e incentivo.

Ao meu co-orientador, o professor Dr. Humberto Llanos pelo apoio e paciência durante todo o período de curso.

Agradeço também aos grandes amigos do Laboratório de Automotiva da FGA, aos alunos da disciplina Projeto Integrador II, que plantaram a semente desse trabalho, a empresa Barros Automóveis por ceder a estrutura para a primeira etapa da conversão, aos colegas do GRACO, aos alunos Fred Aragão e Felipe Soares pelo valioso e indispensável apoio.

Aos colegas do MCTI, Eduardo Soriano, Rafael Menezes, Pedro Borges, Joao Bin, José Silvério, Elzivir Guerra e todos os colegas da SETEC, ao grande companheiro José Manoel e aos colegas da GIZ.

Muito obrigado a todos! 


\section{LISTA DE SIGLAS E ABREVIAÇÕES}

ABNT

ABVE

BEV

BMWi

C

CLP

CPU

$\mathrm{CV}$

D

DC

DEMIC-FEEC

eNterop

ECE

EUDC

EV

FCEV

UNICAMP

FEI

FINEP

HEV

HIS

ICE

IEC

IEEE

IGBT
Associação Brasileira de Normas Técnicas

Associação Brasileira do Veículo Elétrico

Battery Electric Vehicle

Bundesministerium für Wirtschaft und

Energie

Capacitor

Controlador Lógico Programável

Unidade Central de Processamento

Cavalo Vapor

Diodo

Direct Current (Corrente Contínua)

Departamento de Eletrônica e

Microeletrônica

Projeto de interoperabilidade de carros

elétricos

Urban Driving Cycles

Extra-urban driving cycles

Electric Vehicle

Fuel Cell Vehicle

Universidade Estadual de Campinas

Faculdade de Engenharia Industrial

Financiadora de Estudos e Projetos

Hybrid Electric Vehicle

Hardware-in-the-loop

Internal Combustion Engine

International Electrotechnical Commission

Instituto de Engenheiros Eletricistas e

Eletrônicos

Insulated Gate Bipolar

Transistor ( Transistor Bipolar de porta

Isolada) 
IHM/HMI

IP

ISET-Lib

IWES

NBR

PC

PLC

PNI

PWM

$\mathrm{R}, \mathrm{S}, \mathrm{T}$

SAE

SI

Systec

TPE

$\mathrm{U}, \mathrm{V}, \mathrm{W}$

UL

$\mathrm{UnB}$

V2G
Interface Homem-Máquina

Grau de Proteçao Elétrica

Software de simulação de baterias de ions de lítio

Institut für Windenergie und

Energiesystemtechnik

Norma Brasileira

Personal Computer

Power Line Communication

Grid Integration Research

Modelação por Largura de Pulso

Tensão trifásica de entrada

Society of Automotive Engineers

Sistema Internacional de Unidades

Test Centre for Inteligent Networks and

Eletromobility

Electromobility Test and Proving Centre

Tensão trifásica de saída

Underwriters Certificação internacional

Universidade de Brasília

Vehicle-to-Grid 


\section{LISTA DE SIMBOLOS}

\begin{tabular}{|c|c|c|}
\hline Simbolo & Descrição & Unidade \\
\hline “ & polegadas & Pol \\
\hline$a$ & Aceleração & $m / s^{2}$ \\
\hline$A C$ & Alternating Current (Corrente Alternada) & $V a c$ \\
\hline$A f$ & Área frontal & $m^{2}$ \\
\hline$c c$ & Cilindrada & $\mathrm{cm}^{3}$ \\
\hline$C C$ & Corrente contínua & $A$ \\
\hline$C n$ & Conjugado Nominal & $\mathrm{Nm}$ \\
\hline$C p$ & Conjugado de Partida & $\mathrm{Nm}$ \\
\hline $\mathrm{Cr}$ & Coeficiente de Resistência ao Rolamento & \\
\hline$c v$ & Cavalo Vapor & $C v$ \\
\hline$C x$ & Coeficiente de Arrasto Aerodinâmico & \\
\hline$D C$ & Direct Current (Corrente Contínua) & $A$ \\
\hline$F$ & Força & $N$ \\
\hline$f$ & Frequência & $\mathrm{Hz}$ \\
\hline$F A$ & Força de Arrasto & $N$ \\
\hline Fad & Força Aerodinâmica & $N$ \\
\hline$f b$ & frequência de base & $H z$ \\
\hline$F i$ & Força de Inércia & $N$ \\
\hline$F p$ & Fator de Potência & Adimensional \\
\hline$F P$ & Fator de proteção & \\
\hline Frr & Força de resistência ao rolamento & $N$ \\
\hline$F t$ & Força de Tração & $N$ \\
\hline$g$ & Grama & $g$ \\
\hline$h p$ & Horse power & $h p$ \\
\hline$I$ & Ampere & $A$ \\
\hline$i c$ & Inércia do câmbio & \\
\hline Id & Corrente de disparo & $A$ \\
\hline id & Inércia do diferencial & \\
\hline In/Inom & Corrente Nominal & $A$ \\
\hline$I p$ & Corrente de partida & $A$ \\
\hline$J$ & Momento de inércia & $\mathrm{kg} / \mathrm{m}^{2}$ \\
\hline
\end{tabular}




\begin{tabular}{|c|c|c|}
\hline$J m$ & Inércia do motor & $\mathrm{kg} / \mathrm{m}^{2}$ \\
\hline$J r$ & Inércia das rodas & $\mathrm{kg} / \mathrm{m}^{2}$ \\
\hline$J t$ & Inércia da transmissão & $\mathrm{kg} / \mathrm{m}^{2}$ \\
\hline$K$ & Constante do motor elétrico & \\
\hline$k$ & Quilo $\left(1 \times 10^{3}\right)$ & Constante \\
\hline$K g f$ & Kilograma força & $K g f$ \\
\hline$K g f m$ & Kilograma força metro & $K g f m$ \\
\hline$K w h$ & Kilowatt hora & $W h$ \\
\hline$M$ & Massa & $G$ \\
\hline$M$ & Momento & $N m$ \\
\hline$m e$ & massa equivalente & $g$ \\
\hline$m m$ & Milímetro & $M m$ \\
\hline$P$ & Potência & $w$ \\
\hline$P b$ & Potência de base & $w$ \\
\hline$P m$ & Potência no motor & $w$ \\
\hline $\operatorname{Pr}$ & Potência na roda & $w$ \\
\hline$Q i$ & Resistência de inércia & $K g / m^{2}$ \\
\hline$r$ & Raio & $m$ \\
\hline$r d$ & raio dinâmico & $m$ \\
\hline Rpm & Rotações por minuto & $R p m$ \\
\hline$R t$ & Relação de transmissão & Adimensional \\
\hline$S$ & Escorregamento & $\%$ \\
\hline$t$ & Тетро & $s$ \\
\hline$T$ & Torque & $N m$ \\
\hline Tco & Tempo de acostamento & $s$ \\
\hline$T b$ & Tempo de frenagem & $s$ \\
\hline To & Teтро осіоso & $s$ \\
\hline$T c$ & Tempo de cruzeiro & $s$ \\
\hline temp & Temperatura & ${ }^{o} \mathrm{C}$ \\
\hline$T i$ & Teтро осіоso & $s$ \\
\hline$T m$ & Tração no motor & $N m$ \\
\hline $\operatorname{Tr}$ & Tração na roda & $N m$ \\
\hline$v$ & Velocidade & $m / s$ \\
\hline
\end{tabular}




\begin{tabular}{|c|c|c|}
\hline$V$ & Volts & $V$ \\
\hline$V / f$ & Relação tensão por frequência & \\
\hline$V b$ & Tensão de base & $V$ \\
\hline$w$ & Potência & $W$ \\
\hline$\alpha$ & Aceleração angular & $\mathrm{Rad} / \mathrm{s}^{2}$ \\
\hline$\delta$ & Momento equivalente & $\mathrm{kg} / \mathrm{m}^{2}$ \\
\hline$\varepsilon$ & Energia & Joule \\
\hline$\eta$ & Rendimento & Adimensional \\
\hline$\eta t$ & Rendimento & Adimensional \\
\hline$\theta$ & inclinação & $\operatorname{Graus}\left({ }^{o}\right)$ \\
\hline$\pi$ & $P i$ & Adimensional \\
\hline$\rho$ & Densidade do ar & $\mathrm{Kg} / \mathrm{m}^{3}$ \\
\hline$\tau$ & Trabalho & $\mathrm{Nm}$ \\
\hline$\Phi m$ & Fluxo magnético & Weber \\
\hline $\boldsymbol{\psi}$ & Aclive & $\operatorname{Graus}\left({ }^{\circ}\right)$ \\
\hline$\omega$ & Velocidade angular & $\mathrm{Rad} / \mathrm{s}$ \\
\hline
\end{tabular}




\section{LISTA DE FIGURAS}

Figura 1 - Tipos de motorização de veículo elétricos e híbridos ........................................... 1

Figura 2 - Forças atuantes em um veículo em movimento em um aclive............................... 11

Figura 3 - Transferência de movimento entre engrenagens ................................................ 16

Figura 4 - Configurações possíveis de motor(s) elétricos na tração ...................................... 20

Figura 5 - Gráfico tensão x Frequência.......................................................................... 23

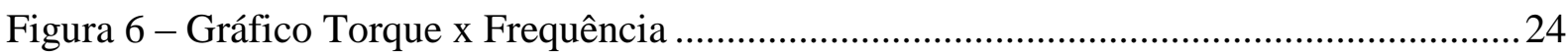

Figura 7 - Gráfico Potência x Frequência ...............................................................................24

Figura 8 - Disposição de motor dianteiro transversal ....................................................... 29

Figura 9 - Cofre do motor onde será instalado o motor elétrico …........................................ 31

Figura 10 - Vista Frontal do ponto onde será acoplado o motor elétrico com o flange ............32

Figura 11 - Vista em corte carcaça do motor refrigerado a água ...........................................35

Figura 12 - Fluxo de água no sistema de arrefecimento de circulação forçada ar-água de um

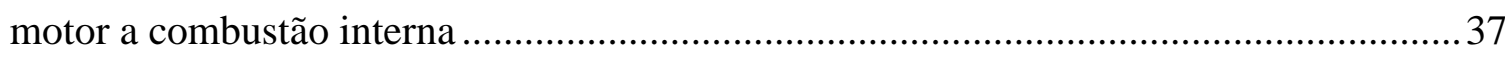

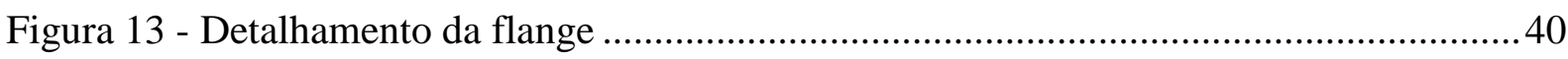

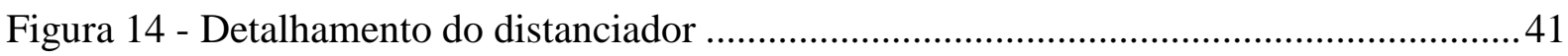

Figura 15 - Vista explodida do motor elétrico com flanges e acoplamento ............................. 41

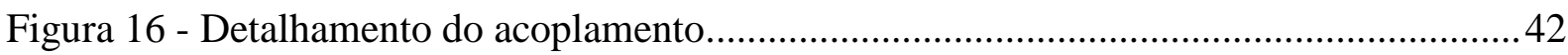

Figura 17 - Conjunto motor, flange, acoplamento e câmbio sendo montados ........................ 42

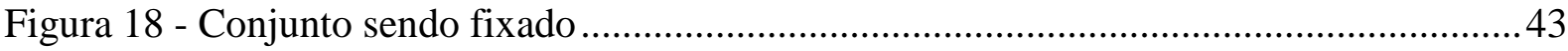

Figura 19 - Diagrama dos componentes da banca de ensaios.............................................4 44

Figura 20 - Trifilar das proteções da bancada de ensaios .....................................................46

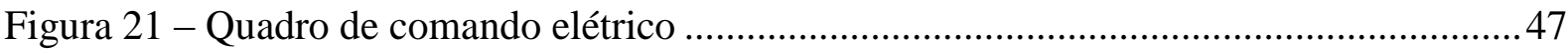

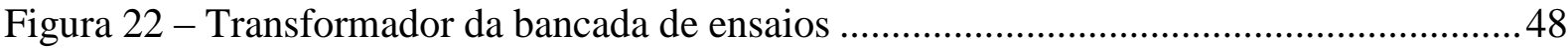

Figura 23 - Diagrama de um inversor de frequência típico .................................................49

Figura 24 - Tela do software Super Drive G2 …..........................................................5

Figura 25 - Foto da bancada elétrica montada .............................................................. 51 
Figura 26 - Princípio de funcionamento do dinamômetro de Corrente de Foucault

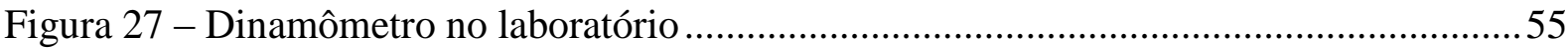

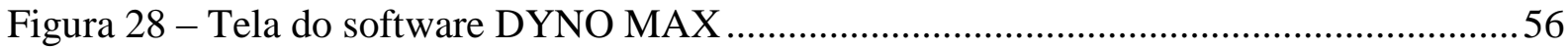

Figura 29 - Diagrama de blocos do funcionamento do Dinamômetro (A) com software (B)

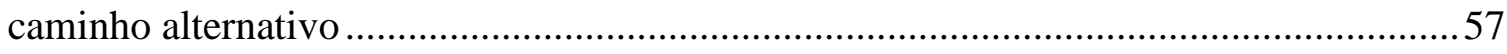

Figura 30 - Esquemático da instrumentação no dinamômento .................................................58

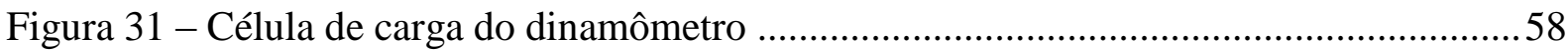

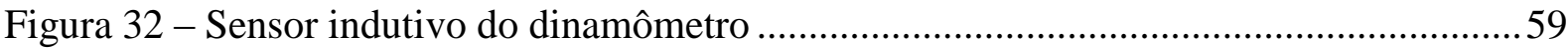

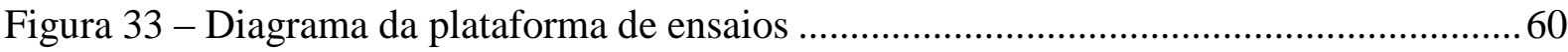

Figura 34 - Ilustração da disposição dos sensores .................................................................61

Figura 35 - Grafico da elevação da temperatura durante o ensaio..........................................62

Figura 36 - Curva de Torque e Potência do veículo .................................................................. 63

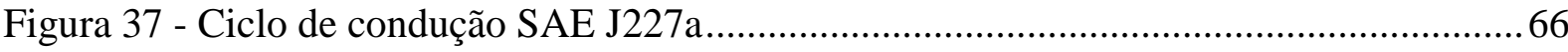

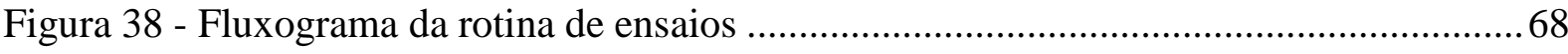

Figura 39 - Ciclo C SAE j227a - todos os parâmetros ............................................................... 70

Figura 40 - Ciclo C SAE J227a - Velocidade e Torque no Motor......................................... 71

Figura 41 - Ciclo C SAE J227a - Tensão e Corrente no Motor............................................... 72

Figura 42 - Ciclo C SAE J227a - Potência de saída no Motor ................................................... 73

Figura 43 - Ciclo C SAE J227a - Potência consumida no Motor em Kwh ............................. 73

Figura 44 - Ciclo D SAE J227a - Todos os parâmetros......................................................... 75

Figura 45 - Ciclo D SAE J227a - Velocidade e Torque no Motor ........................................ 76

Figura 46 - - Ciclo D SAE J227a - Tensão e Corrente no Motor ............................................ 77

Figura 47 - Ciclo D SAE J227a - Potência de saída no Motor ................................................ 78

Figura 48 - Ciclo D SAE J227a - Potência consumida no Motor ............................................78 


\section{LISTA DE TABELAS}

Tabela 1 - Dados comparativos de motores elétricos para tração..........................................21

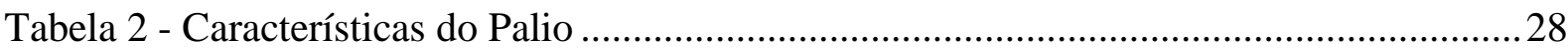

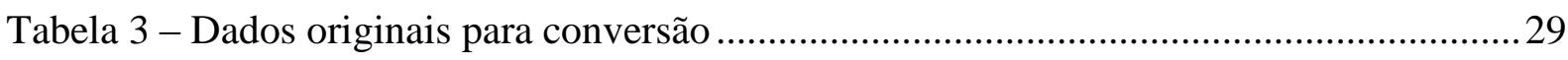

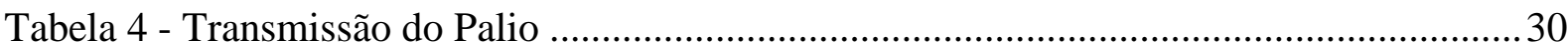

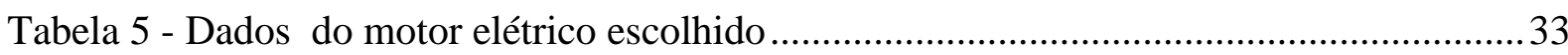

Tabela 6 - Vantagens do motor elétrico refrigerado a água............................................... 34

Tabela 7 - Dados de vazão e elevação de temperatura ......................................................... 35

Tabela 8 - Classificação de materiais e sistemas isolantes ................................................... 38

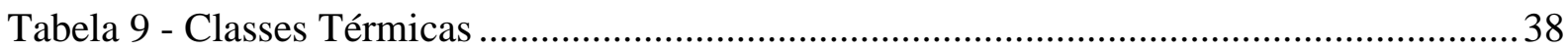

Tabela 10 - Composição da Temperatura em função da classe de isolamento .........................39

Tabela 11 - Dados do ensaio de torque e potência do veículo................................................. 64

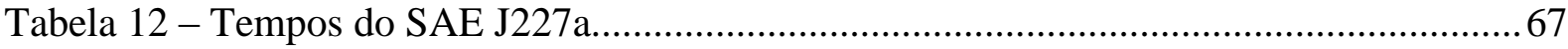

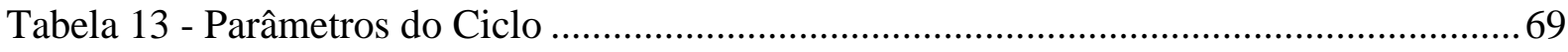

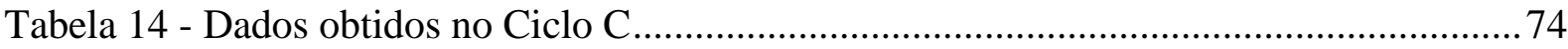

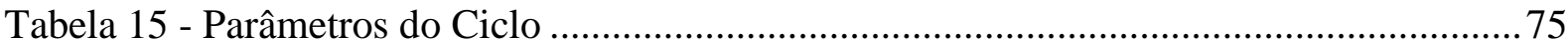

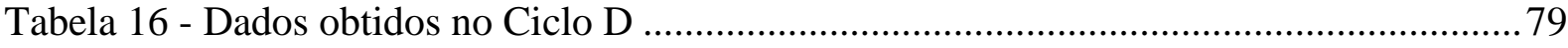


RESUMO

\title{
PROJETO DE PLATAFORMA dE ANÁliSE DE CONVERSÃO DE TRAÇÃO DE VEÍCULOS COM MOTOR A COMBUSTÃO INTERNA PARA TRAÇÃO ELÉTRICA.
}

\author{
Autor: Marcos de Oliveira Costa \\ Orientador: Rudi Henri van Els
}

Programa de Pós-graduação em Sistemas Mecatrônicos

Brasília, 12 de fevereiro de 2015

Este trabalho demonstra o projeto e a execução da plataforma de análise de conversão de veículos, dotados originalmente com motores a combustão interna, para tração elétrica. A metodologia consistiu de uma revisão bibliográfica de aspectos teóricos pertinentes para embasar a conversão da tração de um veículo, seguida do projeto e da execução de uma bancada como fonte de energia elétrica e estrutura de controle para o motor elétrico. Posteriormente, um dinamômetro de rolos foi associado. Diversos equipamentos para quantificação e análise das grandezas torque, potência, rendimento e consumo, foram integrados à bancada e ao dinamômetro, compondo assim, uma plataforma de análise. Um veículo Fiat Palio, convertido com um motor elétrico trifásico de indução refrigerado a água foi analisado na plataforma através do ciclo da SAE J227a. Concluiu-se então, que a plataforma insere-se em um ambiente altamente propício, pois permite avaliar, sob diversos aspectos, os veículos elétricos convertidos. Essa funcionalidade terá papel fundamental na formação de estudantes de engenharia e no desenvolvimento de projetos acadêmicos para mobilidade elétrica.

Palavras-chave: veículo elétrico; conversão; tração elétrica; plataforma de análise. 


\begin{abstract}
DEVELOPMENT OF A ANALYSIS PLATFORM TO ANALYZE THE TRANSFORMATION OF THE TRACTION OF A VEHICLE WITH INTERNAL COMBUSTION ENGINES TO ELECTRIC TRACTION.
\end{abstract}

\author{
Author: Marcos de Oliveira Costa \\ Supervisor: Rudi Henri van Els \\ Post-graduate program in Mechatronic Systems
}

Brasilia, February 12, 2015

This work demonstrates the design and implementation of vehicle conversion analysis platform, equipped originally with internal combustion engines to electric traction. The methodology consisted of a literature review of relevant theoretical aspects to support the conversion of traction of a vehicle, then the design and implementation of a bench as a source of power and control structure for the electric motor. Later, a dynamometer rollers was associated. Miscellaneous equipment for measurement and analysis of magnitudes torque, power, income and consumption, were integrated into the bench and dynamometer, making thus an analysis platform. A vehicle Fiat Palio, converted a three-phase electric induction motor cooled water was analyzed on the platform through the SAE J227a cycles. It was therefore concluded that the platform is inserted in a highly supportive environment because it allows evaluating, in many ways, the converted electric vehicles. This functionality will have a key role in training of engineering students and developing academic projects for electric mobility.

Keywords: electric vehicle; conversion; electric traction, analysis platform. 


\section{SUMÁRIO}

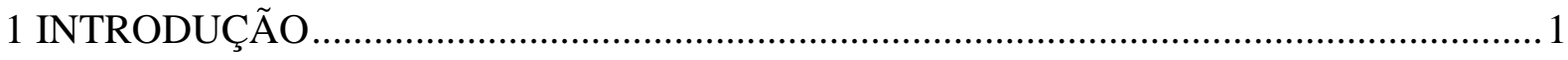

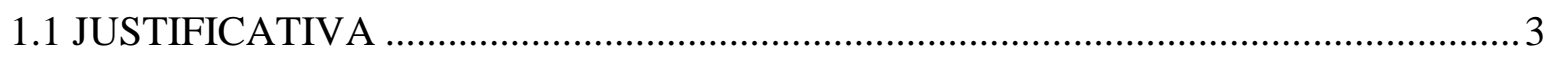

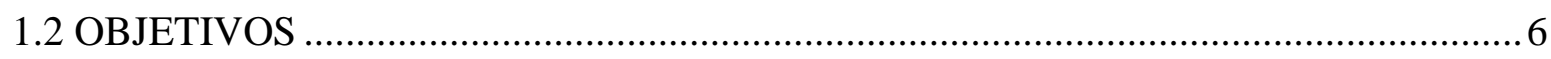

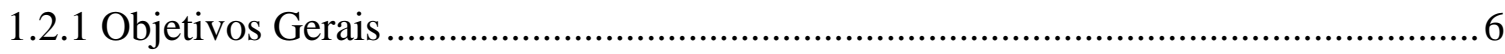

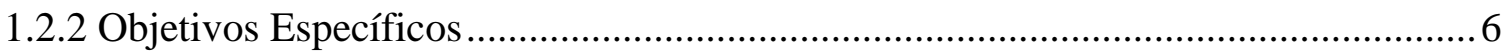

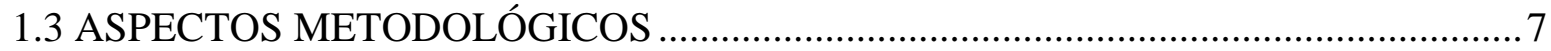

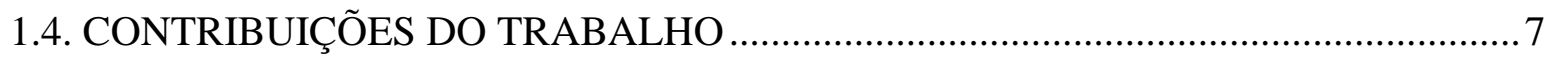

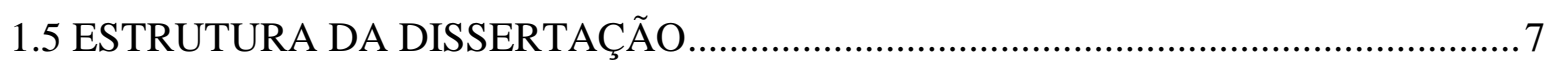

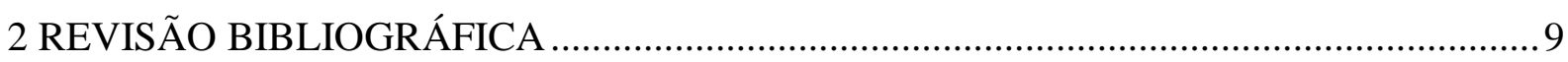

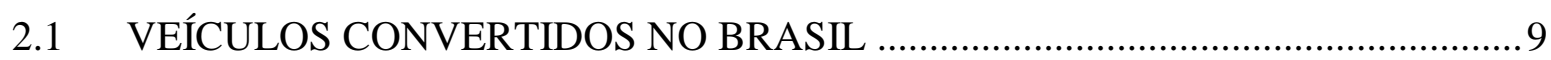

2.2 VEÍCULOS ELÉTRICOS DE FÁBRICA …………………........................................ 10

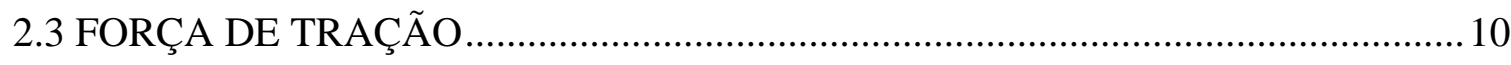

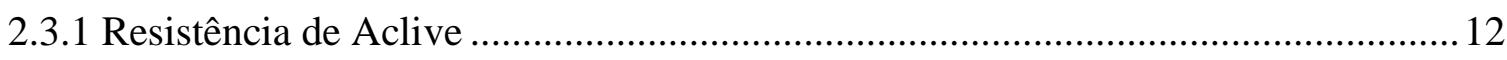

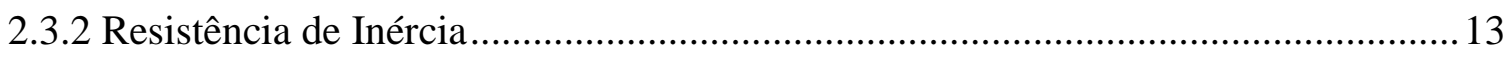

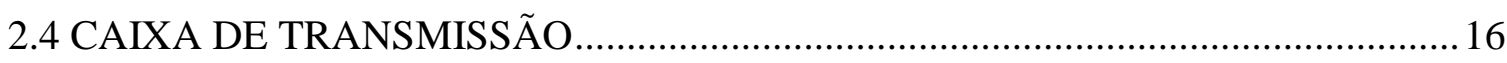

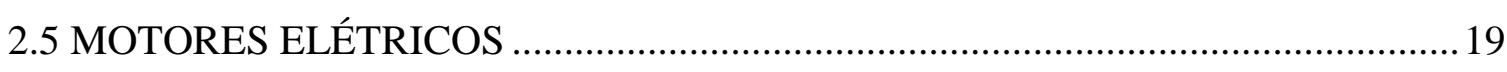

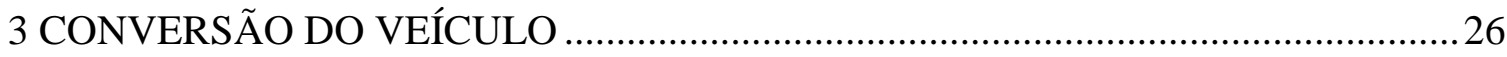

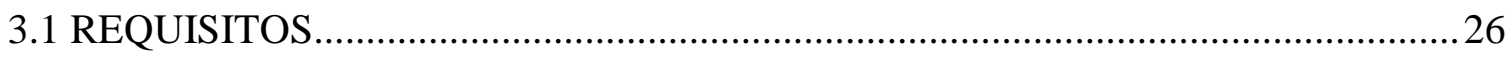

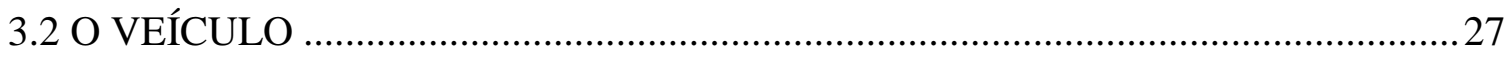

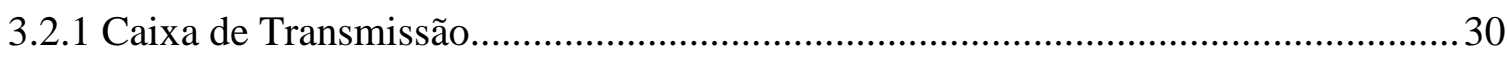

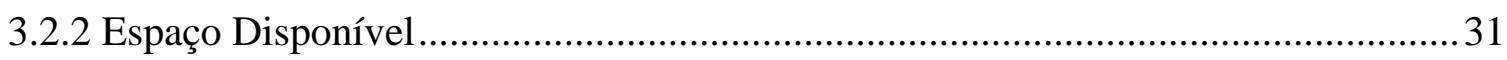

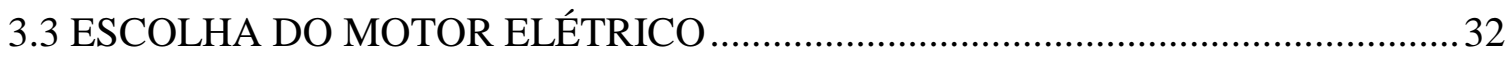

3.3.1 Motor Elétrico Refrigerado a Água...........................................................................3

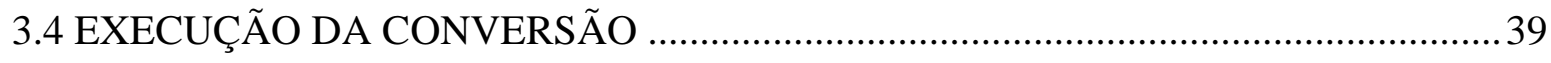

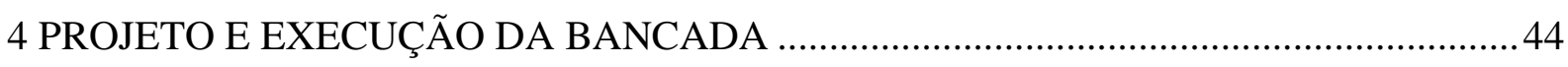

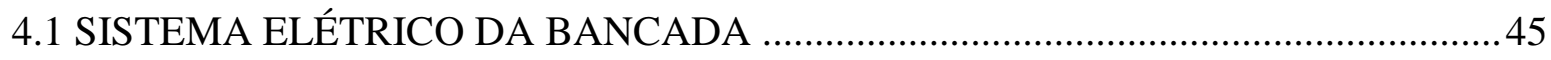

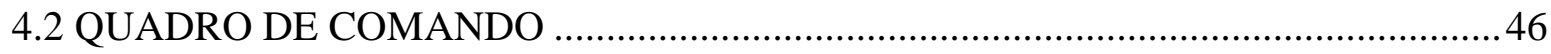

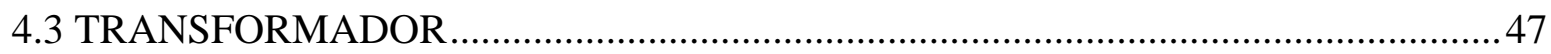

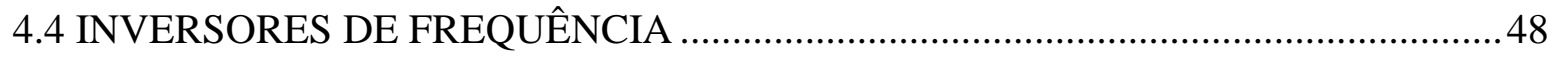

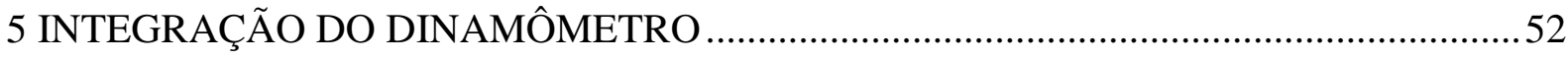

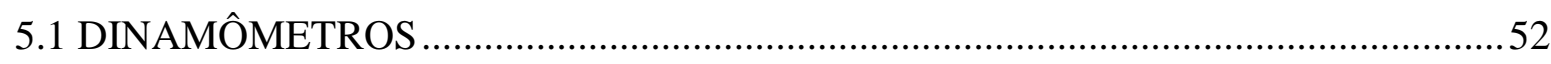


5.1.1 Dinamômetro De Correntes De Foucault ................................................................... 53

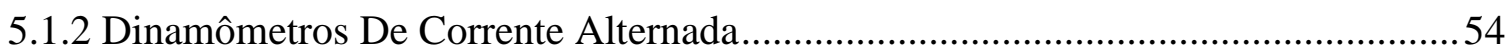

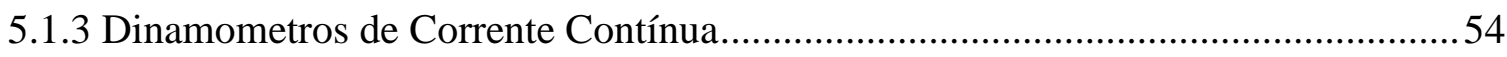

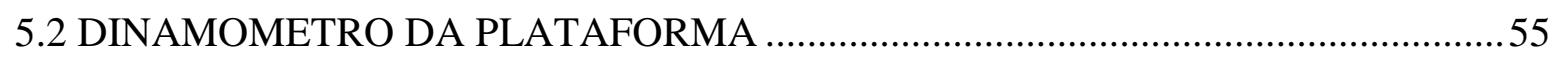

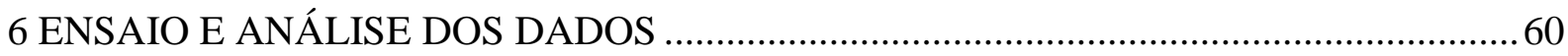

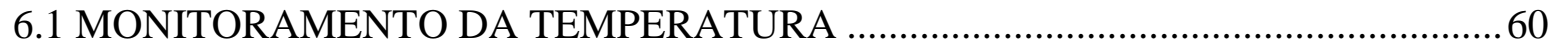

6.2 ANALISE DE TORQUE E POTENCIA NO DINAMÔMETRO ..............................63

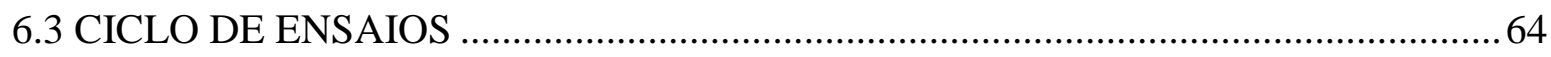

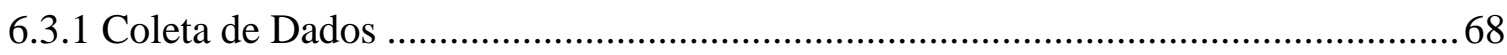

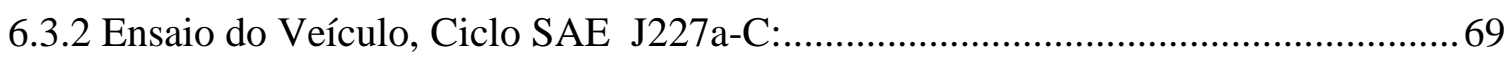

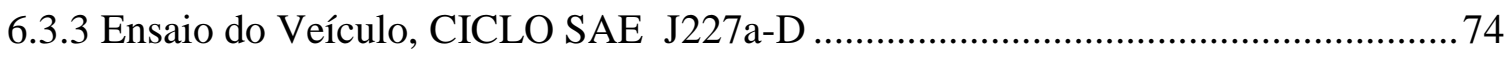

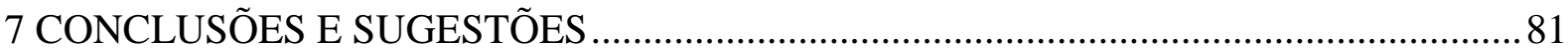

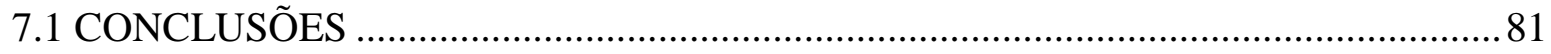

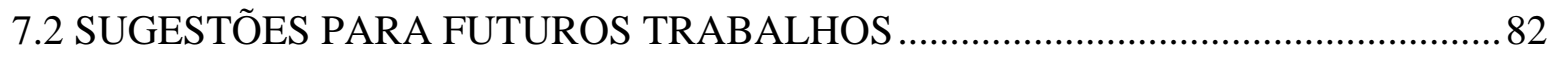

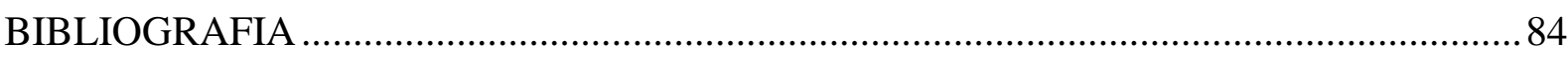

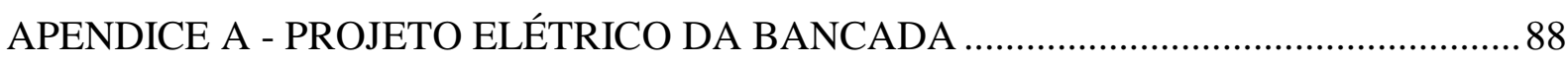

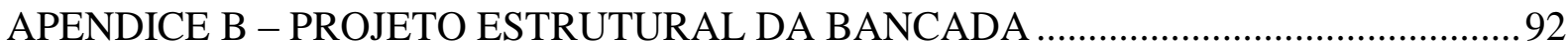

APENDICE C - PROJETO DO FLANGE DE ACOPLAMENTO …................................. 94 


\section{INTRODUÇÃO}

Diminuir a dependência de combustíveis fósseis é de suma importância, dados do Banco Mundial de 2013 dão conta que o setor dos transportes contribui com $20 \%$ de todas as emissões de CO2 relacionadas com a energia, com crescimento de emissões de cerca de 1,7\% ao ano desde 2000, assim os veículos elétricos despontam como uma grande alternativa por todas as suas vantagens do ponto de vista ambiental, tecnológicos e de segurança energética. A questão que fica é, como efetivamente contribuir para o desenvolvimento da mobilidade elétrica?

O Veículo Elétrico pode ser definido como um veículo para transporte de passageiros ou cargas com pelo menos um motor elétrico no seu sistema de tração. A partir desta definição mais ampla, podemos incluir os veículos puros (EV), os veículos elétricos a bateria (BEV), os veículos elétricos híbridos (HEV) e veículos elétricos dotados de células de combustível a hidrogênio (FCEVs), alguns tipos de arranjos possíveis no uso de motores elétricos é mostrado na figura 1.

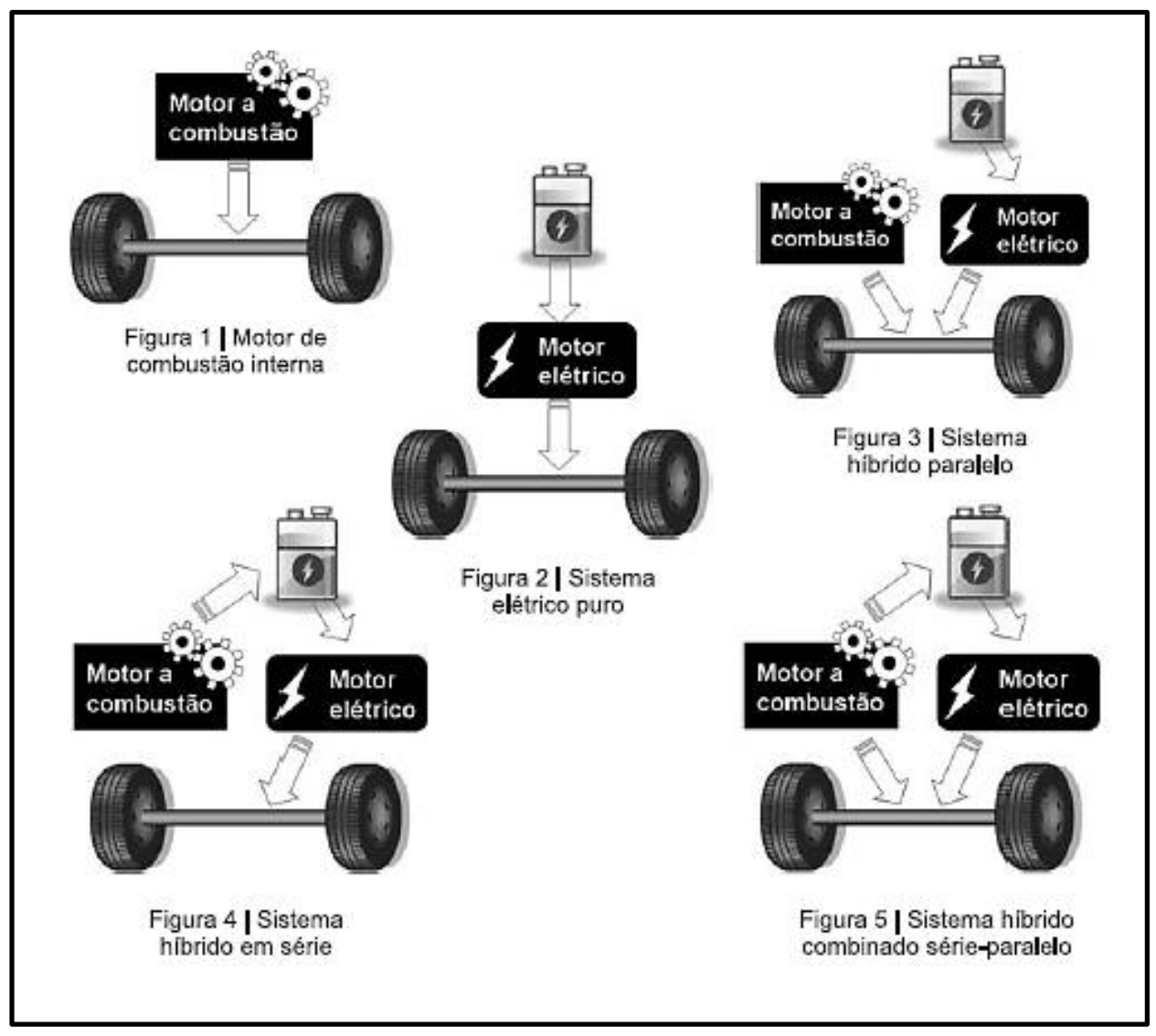

Figura 1 - Tipos de motorização de veículo elétricos e híbridos Fonte: Castro, 2010 
A conceituação do Veículo Elétrico é um assunto multidisciplinar que abrange amplos e complexos aspectos. No entanto, existem tecnologias de núcleo, como tecnologias de chassis e carrocerias, tecnologias de propulsão, uso, armazenamento e reabastecimento de energia, as quais permitem que um veículo possa ser projetado de fábrica ou convertido a partir de outro veículo já existente.

Nos dois casos existem vantagens e dificuldades. A opção de um projeto de fábrica no Brasil encontra entraves significativos em função do tratamento tributário que aumenta bastante o custo, por outro lado o mesmo propicia ganhos de otimização em várias partes do projeto. A conversão pode apresentar um custo sensivelmente reduzido com a aquisição de componentes de indústrias locais e o aproveitamento de vários componentes originais do ve;iculo, mas pode ter aspectos de segurança diminuída.

Um importante detalhe para se projetar ou mesmo converter um veículo para tração elétrica é se ter em mente algumas características necessárias no quesito do motor elétrico a ser usado na aplicação, que são: (a) alta densidade e energia de torque; (b) larga faixa de velocidade, com torque alto a baixa velocidade e com torque baixo a alta velocidade; confiabilidade e robustez para atender as constantes partidas e paradas; (c) alta eficiência em larga faixa de velocidade e torque; (d) bom desempenho em regimes transitórios; (d) facilidade de controle. (CHAN, 1996).

Se fizermos uma análise, a conversão de veículos com motores a combustão interna para tração elétrica é mais atrativa do que adquirir um veículo elétrico produzido de fábrica. Impostos para veículos elétricos no Brasil, são extremamente elevados.

A conversão, desde que consiga reunir componentes produzidos no Brasil, tem custo menor que um veículo elétrico de fábrica. Mas temos que ter em mente que alguns detalhes de projeto tais como peso do motor elétrico, tamanho e peso do banco de baterias, volume do porta-malas e dimensões de uma forma geral do veículo a ser convertido pode implicar em diminuição da capacidade de carga e espaço para passageiros. Em se tratando de veículos elétricos de fabrica, todas essas questões podem ser avaliadas e prontamente modificadas. Um ponto importante se refere ao banco de baterias, pois as baterias de lítio, a melhor opção em relação a peso e potência, têm de ser importadas no Brasil.

O professor Illah Nourbakhsh junto com pesquisadores da Universidade Carnegie Mellon, desenvolveram o projeto ChargeCar Comunity Convertions onde avaliam 
informações de necessidade diária de mobilidade de moradores de Pittsburg e a combinação de banco de baterias com supercapacitores gerenciados por uma sistema de controle com inteligência artificial no uso da energia. A conclusão é que a conversão hoje de veículos com motores a combustão interna é viável, tanto do ponto de vista econômico, quanto do ponto de vista de autonomia, atendendo as necessidades de locomoção das pessoas. Esta é válida mesmo frente aos veículos elétricos de fábrica, que tem ganhos incorporados ainda na fase de projeto.

Este trabalho propõe uma alternativa na avaliação da conversão de veículos originariamente concebidos com motores a combustão interna na tração para tração elétrica com o uso de motores de corrente alternada. Uma bancada como fonte de energia e um inversor de frequência aliada a um dinamômetro de rolos para ensaio e avaliação do veículo convertido. Questões como potência, torque e autonomia poderão ser avaliadas no ambiente controlado do laboratório.

\subsection{JUSTIFICATIVA}

Até o presente momento, a única iniciativa de se ter uma bancada para ensaios e desenvolvimentos relativos exclusivamente ao veículo elétrico noticiada no Brasil, aconteceu no Centro de Pesquisa, Desenvolvimento e Montagem de Veículos Elétricos de Itaipú. De autoria dos engenheiros mecânicos Rui Marcos Faria de Souza e Luiz Diogo Filho, com colaboração de equipe da empresa, foi desenvolvido uma bancada de testes que reúne todos os componentes eletrônicos e a bateria do veículo elétrico em um único módulo, assim o grupo pretende avaliar o comportamento das partes e peças usadas em seus veículos, que são normalmente usados no clima tropical pois todos os componentes usados atualmente são importados. (PORTAL FATOR BRASIL, 2008).

Em fevereiro de 2014 o autor desta dissertação teve a oportunidade de visitar o Instituto Fraunhofer de Energia Eólica e Tecnologia de Sistema de Energia IWES na cidade de Kassel na Alemanha, o Instituto realiza pesquisas que abrangem todos os aspectos da energia eólica e da integração de fontes renováveis em estruturas de fornecimento de energia. 
Funcionando desde 2011, o IWES SysTec (Test Centre for Inteligent Networks and Eletromobility é composto de três unidades, o PNI Grid Integration Research and Test Laboratory, o TPE Electromobility Test and Proving Centre e o Photovoltaic System Outdoor Test Areas.

Para criar plataformas de desenvolvimento virtuais para baterias de íon de lítio, unidades de carregamento e simuladores de rede (Smart Grids), vários departamentos do Fraunhofer IWES reuniram o seu know-how e criaram o Centro de Testes para Eletro mobilidade (IWES - TPE) e também firmaram um acordo de colaboração com a Universidade de Kassel. Neste contexto, o trabalho colaborativo está sendo expandido através da Aliança de Pesquisa de Tecnologia de Sistema de Veículos. O foco da Fraunhofer IWES é a integração da rede e da oferta de energias renováveis, por outro lado a Universidade de Kassel está se concentrando na tecnologia de sistemas do veículo.

Testes especiais reprodutíveis num hardware -in -the- loop (HIS) na unidade, são possíveis através da combinação de um dinamômetro de chassis com baterias virtuais. $\mathrm{O}$ tempo gasto em processos de otimização de compatibilidade entre veículos e baterias de diferentes tipos em condições diversas pode ser reduzida.

Os pesquisadores acreditam que as baterias de íon lítio terão um papel fundamental na Eletro Mobilidade. Suas características dinâmicas e comportamentos de envelhecimento desempenham um papel importante no desenvolvimento de futuros veículos híbridos e elétricos, assim como no projeto de sistemas inteligentes para ligação à rede bi- direcional. Portanto, bons modelos de simulação de baterias de íons de lítio são de grande importância para pesquisa e desenvolvimento no campo da mobilidade elétrica. O pacote de software ISET -Lib para bateria ion -Lithium de simulação foi desenvolvida na mesma base. No software, variantes em tempo real são usados para construir baterias virtuais que simulam fisicamente comportamento real das baterias.

Neste centro são desenvolvidos vários projetos, entre eles cabe destacar o projeto "eNterop" iniciado em julho de 2012 objeto de um consórcio entre as empresas BMW, Continental, Daimler, Fraunhofer, RWE, Siemens, TU Dortmund, Volkswagen e o Ministério Federal da Economia e Tecnologia (BMWi).

O projeto com duração prevista de dois anos e um volume de aproximadamente 4,6 milhões de euros é financiado em 50 por cento pelos parceiros da indústria. Pesquisas naquele 
país preveem que em 2020 serão inseridos um milhão de veículos elétricos no mercado Alemão, diante disto o principal objetivo deste projeto é garantir uma comunicação interoperável entre o veículo elétrico e infra-estrutura de carregamento - um pré-requisito importante para uma ampla aceitação de eletro mobilidade. Para isto o projeto pretende entre outras coisas, discutir com vários setores a norma internacional para a ISO / IEC 15118, vehicle-to-grid (V2G), que trata da interface de comunicação, que é fator chave para a interoperabilidade dos veículos elétricos que no futuro demandará infraestruturas, bem como a integração da eletro mobilidade na cadeia de valor econômico-energético. (Fraunhofer IWES, 2014)

Como citado em (Reis Velloso, 2010, p 8), o mercado mundial se volta para o carro elétrico tendo uma matriz de energia desfavorável. O tema veículos elétricos é multidisciplicnar e tem tecnologias de núcleo, como tecnologias de chassis e carrocerias, tecnologias de propulsão, uso, armazenamento, e reabastecimento de energia. Todas essas possibilidades constituem grandes desafios numa abordagem de desenvolvimento de projetos, neste contexto a plataforma de ensaios pretende ser um catalisador na disseminação da mobilidade elétrica e no desenvolvimento de massa crítica no ambiente da universidade.

Diante das diversas opções, neste trabalho optou-se por uma estrutura modular, ou seja, uma bancada de ensaios e um dinamômetro, onde se disponibilizaria de:

(a) uma fonte de energia

(b) de uma estrutura de chaveamento e controle, para aplicações de motorização com motor de corrente alternada produzido pela WEG Motores para aplicação em veículos elétricos

(c) de um sistema de controle a partir de um inversor de frequência de CFW11 também da WEG; atendendo assim às solicitações de projeto e desenvolvimento numa única estrutura, capaz de simular diferentes tipos de regime de uso como normal, severo, trechos de aclive além da possibilidade de usar diferentes velocidades no ambiente do laboratório. 


\subsection{OBJETIVOS}

\subsubsection{Objetivos Gerais}

Projetar e executar uma plataforma de análise da conversão da tração de veículos dotados originariamente com motores a combustão interna para tração elétrica para avaliar as grandezas torque, potência mecânica e consumo de energia elétrica no veículo convertido em bancada em escala laboratorial.

\subsubsection{Objetivos Específicos}

Este trabalho propõe uma alternativa na avaliação de veículos convertidos para tração elétrica com o uso de uma bancada como fonte de energia externa e um inversor de frequência, aliada a um dinamômetro de rolos para ensaio do veículo convertido. Especificamente, os objetivos deste trabalho são:

- Converter a tração do veiculo a ser ensaiado;

- Projetar e produzir uma bancada dotada de equipamentos para fornecimento de energia e controle na tração elétrica;

- Integrar a bancada de ensaios e dinamômetro de rolos;

- Ensaiar o veiculo convertido na plataforma de ensaios;

- Levantar as curvas de torque e potência do veículo convertido na Plataforma de Ensaios;

- Determinar o consumo de energia elétrica durante os ensaios. 


\subsection{ASPECTOS METODOLÓGICOS}

Para a concepção da Plataforma de Análise de Conversão de Tração de Veículos com Motores a Combustão Interna para Tração Elétrica, as atividades foram divididas em etapas distintas, tais como: (a) revisão bibliográfica através de teses, dissertações, artigos científicos e livros sobre a temática, (b) a conversão de um veículo que seria objeto de avaliação, (c) o projeto e a execução de uma bancada, contendo a fonte de energia a partir da rede elétrica, e (d) o projeto da estrutura de controle da plataforma, até posterior integração do mesmo a um dinamômetro.

\subsection{CONTRIBUIÇÕES DO TRABALHO}

Durante a produção desta dissertação foi apresentado o artigo científico "PROJETO DE PLATAFORMA DE ANÁLISE DE CONVERSÃO DE TRAÇÃO DE VEÍCULOS COM MOTOR A COMBUSTÃO INTERNA PARA TRAÇÃO ELÉTRICA” no X Congresso Latino Americano de Veículo Elétrico o qual foi premiado pelo comitê científico.

\subsection{ESTRUTURA DA DISSERTAÇÃO}

O presente trabalho está dividido em 7 capítulos com a seguinte disposição.

O capítulo 1 faz uma contextualização da fabricação e conversão de veículos elétricos, discorre sobre a justificativa e objetivos que se pretende atingir e descreve a estrutura da dissertação.

O capítulo 2 define, a partir da revisão bibliográfica, conceitos básicos envolvidos na conversão de veículos para tração elétrica, além de apresentar os tipos de motores elétricos usualmente aplicados em tração e suas características.

O capítulo 3 trata dos requisitos para conversão, das características do veículo a ser convertido, da escolha do motor elétrico refrigerado a água e das suas vantagens. 
O capítulo 4 aborda o projeto e execução da bancada da plataforma de ensaios, do transformador, do inversor de frequência e do quadro de comandos elétricos, bem como da segurança e funcionalidade da bancada.

O capítulo 5 cita a integração do dinamômetro de rolos a plataforma de ensaio. Mostra também tipos de dinamômetros, respectivos aspectos funcionais e apresenta o equipamento com suas características e instrumentação.

O capítulo 6 descreve os ensaios em três etapas distintas. A primeira a análise do comportamento da temperatura do motor elétrico refrigerado a água, em seguida o levantamento das curvas de torque e potência do veículo convertido e por último os ensaios por meio do ciclo de condução SAE J227a.

Por fim, o capítulo 7 constam as principais conclusões e sugestões para futuros trabalhos. 


\section{REVISÃO BIBLIOGRÁFICA}

Este capítulo faz uma revisão bibliográfica, onde são discutidos conhecimentos e conceitos básicos indispensáveis para a execução da conversão da tração de um veículo, que foi projetado inicialmente para usar um motor a combustão interna, e também uma descrição das características de motores elétricos que são usualmente utilizados em tração veicular.

\subsection{VEÍCULOS CONVERTIDOS NO BRASIL}

Existem diversas experiências no Brasil de conversão de veículos elétricos. A maioria delas feitas em Universidades em projetos científicos. Abaixo são citados alguns exemplos:

- Kombi elétrica da Unicamp, ano 1984. Foi parte do projeto de mestrado do Engenheiro Gilmar Barreto defendido em 1986. (COSTA, 2009).

- Super Mini elétrico da Unicamp. Desenvolvimento de kit de baixo custo para conversão de veículos com motor a combustão interna para veículos a tração elétrica, ano 2007. Foi usado um veículo Gurgel Supermini pelo Departamento de Eletrônica e Microeletrônica, DEMIC-FEEC-UNICAMP, em Campinas, São Paulo. (COSTA, 2009).

- Conversão de um veículo modelo saveiro para tração elétrica pela WEG, em 2007. A conversão foi feita na fábrica da Weg em Jaraguá do Sul com componentes produzidos na própria empresa e equipe própria atuou na conversão. (COSTA, 2009).

- Conversão de automóvel Astra para veículo elétrico da Fundação Educacional Inaciana (FEI). Essa conversão tem a peculiaridade de usar um gerador a gasolina e um banco de baterias, o que permite ganho em autonomia. (COSTA, 2009).

- Veículos Elétricos de Itaipú (Projeto VE). Os processos tiveram início 2004 com uma parceria entre Itaipú e KWO e em seguida com a conversão de veículos Pálio Weekend para tração elétrica. Hoje existe também o Daily Elétrico, que é um caminhão para cargas pequenas e o Granmini Elétrico, um mini-ônibus. O projeto já produziu diversas unidades que são usadas em Itaipú e também pelos parceiros com a Fiat Automóveis, Eletrobrás, Copel, Weg e KWO. Esse projeto também pretende 
promover transferência de tecnologia na produção das baterias de sódio no Brasil. (FINEP, 2013).

- Conversão de um veículo Gol Geração 4 com tração com motor a combustão interna para tração elétrica. Desenvolvido pelo engenheiro Elyfas Gurgel, em 2008.

- Conversão de veículos da marca Fiat em veículos elétricos, 2012. Desenvolvido pelo engenheiro Maurício dos Santos Anjo.

\subsection{VEÍCULOS ELÉTRICOS DE FÁBRICA}

O primeiro trabalho desenvolvido foi pela indústria brasileira Gurgel Motores, fundada em 1969 pelo engenheiro mecânico engenheiro mecânico e eletricista João Augusto Conrado do Amaral Gurgel, que funcionou por 25 anos produzindo diversos veículos e entre eles dois de propulsão elétrica, o Gurgel Itaipu e Itaipu E400. Adicionalmente, existem hoje ofertas para aquisição de veículos elétricos e híbridos de fábrica, porém, os preços ainda são um grande problema dado o tratamento tributário dispensado a esse tipo de produto.

Neste contexto, uma lista completa contendo os veículos da Gurgel, websites, projetos acadêmicos e produtores independentes pode ser acessada na página da Associação Brasileira do Veículo Elétrico (ABVE).

\subsection{FORÇA DE TRAÇÃO}

Usando a mecânica newtoniana pode-se determinar qual a força de tração (Ft) que será necessária para transpor a resistência aerodinâmica, a resistência ao rolamento, o aclive (figura 2) e a própria inércia do veículo (Larmine, 2003). 


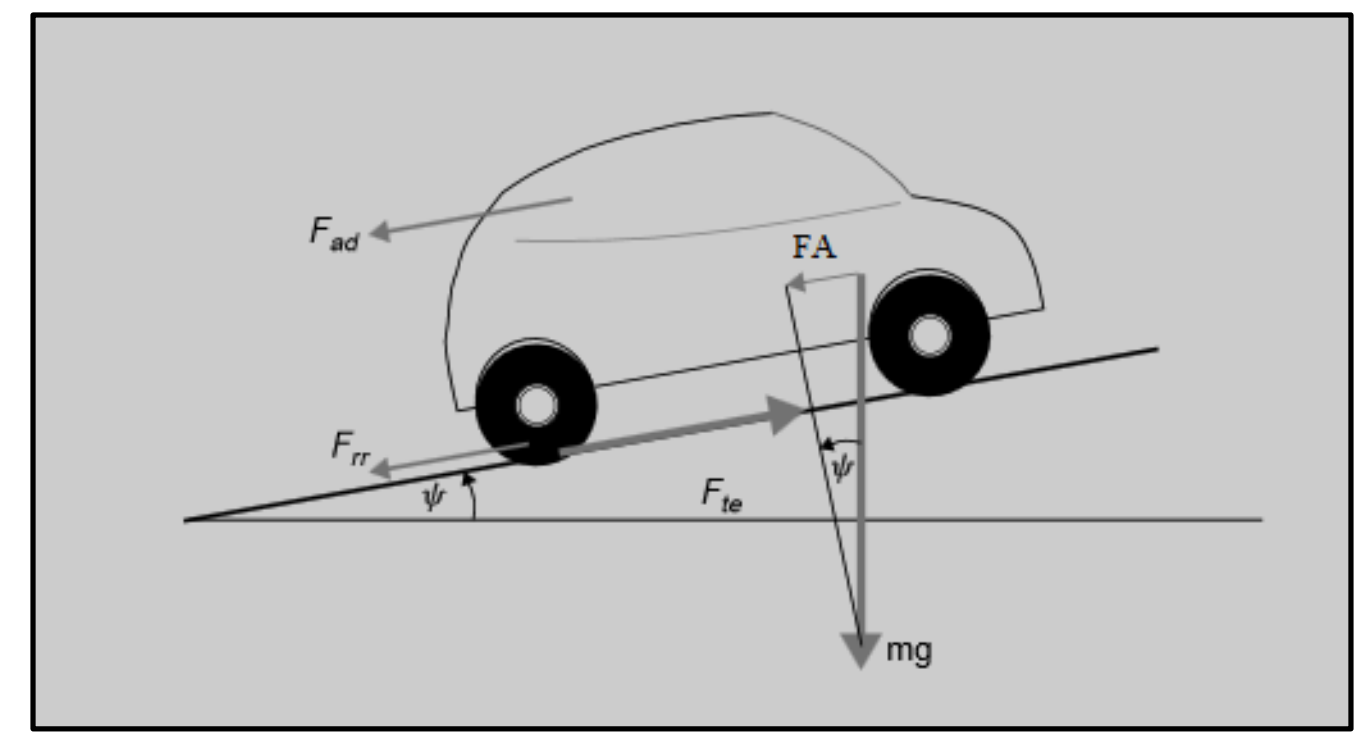

Figura 2 - Forças atuantes em um veículo em movimento em um aclive Fonte: Larminie, 2003

Assim, a equação (1) mostra que:

$$
F t=F r r+F a d+F A+F i
$$

Onde:

$$
F r r=c r \cdot m \cdot a
$$

$F r r=$ Força de resistência ao rolamento $-[\mathrm{N}]$

$c r=$ Coeficiente de resistência ao rolamento - [adimensional]

$m=$ Massa $-[\mathrm{Kg}]$

$$
F a d=\frac{1}{2} \rho \cdot A f \cdot C x \cdot v^{2}
$$

Onde:

Fad $=$ Força Aerodinâmica $-[\mathrm{N}]$ 
$\rho=$ Densidade do ar $\left[\mathrm{kg} / \mathrm{m}^{3}\right]$

$A f=$ Área frontal $-\left[\mathrm{m}^{2}\right]$

$C x=$ Coeficiente de arrasto aerodinâmico - [adimensional $]$

$v=$ Velocidade $-[\mathrm{m} / \mathrm{s}]$

$a=$ aceleração $-\left[\mathrm{m} / \mathrm{s}^{2}\right]$

$$
F a=m \cdot a \cdot \operatorname{sen} \theta
$$

Onde:

$F a=$ Força no aclive $-[\mathrm{N}]$

$m=\operatorname{massa}-[\mathrm{Kg}]$

$a=$ aceleração $-\left[\mathrm{m} / \mathrm{s}^{2}\right]$

$\theta=$ ângulo de inclinação do pavimento - [graus]

\subsubsection{Resistência de Aclive}

Quando um veiculo se desloca em um aclive,(figura 2) uma parcela de seu peso é absorvido pela superfície do solo na forma de força normal, a parcela restante age sobre o centro de gravidade do veículo, paralelamente ao plano inclinado tendendo a fazer o veículo descer. A esta componente do peso dá-se o nome de resistência de aclive. Para que haja equilíbrio estático esta componente deve ser vencida pela força de tração. (Nicolazzi et al. 2001)

$$
F i=m e . a
$$

Onde:

$\mathrm{Fi}=$ Força para vencer a Inércia $-[\mathrm{N}]$

me $=$ massa equivalente já com a inércia do sistema $-[\mathrm{Kg}]$

$\mathrm{a}=$ aceleração $-\left[\mathrm{m} / \mathrm{s}^{2}\right]$ 


\subsubsection{Resistência de Inércia}

De acordo com a leis de Newton, para alterar o movimento de corpo, esteja ele em repouso ou movimento retilíneo uniforme, faz-se necessário a aplicação de uma força. Para calcular a força a ser aplicada em um automóvel, sendo este um conjunto de inércias em translação e rotação, é preciso computar a translação das massas e as inércias rotativas. Quando o automóvel está em aceleração, as inércias rotativas na caixa de transmissão e no diferencial são submetidas a acelerações angulares proporcionais a linear o que pode representar expressiva parcela de consumo de força e potência. Por isso, é importante considerar as componentes de inércia de rotação e translação para então definir a inércia equivalente. (Nicolazzi et al. 2001)

A resistência de inércia de translação pode ser descrita por

$$
Q i^{\prime}=m a
$$

Onde

$Q i^{\prime}=$ resistência de inércia

Para produzir uma aceleração angular, $\alpha$, em uma inércia rotacional é necessário aplicar-se um momento, $M$, dado por:

$$
M=J \alpha
$$

onde:

$\alpha=$ aceleração angular $-\left[\mathrm{rad} / \mathrm{s}^{2}\right]$

,J= inércia de rotação - [kg/m2],

O fato do veículo dispor de caixas de redução de rotações, têm-se diferentes inércias girando a velocidades diferentes. Assim, se faz necessário dividir as inércias rotativas de formas distintas, organizados da seguinte forma:

$\mathrm{Jr}$ - Inércias das rodas e agregados tais como: rodas dianteiras, traseiras, parte do diferencial do lado das rodas, dos discos e tambores de freio e dos cubos de roda.

Jt - Inércia da transmissão. Parte do diferencial do lado da caixa mais eixo cardam e 
juntas, bem como a parte acionada da caixa.

Jm - Inércia do motor. Motor e acessórios, volante, embreagem e parte acionante da caixa de marchas.

Para obter a força de equivalente a de inércia no ponto de contato com o solo, é necessário dividir o momento dado pela equação (7) pelo raio dinâmico do pneu como segue:

$$
Q i^{\prime \prime}=\frac{M}{r d}
$$

onde:

$r d=$ raio dinâmico do pneu $[\mathrm{m}]$

Ocorre variação do diâmetro do pneu em função de sua elasticidade e da velocidade como efeito da força centrífuga. O raio dinâmico, rd, é então definido pela distância perimetral percorrida pelo pneu na condição de carga máxima com velocidade padrão de $60 \mathrm{~km} / \mathrm{h}$. (Nicolazzi et al. 2001).

O fato de haver diferenças entre as velocidades das inércias $J t$ e $J m$, impossibilita uma soma direta das grandezas, assim, para se obter a inércia equivalente, supõem-se uma inércia unida a um eixo que através de uma redução $i$ transmite movimento, e a mesma energia cinética, ao outro extremo desse eixo.

Deste modo se pode calcular uma inércia equivalente a do motor e da transmissão, nas rodas, considerando a $j$ ésima relação de transmissão da caixa de câmbio (icj) e do diferencial (id), desse forma:

$$
J=J r+i^{2}\left(J t+i c j^{2} J m\right)
$$

A resistência total da aceleração é então dada pela soma das inércias de translação e da rotação. 


$$
Q i=Q^{\prime}+Q^{\prime \prime}
$$

$\mathrm{Ou}$

$$
Q i=m a\left(1+\frac{J}{m \cdot r d^{2}}\right)
$$

Ou ainda

$$
Q i=m a(1+\delta)
$$

Onde:

$$
\delta=\left(\frac{J}{m \cdot r d^{2}}\right)
$$

A inércia equivalente, $\delta$, representa o aumento da massa do veículo devido a necessidade de acelerar as inércias rotativas. Segundo (Nicolazzi et al. 2001) uma boa estimativa de inércia equivalente para o anteprojeto de um automóvel, pode ser calculado por:

$$
\delta=0,004+0,05 \cdot i c j^{2}
$$

De posse do valor da força de tração é possível calcular o torque na roda do veículo.

$$
\operatorname{Tr}=F t . r
$$

Onde:

$\mathrm{Tr}=$ Torque na roda $-[\mathrm{Nm}]$

$\mathrm{Ft}=$ Força de tração $-[\mathrm{N}]$

$\mathrm{r}=$ raio da roda $-[\mathrm{m}]$

Com isso, pode-se calcular Torque no motor elétrico que é uma razão entre o Torque na Roda e o produto da relação da caixa de transmissão com o seu respectivo rendimento.

$$
T m=\frac{T r}{R t \cdot \eta t}
$$

Onde:

$\mathrm{Tm}=$ Torque no motor $-[\mathrm{Nm}]$ 
$\operatorname{Tr}=$ Torque na roda $-[\mathrm{Nm}]$

$\mathrm{Rt}=$ Relação da caixa de transmissão - [admensional $]$

$\eta t=$ Rendimento da transmissão - [adimensional $]$

\subsection{CAIXA DE TRANSMISSÃO}

Também conhecido com Caixa de Câmbio é o equipamento utilizado por máquinas e veículos para converter a potência do eixo dos motores em velocidade e ou torque, de acordo com a aplicação da máquina ou veículo.

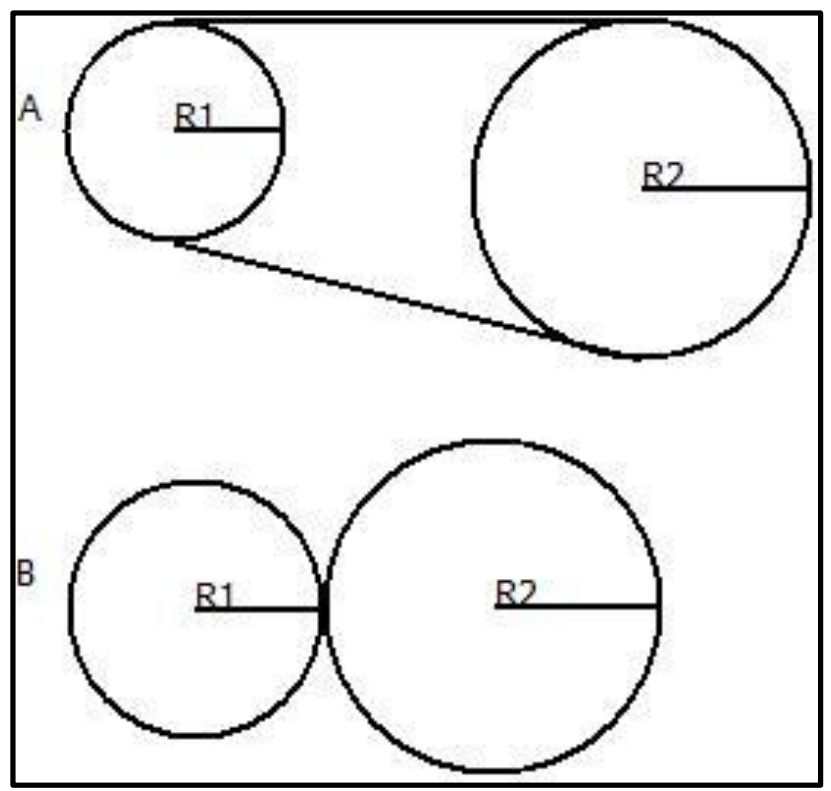

Figura 3 - Transferência de movimento entre engrenagens Fonte: $\mathrm{O}$ autor, 2013

Para relatar, de forma sucinta o funcionamento da caixa de câmbio, faz-se necessário observar na figura 3, a ilustração A, a transferência de força e velocidade da estrutura motriz com o raio $\mathrm{R} 1$, que é menor que $\mathrm{R} 2$ é acoplado através de uma correia ou corrente. $\mathrm{Na}$ ilustração A o sentido de rotação é o mesmo, já na ilustração B com acoplamento de duas engrenagens através de seus dentes, a rotação de R2 será inversa a de R1.

Com as ilustrações da figura 1 é possível agora avaliar o comportamento da força e velocidade angular transferida nesses dois tipos de acoplamento. 
Primeiramente, analisando o acoplamento por correias, pode-se dizer que se não houver deslizes por parte da correia, a velocidade de R1 e R2 será igual, portanto,

$$
v=\omega r
$$

Onde:

$\mathrm{v}=$ Velocidade escalar $-\mathrm{m} / \mathrm{s}$

$\omega=$ Velocidade angular $-\mathrm{rad} / \mathrm{s}$

$r=$ raio da circunferência $-m$

E se v1=v2, então, $\mathrm{F} 1=\mathrm{F} 2$, então:

$$
\omega 1 R 1=\omega 2 R 2
$$

Sabendo-se que:

$$
\omega=2 \pi f
$$

Onde,

$f=$ frequência $-\mathrm{Hz}$

Então:

$$
2 \pi f 1 R 1=2 \pi f 2 R 2
$$

Daí, tem-se que:

$$
f 2=f 1 \cdot \frac{R 1}{R 2}
$$

A equação (12) demonstra que pelo fato de R1 ser menor que R2 a razão entre elas dará um resultado menor que a unidade, isto implica que a velocidade f2 é menor que f1, resultando no que é chamado de redução de velocidade.

Agora, sob o aspecto de Torque, pode-se avaliar a ilustração B que representa duas engrenagens, onde a menor (de raio $\mathrm{R} 1$ ), movimenta a segunda de raio $\mathrm{R} 2$.

Lembrando que Torque é a o produto da Força pelo Raio:

$$
T=F \cdot r
$$


Tem-se que:

$$
\begin{gathered}
T 1=F 1 \cdot R 1 \\
\mathrm{e} \\
T 2=F 2 \cdot R 2
\end{gathered}
$$

Então ,

$$
F 1=\frac{T 1}{R 1} \text { e } F 2=\frac{T 2}{R 2}
$$

Se F1=F2, então:

$$
\frac{T 1}{R 1}=\frac{T 2}{R 2}
$$

Isto implica que:

$$
T 2=T 1 \frac{R 2}{R 1}
$$

A equação (14) demonstra que pelo fato de $\mathrm{R} 2$ ser maior que $\mathrm{R} 1$ a razão entre elas dará um resultado maior que a unidade, isto implica que o Torque em T2 é maior que T1, resultando no que é chamado de vantagem mecânica.

As duas últimas demonstrações mostram que para uma certa entrada, resultará uma saída proporcional, se houver diminuição de velocidade, resultará em aumento de torque e assim sucessivamente, em outras palavras, isso é a lei de conservação de energia. Todos os projetos que fazem uso de equipamentos redutores avaliam o que é mais vantajoso: torque, potência ou uma combinação dos dois.

Rendimento é um número adimensional que representa em valores percentuais, quanto efetivamente de energia em um motor é transformado em trabalho. Toda máquina sofre perdas no seu funcionamento, sejam perdas mecânicas ou térmicas, por isso o rendimento jamais será igual a $100 \%$.

$$
\eta=\frac{\tau}{\varepsilon} \cdot 100
$$


Onde:

$\eta$ : Rendimento [admensional]

$\tau$ : Trabalho produzido $[\mathrm{Nm}]$

$\varepsilon$ : Energia recebida $[\mathrm{J}]$

De uma forma ampla, os motores convertem energia em trabalho, porém essa conversão sempre tem perdas associadas, daí o rendimento completo, 100\%, ser apenas teórico. A evolução das máquinas desde a vapor até os dias atuais sempre buscou melhorar o rendimento. O fato dos veículos de transporte em sua grande maioria usarem diesel e não gasolina ou etanol é porque o diesel tem eficiência da ordem de $45 \%$, enquanto os veículos a gasolina aproximadamente $30 \%$, já os motores a etanol são menos eficientes ainda. A opção das indústrias utilizarem motores elétricos também está associada ao rendimento que pode ultrapassar $90 \%$ e por isso apresenta-se como uma interessante forma de propulsão..

Assim, pode-se resolver a equação (7) e em seguida calcular a potência elétrica do motor elétrico para tração.

$$
P m=T \cdot \frac{r p m}{9549}
$$

Onde:

$P m=$ Potência do motor elétrico $[\mathrm{w}]$

$T=$ Torque $[\mathrm{Nm}]$

$r p m=\operatorname{rotação~}[\mathrm{rpm}]$

$9549=$ constante

\subsection{MOTORES ELÉTRICOS}

Diversas são as opções para aplicação de motores elétricos em sistemas de tração.

Os motores elétricos podem usar uma configuração padrão usada de um motor a combustão, longitudinal ou transversal, dianteiro ou traseiro ou ainda ser instalado direto nas rodas com ou sem caixa redutora, figura 4. 
Segundo Chau (2008), os motores de imã permanente sem escovas (brushless) têm vantagens importantes sobre os demais por sua alta densidade de energia, alta eficiência e confiabilidade. Vantagens essas que só foram possíveis devido a descoberta de novos materiais para a fabricação de imãs (terras raras) e o desenvolvimento dos motores de corrente contínua (DC) que passaram a ser usados sem escovas o que diminuiu consideravelmente perdas por centelhamento, comutação, ruídos eletromagnéticos além de não dependerem tanto de manutenção como os antecessores com escovas e coletores.

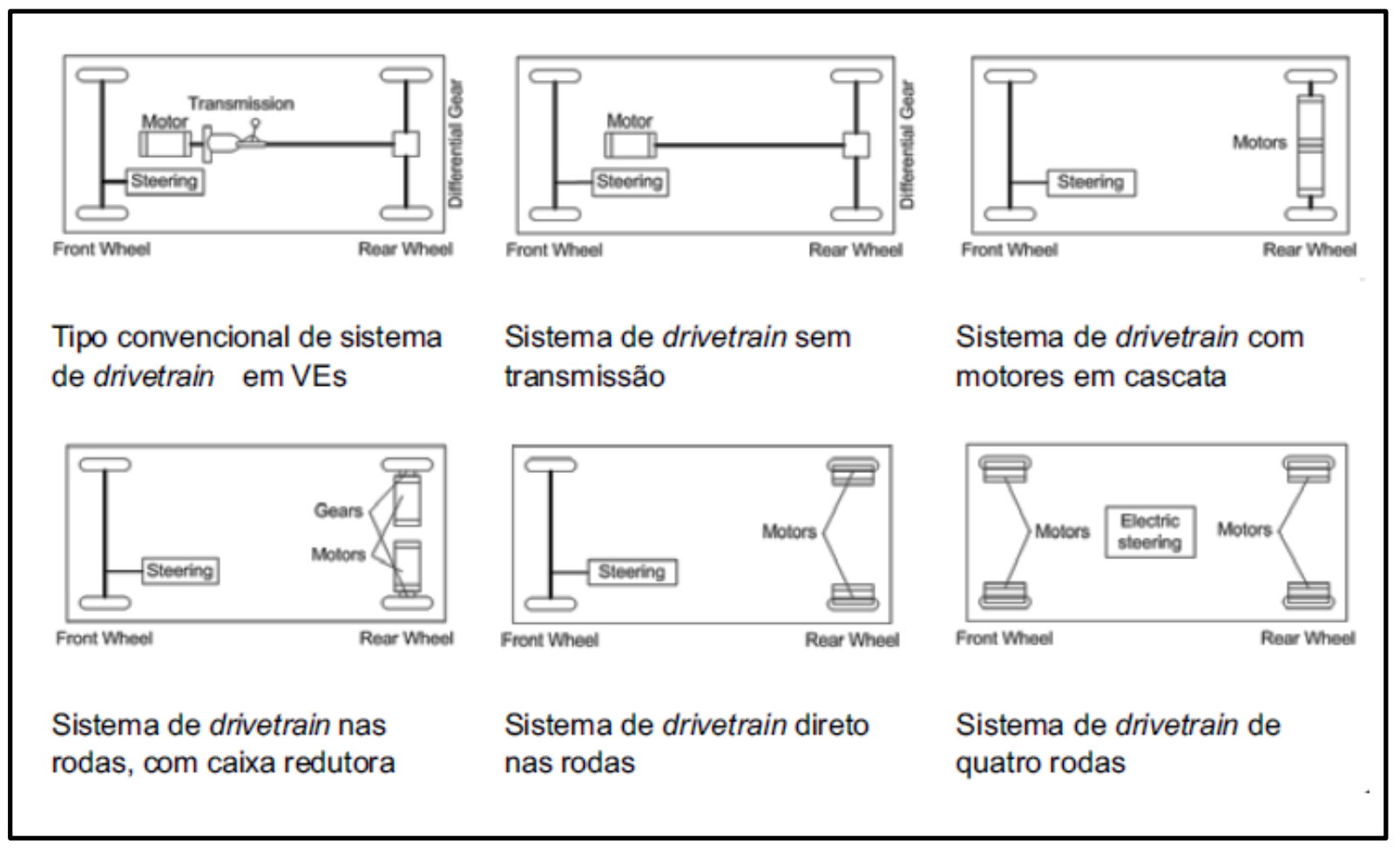

Figura 4 - Configurações possíveis de motor(s) elétricos na tração Fonte: Fonte: Xue et al. (2008)

Para aplicações em ambientes restritos e a baixas velocidades, como fábricas, depósitos e campos de golfe, os veículos elétricos normalmente usam motores (DC) com comutadores e também o motor sem escovas DC com excitação a imã permanente.

A grande maioria dos veículos elétricos de passeio nos dias de hoje usam motores de corrente alternada (AC), com destaques para os motores de indução e os motores síncronos com imãs permanentes.

Sobre o aspecto construtivo, a principal diferença entre eles encontra-se no rotor. O motor AC de indução tem barras de cobre ou alumínio curto circuitadas a discos formando uma gaiola, daí o nome gaiola de esquilo e a corrente é induzida pelo estator para formar o 
campo, no motor $\mathrm{AC}$ de imãs permanentes o campo é permanente pelo fato do rotor já ter inserido na sua estrutura material magnético.

Sobre aspecto da eficiência, os motores $\mathrm{AC}$ a imã permanente levam vantagem pois a velocidade do campo girante do estator é mesma velocidade do rotor, que é a característica de uma máquina síncrona. Já nos motores $\mathrm{AC}$ de indução, existe o escorregamento que é uma pequena defasagem entre a velocidade do campo girante e a velocidade do rotor.

Em (Costa, 2009) foi apresentado um quadro comparativo relacionado as tecnologias de motores para veículos elétricos, como apresentado na tabela 1.

Tabela 1 - Dados comparativos de motores elétricos para tração

\begin{tabular}{|c|c|c|c|c|c|}
\hline $\begin{array}{c}\text { Elementos } \\
\text { De } \\
\text { Comparação }\end{array}$ & Motor CC & $\begin{array}{c}\text { Motor } \\
\text { de } \\
\text { indução }\end{array}$ & $\begin{array}{c}\text { Motor a } \\
\text { ima } \\
\text { permanente } \\
\text { sem } \\
\text { escovas }\end{array}$ & $\begin{array}{l}\text { Motor } \\
\text { a } \\
\text { relutância }\end{array}$ & $\begin{array}{c}\text { Motor } \\
\text { a imã } \\
\text { permanente } \\
\text { hibrido }\end{array}$ \\
\hline $\begin{array}{l}\text { Densidade de } \\
\text { potência }\end{array}$ & 2 & 3 & 5 & 3 & 4 \\
\hline Eficiência & 2 & 3 & 4 & 3 & 5 \\
\hline Controlabilidade & 5 & 3 & 4 & 3 & 5 \\
\hline Confiabilidade & 3 & 5 & 4 & 5 & 4 \\
\hline Maturidade & 5 & 5 & 4 & 3 & 2 \\
\hline Custo & 4 & 5 & 2 & 4 & 2 \\
\hline Total & 20 & 24 & 24 & 21 & 22 \\
\hline
\end{tabular}

Motores de indução tem extensa aplicação na área industrial,pois o seu custo é atraente além de ser uma tecnologia madura. Normalmente utilizam conversores estáticos de frequência, mais conhecidos como inversores de frequência, no seu sistema de controle. 
Tais equipamentos proporcionam diversas vantagens quanto a variação de velocidades e torque.

A velocidade é controlada variando a frequência, conforme mostra a equação (26):

$$
n=\frac{120 \cdot f 1 \cdot(1-s)}{p}
$$

Onde:

$n=\operatorname{rotação}-\mathrm{rpm}$

$f l=$ frequência de alimentação - Hertz

$p=$ número de pólos

$s=$ escorregamento

Analisando, pode-se observar que variando a frequência de alimentação, pode-se variar a rotação. A rede de alimentação fornece tensão com amplitude e frequência constantes, os inversores transformam a amplitude e a frequência em variáveis. Assim, além de variar a velocidade, pode-se variar o torque do motor alterando a amplitude da tensão.

O torque do motor é definido pela seguinte equação:

$$
T m=K . \Phi m . I r
$$

Onde:

$T m=$ Torque no motor $-[\mathrm{Nm}]$

$\mathrm{K}=$ constante do motor

$\Phi m=$ fluxo magnético $-[\mathrm{Wb}]$

$I r=$ Corrente rotatórica $[\mathrm{A}]$

Para garantir diferentes velocidades é preciso não somente variar a frequência, mas também variar proporcionalmente a amplitude da tensão, assim será possível operar com o fluxo constante, o que garante torque constante. 
A figura 2, demonstra que a relação entre tensão e frequência $(V / f)$ é linear até a frequência de base $\omega b$, que é a frequência nominal do motor. Acima dessa frequência a tensão atinge o valor de tensão nominal do motor.

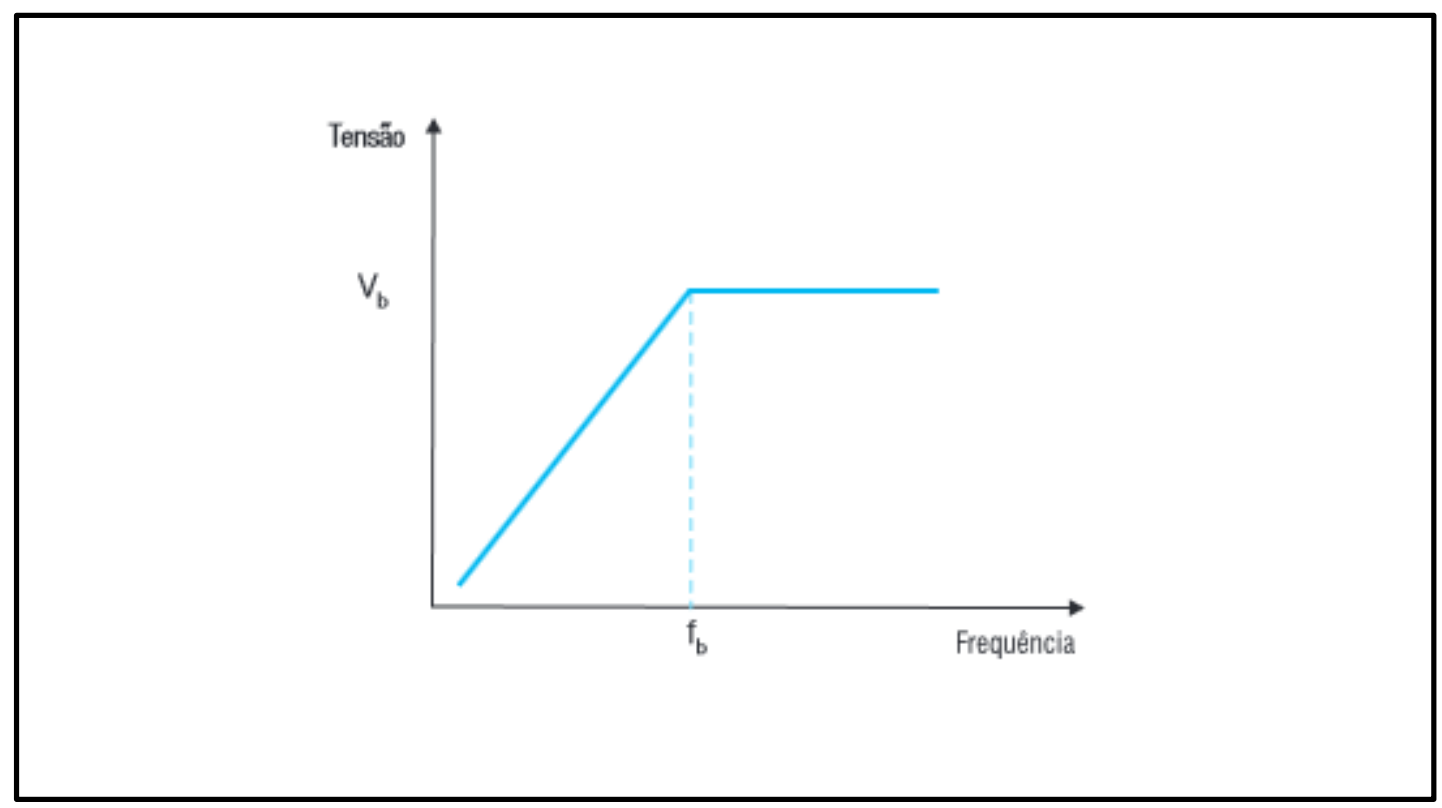

\section{Figura 5 - Gráfico tensão x Frequência}

Fonte: ecatalog.weg.net

O torque permanece constante até atingir a frequência de base. A partir desse ponto ocorre a diminuição do fluxo magnético com o enfraquecimento do campo e a redução do torque, como pode-se observar na figura 3. 


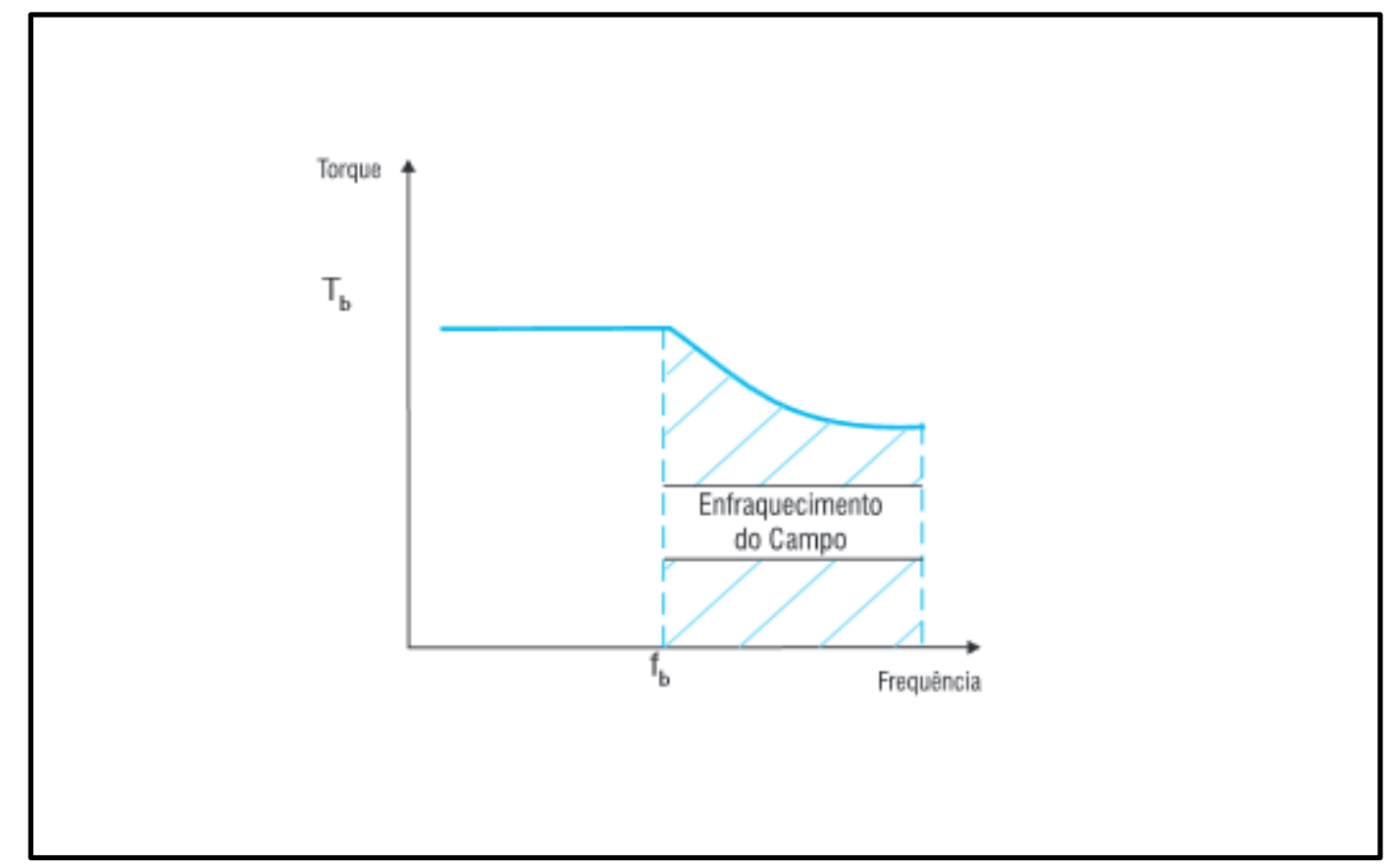

Figura 6 - Gráfico Torque x Frequência

Fonte: ecatalog.weg.net

Em relação a potência, por ser diretamente proporcional ao torque e a velocidade de rotação, ela cresce linearmente até atingir a frequência de base e passa a ser constante acima desta frequência.

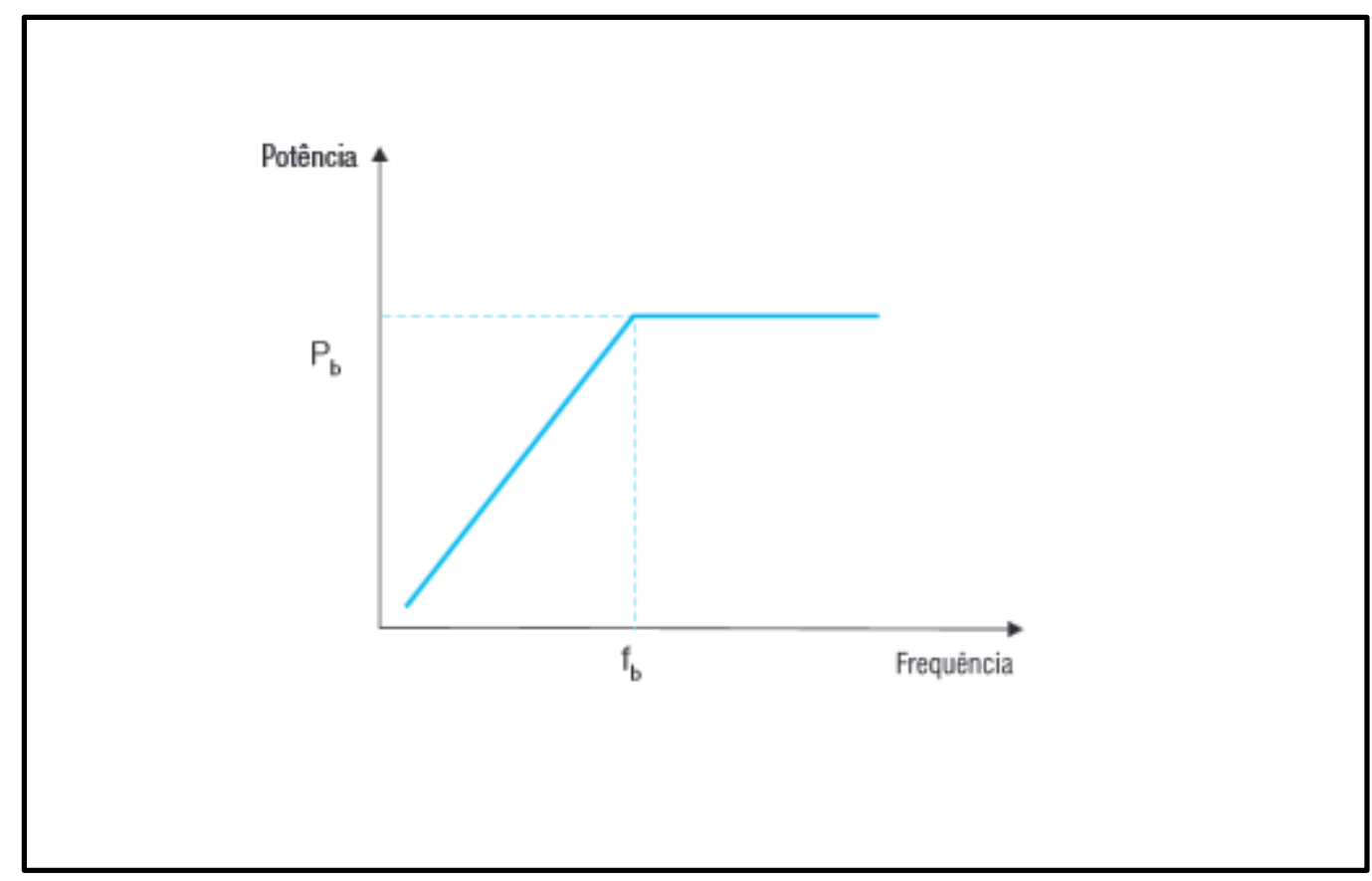

Figura 7 - Gráfico Potência x Frequência

Fonte: ecatalog.weg.net 
Baseado nas condições expressas na tabela 1, iniciou-se a avaliação sobre qual seria a opção mais adequada, levando-se em consideração também a disponibilidade no mercado brasileiro. No capítulo 3 será detalhado outros aspectos que influenciaram na escolha. 


\section{CONVERSÃO DO VEÍCULO}

Para a conversão de um veículo que utiliza na tração motor a combustão para um motor elétrico, algumas questões necessitam ser equacionadas para que se possa visualizar o objetivo a ser alcançado. Por exemplo, qual será a aplicação do veículo, (transporte de cargas ou passageiros), qual será o regime de utilização, qual serão os percursos, qual a necessidade de torque e velocidade? Tais respostas balizarão as condições de contorno do projeto.

Com todos os veículos a previsão de desempenho e alcance é importante. Acima de tudo, os métodos baseados em computador permite-nos rapidamente executar experiências com os aspectos do veículo, tais como potência do motor, o tipo e o tamanho da bateria, peso e assim por diante. Além disso permite avaliar como as mudanças afetam o desempenho e o alcance. (LARMINE, 2003).

O primeiro parâmetro que servirá de modelo é o desempenho do veículo. Pelo desempenho entende-se aceleração e velocidade máxima, uma área onde os veículos elétricos têm uma reputação questinável. É necessário que qualquer veículo elétrico tenha um desempenho que permita, no mínimo, trafegar com segurança no tráfego de uma cidade. Muitos argumentam que o desempenho deve ser pelo menos tão bom quanto os veículos com motor de combustão interna atuais. (LARMINE, 2003).

\subsection{REQUISITOS}

Segundo (Costa, 2009), a conversão de um veículo para tração elétrica segue 12 passos, que vão desde a escolha do veículo até a revisão na legislação vigente, além de recomendar uma visão crítica que permita aperfeiçoamentos durante a realização do trabalho, conforme a seguir:

1) Escolha do veículo;

2) Determinação do trajeto, fixando-se a autonomia mínima pretendida;

3) Definição da velocidade máxima requerida;

4) Elaboração dos cálculos preliminares para obtenção dos valores de torque e potência exigidos;

5) Avaliação do sistema de transmissão original do veículo; 
6) Identificação do motor elétrico mais adequado;

7) Definição do sistema de controle de velocidade para o motor;

8) Escolha do banco de baterias para o veículo, levando em conta: a tensão resultante e a corrente máxima, de forma a compatibilizá-la com o controlador que atuará no motor. Ademais, outras condições características devem satisfazer os critérios do projeto: densidade de energia e potência, espaço disponível e arranjos das conexões;

9) Elaboração de simulações utilizando como dado o peso total do veículo com a máxima carga prevista a ser transportada, considerando a retirada dos componentes de propulsão originais e inserindo os novos dispositivos previstos para a adaptação. Verificar o desempenho em trechos horizontais e em aclives;

10) A partir dos cálculos iniciais, otimizar o sistema adaptado para que se obtenha a maior eficiência possível durante o funcionamento do veículo;

11) Com os passos anteriores definidos, faz-se necessário consultar as legislações pertinentes para viabilizar a legalização do veículo para circulação e compatibilizar o projeto com a legislação vigente;

12) Executar a conversão com uma visão crítica em relação ao projeto previsto, tendo como objetivo aperfeiçoá-lo durante a realização do trabalho.

\subsection{O VEÍCULO}

O veículo a ser convertido já era de propriedade da Universidade de Brasília (UnB) o que representou uma vantagem para esta etapa do projeto, pois o primeiro passo recomendo por (Costa, 2009) não seria mais necessário implementar. O automóvel, um Fiat Pálio EDX 1.0 ano 1999 foi doado pela Fiat do Brasil para ser usado em aulas para de alunos de engenharia e também em projetos. A figura 8 ilustra a disposição de uma veículo de tração dianteira com motor transversal e a sua ficha técnica é apresentada na tabela 2. 
Tabela 2 - Características do Palio

\begin{tabular}{|c|c|}
\hline \multicolumn{2}{|r|}{ Dimensões } \\
\hline Comprimento & $3730 \mathrm{~mm}$ \\
\hline Largura & $1610 \mathrm{~mm}$ \\
\hline Altura & $1440 \mathrm{~mm}$ \\
\hline Peso & $910 \mathrm{~kg}$ \\
\hline Porta malas & $210 \mathrm{~L}$ \\
\hline \multicolumn{2}{|r|}{ Motor a Combustão } \\
\hline Tipo & Dianteiro, transversal, 4 cilindros, 8válvulas \\
\hline Potência & 61cv a 6100RPM \\
\hline Potência Especifica & $61,37 \mathrm{cv} /$ litro \\
\hline Torque & $8,1 \mathrm{kgfm}$ a $3000 \mathrm{rpm}$ \\
\hline Torque Especifico & $8,15 \mathrm{kgfm} / 3000 \mathrm{rpm}$ \\
\hline Cilindrada & $994 \mathrm{cc}$ \\
\hline \multicolumn{2}{|r|}{ Suspensão } \\
\hline Dianteira & Independente, Mc Person com braços oscilantes \\
\hline Traseira & $\begin{array}{l}\text { Independente, com braços longitudinais interligados por barras de } \\
\text { torção }\end{array}$ \\
\hline Amortecedores & Hidráulicos e molas helicoidais \\
\hline \multicolumn{2}{|r|}{ Freios } \\
\hline Dianteiros & Disco \\
\hline Traseiros & Tambor \\
\hline \multicolumn{2}{|r|}{ Capacidades } \\
\hline Porta malas & $210 \mathrm{~L}$ \\
\hline $\begin{array}{l}\text { Área frontal } \\
\text { aproximada }\end{array}$ & $2,36 \mathrm{~m}^{2}$ \\
\hline
\end{tabular}

Para os cálculos da conversão serão usados os dados da tabela 3, além do peso do veiculo citado na tabela 2 . 
Tabela 3 - Dados originais para conversão

\begin{tabular}{|c|c|}
\hline \multicolumn{2}{|c|}{ Espaço no Motor } \\
\hline Altura aproximada & $400 \mathrm{~mm}$ \\
\hline Largura aproximada & $350 \mathrm{~mm}$ \\
\hline Profundidade & $450 \mathrm{~mm}$ \\
\hline \multicolumn{2}{|c|}{ Transmissão } \\
\hline Tração & Dianteira \\
\hline \multirow[t]{5}{*}{ Relação } & $1^{\mathrm{a}} 4,27$ \\
\hline & $2^{a} 2,24$ \\
\hline & $3^{\mathrm{a}} 1.52$ \\
\hline & $4^{\mathrm{a}} 1,16$ \\
\hline & $5^{\mathrm{a}} 0,97$ \\
\hline Diferencial & 4,36 \\
\hline Porta malas & $210 \mathrm{~L}$ \\
\hline Área frontal aproximada & $2,36 \mathrm{~m}^{2}$ \\
\hline \multicolumn{2}{|c|}{ Rodas } \\
\hline Aro 13" & Aço \\
\hline Pneu & $185 / 70 / 13$ \\
\hline
\end{tabular}

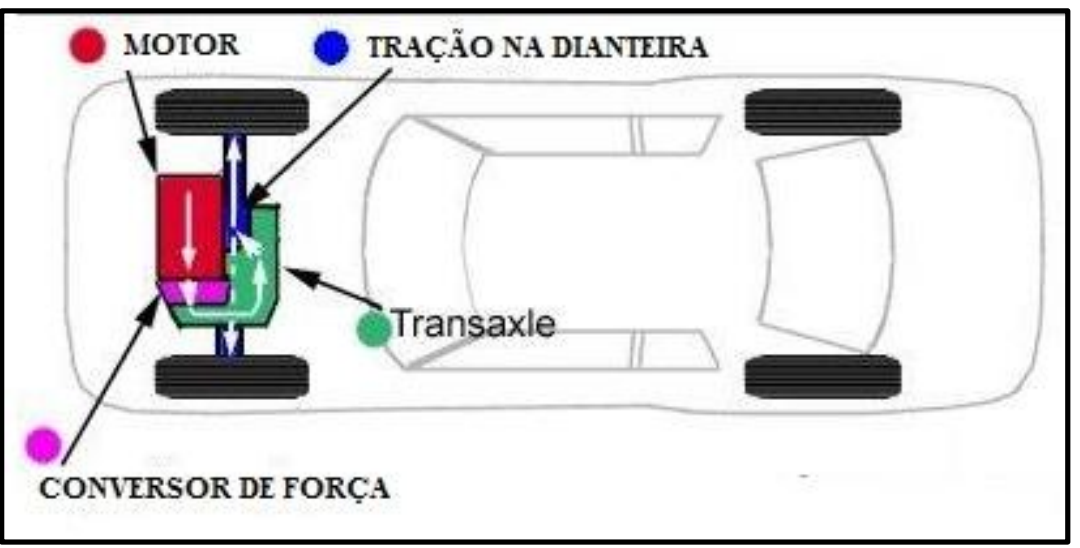

Figura 8 - Disposição de motor dianteiro transversal Fonte: autocenter.blog.br 


\subsubsection{Caixa de Transmissão}

A caixa de transmissão original é manual de cinco marchas, sendo que na tabela 2 temos as relações de câmbio, que basicamente servem para transformar o torque e rotação do motor em torque e rotação nas rodas do veículo. Neste momento faz-se necessária uma breve explanação sobre as informações do pneu, que no caso é um 185/70/13. A centena 185 referese a largura da banda de rodagem e é expressa em milímetros; a dezena 70 é a relação entre altura e largura do pneu, ou seja, a altura é $70 \%$ da largura; e a última dezena 13, é o diâmentro da roda dado em polegadas. Somando as contribuições para o referido conjunto de roda e pneu tem-se aproximadamente, $589 \mathrm{~mm}$ de diâmetro.

A tabela 4 mostra, de forma teórica, a velocidade de saída na transmissão, no diferencial e na própria roda, levando em consideração uma rotação do motor elétrico de 5000 rpm,sendo que a relação do diferencial é 4,36.

Tabela 4 - Transmissão do Palio

\begin{tabular}{|c|c|c|c|c|}
\hline Marcha & Relação & $\begin{array}{c}\text { Rotaçao de saída } \\
\text { Transmissão }-\mathbf{R p m}\end{array}$ & $\begin{array}{c}\text { Rotação de saída } \\
\text { diferencial - } \\
\mathbf{R p m}\end{array}$ & $\begin{array}{c}\text { Velocidade } \\
\text { escalar no pneu } \\
-\mathbf{k m} / \mathbf{h}\end{array}$ \\
\hline $\mathbf{1}^{\mathbf{a}}$ & $4,27: 1$ & 1171 & 269 & 29,81 \\
\hline $\mathbf{2}^{\mathbf{a}}$ & $2,24: 1$ & 2232 & 512 & 56,83 \\
\hline $\mathbf{3}^{\mathbf{a}}$ & $1,52: 1$ & 3289 & 754 & 83,76 \\
\hline $\mathbf{4}^{\mathbf{a}}$ & $1,16: 1$ & 4310 & 988 & 109,75 \\
\hline $\mathbf{5}^{\mathbf{a}}$ & $0,97: 1$ & 3020 & 692 & 131,25 \\
\hline
\end{tabular}

Conforme citado neste capítulo, nas relações do câmbio do Palio, pode-se observar que na primeira marcha há uma sensível redução da velocidade, 4,27:1. Em compensação haverá um ganho no torque, pois os veículos em primeira marcha tem de ser capazes de 
movimentar o seu peso próprio e eventualmente a lotação completa a que lhe é permitida com algum peso extra na mala e também uma certa inclinação no pavimento e outros fatores, ou seja, deve ter alto torque. Já na relação da quinta marcha, 0,97:1, o importante é aumentar a velocidade do veículo.

\subsubsection{Espaço Disponível}

Nesta etapa do projeto foi necessário remover todos os componentes que compunham a estrutura original de tração movidos com motor a combustão interna como motor, escapamentos, tanque, gargalo do tanque, tubulações de alimentação e de retorno de combustível, tubulações e componentes do sistema de evaporação de combustível, unidade de comando eletrônico do sistema de injeção eletrônica e também chicotes elétricos de sensores e atuadores do sistema de injeção eletrônica, alternador e motor de partida. Toda a parte de iluminação interna e externa do veículo será mantida e, oportunamente, será reativada, muito provavelmente com conversor DC/DC conectado a bateria para repor a carga consumida pelos componentes do veículo durante o seu uso.

A figura 5 apresenta em uma vista superior o espaço disponível entre a longarina e a caixa de câmbio.

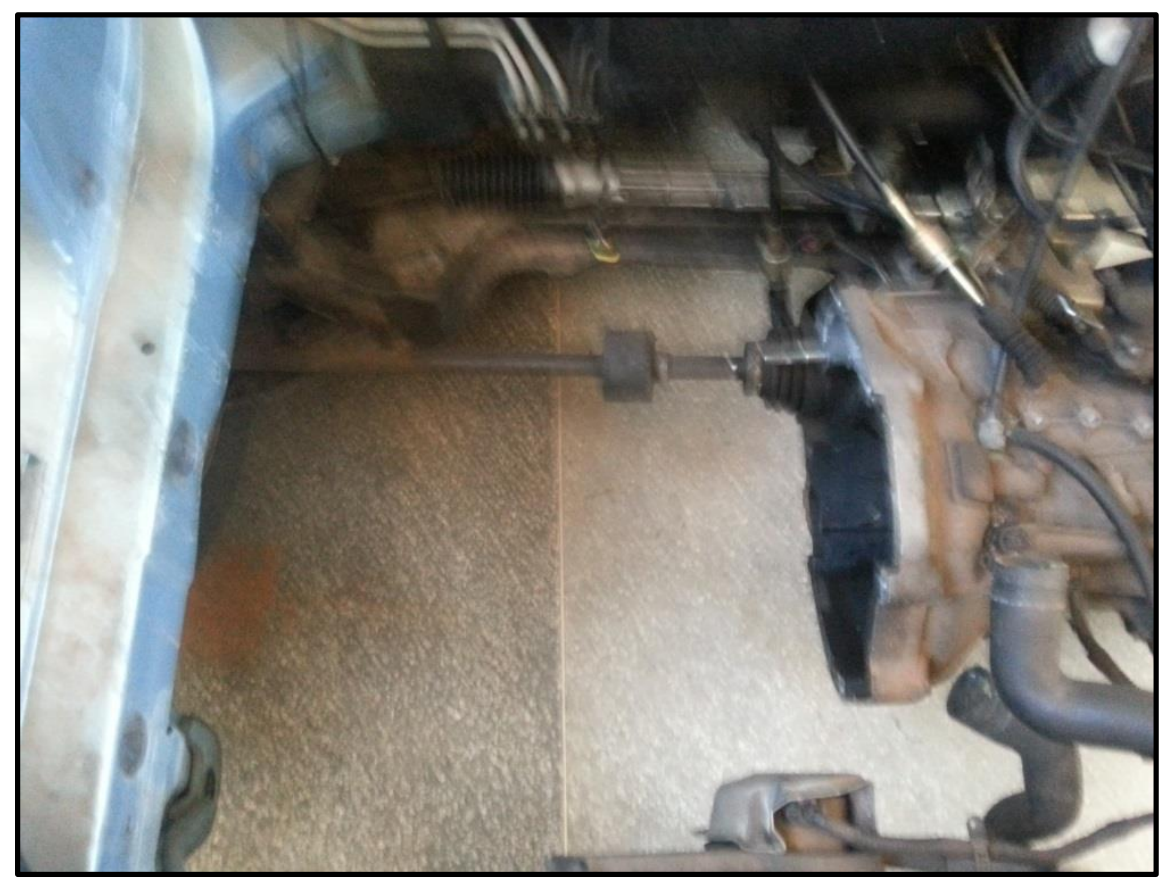

Figura 9 - Cofre do motor onde será instalado o motor elétrico 
A figura 6 apresenta a face da caixa de câmbio que receberá o motor elétrico por meio do flange de acoplamento.

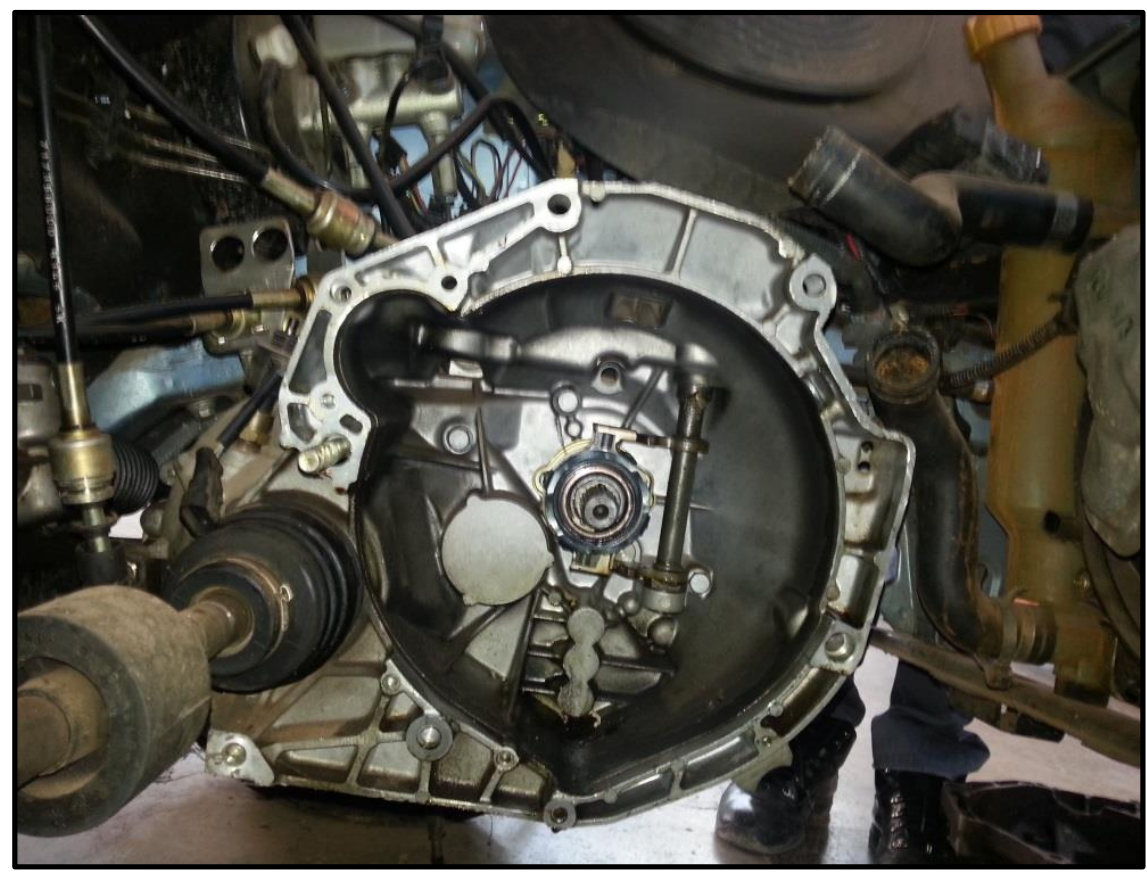

Figura 10 - Vista Frontal do ponto onde será acoplado o motor elétrico com o flange

\subsection{ESCOLHA DO MOTOR ELÉTRICO}

De posse dessas informações procede-se com os cálculos de torque e potência requeridos e em seguida é possível iniciar outra etapa da conversão que é a escolha do motor elétrico. Para tanto é importante avaliar algumas características necessárias ao motor elétrico a ser usado na aplicação que são: alta densidade de energia e torque; larga faixa de velocidade, com torque alto em baixa velocidade e com torque baixo em alta velocidade; confiabilidade e robustez para atender as constantes partidas e paradas; alta eficiência em larga faixa de velocidade e torque; bom desempenho em regimes transitórios; e facilidade de controle. (CHAN, 1996).

Com as informações citadas no item 2.5 é possível avaliar características de alguns motores com destaque para os de indução que tem alta densidade de potência; baixos cutos de manutenção e que por sua larga aplicação industrial e doméstica, tem custo relativamente baixo e tecnologia madura; e possibilidade de ser controlado pelo método escalar ou vetorial. 
Assim optou-se por um motor de indução trifásico assíncrono com potência de $21 \mathrm{~kW}$ da WEG, refrigerado a água e instrumentado para controle da temperatura, com massa e dimensões extremamente reduzidas junto com um inversor de frequência CFW 11, que trabalha com tensão trifásica de 220 Volts e uma corrente de até 105 Amperes conforme mostrado na tabela 5 .

Tabela 5 - Dados do motor elétrico escolhido

\begin{tabular}{|l|l|l|l|}
\hline $\begin{array}{l}\text { Motor de Induçao } \\
\text { Trifásico }\end{array}$ & Gaiola & Fator de Serviço & 1 \\
\hline Corrente Nominal & $84.4 \mathrm{~A}$ & Rendimento & $90,0 \%$ \\
\hline Tensão Nominal & $220 \mathrm{~V}$ & Fator de Potência & 0,79 \\
\hline Potência & $22 \mathrm{Kw} / 30 \mathrm{cv}$ & Frequência & $100 \mathrm{~Hz}$ \\
\hline RPM & 2930 & Número de Pólos & 4 \\
\hline Proteção & IP55 & Classe de isolamento & $\mathrm{H}$ \\
\hline Escorregamento & $3,33 \%$ & Massa aproximada & $57 \mathrm{~kg}$ \\
\hline $\begin{array}{l}\text { Comprimento } \\
\text { Aproximado }\end{array}$ & $327 \mathrm{~mm}$ & Refrigeração & a água \\
\hline Conjugado Nominal & $6.93 \mathrm{kgfm}$ & Conjugado de Partida & $240 \%$ \\
\hline Conjugado Máximo & $350 \%$ & PT-100 para & 9 \\
\hline
\end{tabular}

\subsubsection{Motor Elétrico Refrigerado a Água}

O motor utilizado no projeto tem características diferentes dos motores elétricos convencionais, pois é refrigerado a água, o que permite ao sistema manter a eficiência em diversos regimes de uso, especialmente em baixas rotações quando pode ser aplicado torque máximo. 
O sistema de refrigeração dos motores Water Cooled funciona de forma que a água percorre o interior da carcaça, agindo uniformemente sobre todo o invólucro do motor. Essa refrigeração mantém a alta eficiência térmica, inclusive em velocidades reduzidas, o que permite o uso de inversor de frequência com ampla faixa de velocidade, até mesmo em aplicações que requerem torque constante.

Os motores Water Cooled atendem aos rendimentos estabelecidos pela norma ABNT NBR 17094-1:2008 o que garante menor consumo de energia elétrica e redução dos custos globais de operação dos motores. Tais vantagens tornam os motores ideais para as mais variadas aplicações, principalmente em ambientes com limitações de espaço, ruído e circulação de ar. Aplicações típicas também incluem locais de difícil acesso para manutenção. (Manual WEG - Motores Water Cooled)

Tabela 6 - Vantagens do motor elétrico refrigerado a água

\begin{tabular}{|c|c|}
\hline Atributos & Benefícios \\
\hline $\begin{array}{l}\text { Níveis de rendimento conforme norma NBR } \\
\text { 17094-1: } 2008\end{array}$ & $\begin{array}{l}\text { Menor consumo de energia elétrica e redução } \\
\text { dos custos operacionais }\end{array}$ \\
\hline Refrigeração a água & $\begin{array}{l}\text { Garante maior dissipação térmica, } \\
\text { permitindo maiores potências por tamanho } \\
\text { de carcaça }\end{array}$ \\
\hline Ausência de ventilador externo & Redução do nível de ruído \\
\hline Menor volume & $\begin{array}{l}\text { Otimização de espaços com possibilidade } \\
\text { de redução da máquina do cliente }\end{array}$ \\
\hline Carcaça em ferro fundido em peça única & Não requer vedações adicionais \\
\hline PT-100 nos enrolamentos e mancais & $\begin{array}{l}\text { Permite o monitoramento contínuo da } \\
\text { temperatura de operação do motor }\end{array}$ \\
\hline Customização & $\begin{array}{l}\text { Produto customizado para atender aplicações } \\
\text { específicas }\end{array}$ \\
\hline $\begin{array}{l}\text { Operação com inversores de frequência sem } \\
\text { ventilação forçada }\end{array}$ & $\begin{array}{l}\text { Não necessita de circuitos auxiliares e reduz } \\
\text { o comprimento total do motor }\end{array}$ \\
\hline
\end{tabular}

Fonte: Manual WEG - Motores Water Cooled

A tecnologia desenvolvida pela WEG para a refrigeração do motor Water Cooled dispensa o uso de vedações adicionais entre os componentes. A água percorre um circuito 
totalmente fechado pelo interior da carcaça que, sendo fundida em uma peça única, elimina riscos de vazamentos. A figura 7 apresenta o corte de uma carcaça desse motor.

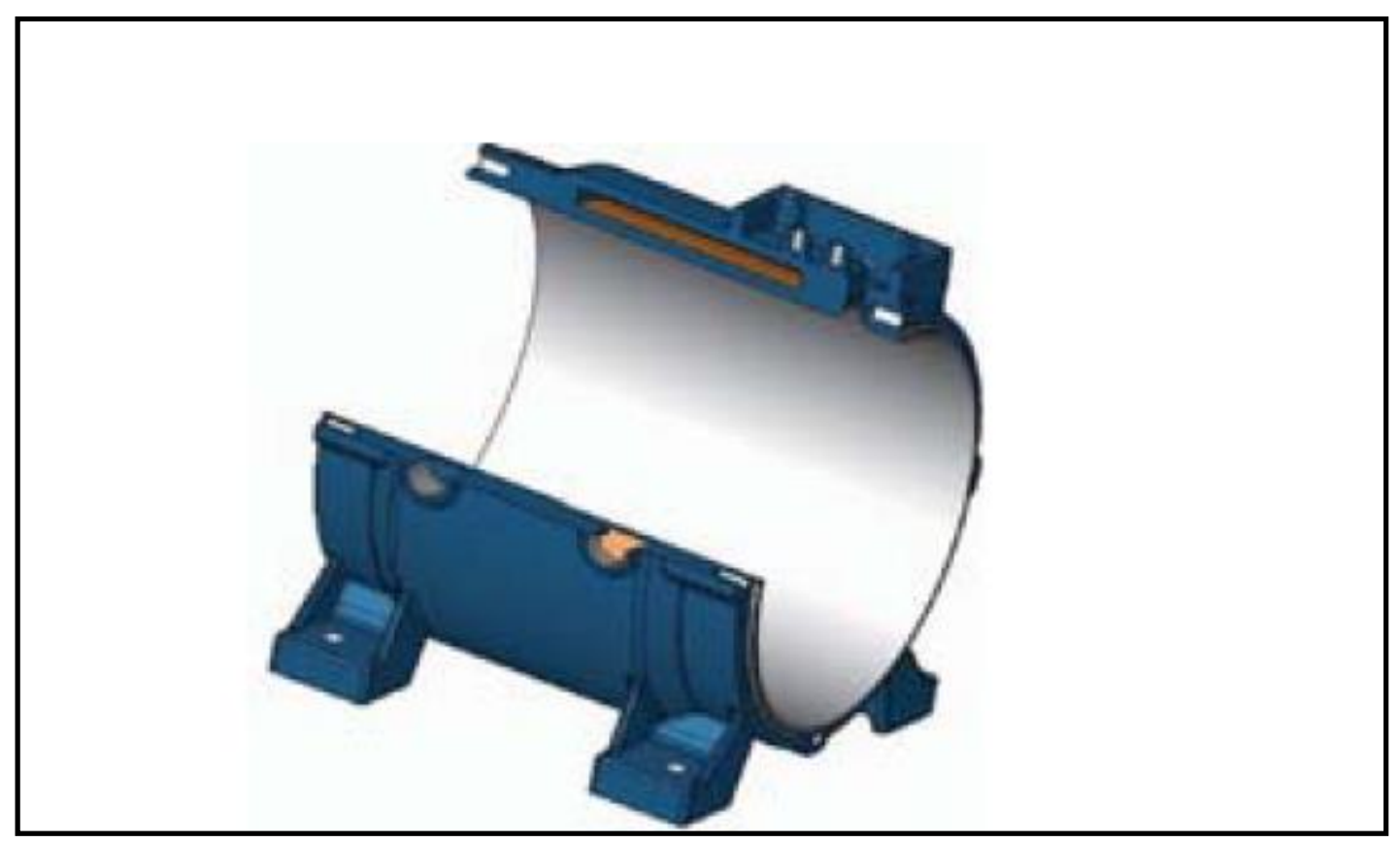

Figura 11 - Vista em corte carcaça do motor refrigerado a água

Fonte: Manual WEG - Motores Water Cooled

Os valores de vazão da água (estimados) para as carcaças refrigeradas à água, bem como a elevação de temperatura da água após circular pelo motor são mostradas na tabela 7.

Tabela 7 - Dados de vazão e elevação de temperatura

\begin{tabular}{|c|c|c|}
\hline Carcaça & $\begin{array}{c}\text { Vazão } \\
\text { (litros/minuto) }\end{array}$ & $\begin{array}{c}\text { Elevação de temperatura de } \\
\text { água }\left({ }^{\circ} \mathrm{C}\right)\end{array}$ \\
\hline $180 \mathrm{~L}$ & 12 & 5 \\
\hline $200 \mathrm{M}$ e $200 \mathrm{~L}$ & 12 & 5 \\
\hline $225 \mathrm{~S} / \mathrm{M}$ & 12 & 5 \\
\hline $250 \mathrm{~S} / \mathrm{M}$ & 12 & 6 \\
\hline $280 \mathrm{~S} / \mathrm{M}$ & 15 & 6 \\
\hline $315 \mathrm{~S} / \mathrm{M}$ & 16 & \\
\hline $355 \mathrm{M} / \mathrm{L}$ & 25 & 5 \\
\hline
\end{tabular}

Fonte: Manual WEG - Motores Water Cooled 
Cabe destacar que a aplicação de um motor elétrico refrigerado a água em um veículo que funcionava anteriormente com um motor a combustão interna, fará uso da estrutura existente no veículo, isso representa uma facilidade dado que num projeto original teriam que ser considerados aspectos aerodinâmicos, o comportamento térmico do motor, tipo e tamanho da tomada de ar para a convecção forçada, potência e perfil da hélice do eletroventilador além de simulações em ferramentas computacionais para a definição do escoamento do fluído de modo a maximizar o potencial de troca térmica, sem no entanto, esquecer detalhes muito importantes na atualidade como desing, potência e economia de combustível.

Em um motor de combustão interna aproximadamente um terço da energia do combustível é transformado em movimento, outro terço é expelido pelo coletor de escapamento e o último terço restante é dissipado sob a forma de calor pelo sistemas de arrefecimento, vide figura 12.

Antigamente, a preocupação era manter a temperatura do motor a combustão o mais próximo possível da temperatura ambiente pois acreditava-se que a elevação da temperatura era prejudicial ao funcionamento. A esse processo atribuia-se o nome de "sistema de refrigeração“, pois sua função era simplesmente reduzir a temperatura. As evoluções tecnológicas levaram o motor a funcionar melhor, mantendo uma temperatura mais elevada e constante, para que a dilatação dos diversos materiais aconteçam de forma controlada, conforme os cálculos da engenharia. A evolução dos sistemas alterou a função básica de reduzir a temperatura para fazer o motor aquecer-se o mais rapidamente possível, para atingir a temperatura ideal de funcionamento, manter essa temperatura e distribuí-la por todo o motor. Assim, o sistema passou a ser chamado de Sistema de Arrefecimento. (MTE- Tomson) 


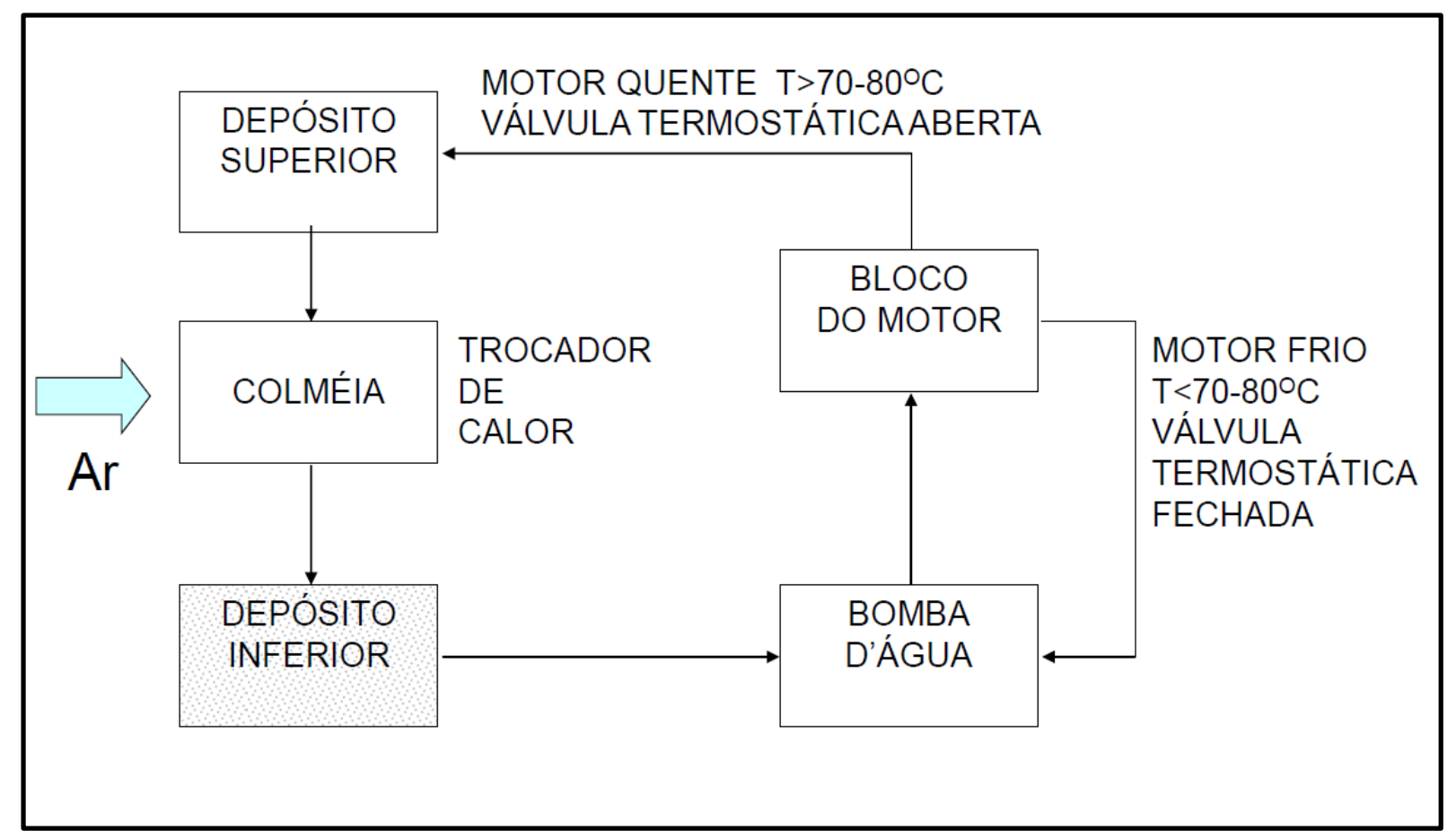

Figura 12 - Fluxo de água no sistema de arrefecimento de circulação forçada ar-água de um motor a combustão interna

Fonte: site UFRJ

Segundo (Quim, Nelson 2007), existem alguns pré-requisitos para o desenvolvimento de um projeto de um sistema de arrefecimento:

a) Uma vazão adequada de líquido de arrefecimento no motor;

b) Um radiador (trocador de calor) eficiente para retirar o calor proveniente do motor; e

c) Um eletroventilador potente acoplado ao radiador para garantir a troca térmica na condição de baixa velocidade, proporcionando temperaturas adequadas aos componentes do motor.

Assim, pode-se inferir que o projeto do sistema de arrefecimento em um projeto de veículo é de extrema importância e influi diretamente no seu resultado final do projeto.

Os motores elétricos são constantemente expostos a condições hostis como esforços mecânicos e elétricos, vibração, umidade, pó, produtos corrosivos e abrasivos e altas temperaturas. Todas contribuem para a diminuição da vida útil da isolação de motores elétricos. Cita-se que a temperatura é causa recorrente de envelhecimento do material isolante. Caso a temperatura nos enrolamentos do motor ultrapasse de 8 a 10 graus acima da temperatura limite definida pela sua classe, o motor pode ter sua vida últil reduzida pela 
metade. Os dados referentes as classes normalmente constam nos dados de placa dos equipamentos elétricos.

Os materiais e sistemas isolantes são classificados conforme sua resistência à temperatura por longos períodos de tempo. As normas citadas na tabela 8 referem-se à classificação de materiais e sistemas isolantes.

Tabela 8 - Classificação de materiais e sistemas isolantes

\begin{tabular}{|l|l|l|}
\hline Materiais & Sistemas & Materias e Sistemas \\
\hline UL 746B & UL 1446 & IEC 60085 \\
\hline IEC 60216 & UL 1561/1562 & \\
\hline & IEC 60505 & \\
\hline & IEEE 117 & \\
\hline
\end{tabular}

Fonte: ecatalogweg.net

As classes térmicas definidas para os materiais e sistemas isolantes são apresentadas na tabela 9 .

Tabela 9 - Classes Térmicas

\begin{tabular}{|l|l|l|}
\hline \multicolumn{3}{|c|}{ CLASSES DE TEMPERATURA } \\
\hline Temperatura $\left({ }^{\circ} \mathrm{C}\right)$ & IEC 60085 & UL 1446 \\
\hline 90 & Y $\left(90^{\circ} \mathrm{C}\right)$ & - \\
\hline 105 & A $\left(105^{\circ} \mathrm{C}\right)$ & - \\
\hline 120 & E $\left(120^{\circ} \mathrm{C}\right)$ & $120(\mathrm{E})$ \\
\hline 130 & B $\left(130^{\circ} \mathrm{C}\right)$ & $130(\mathrm{~B})$ \\
\hline 155 & F $\left(155^{\circ} \mathrm{C}\right)$ & $155(\mathrm{~F})$ \\
\hline 180 & $\mathrm{H}\left(180^{\circ} \mathrm{C}\right)$ & $180(\mathrm{H})$ \\
\hline 200 & $\mathrm{~N}\left(200^{\circ} \mathrm{C}\right)$ & $200(\mathrm{~N})$ \\
\hline 220 & $\mathrm{R}\left(220^{\circ} \mathrm{C}\right)$ & $220(\mathrm{R})$ \\
\hline 240 & - & $240(\mathrm{~S})$ \\
\hline Acima de $240{ }^{\circ} \mathrm{C}$ & - & \multirow{2}{*}{ Acima de $240\left({ }^{\circ} \mathrm{C}\right)$} \\
\hline 250 & 250 & \multicolumn{1}{|c|}{} \\
\hline
\end{tabular}

Fonte: ecatalogweg.net 
No Brasil as classes de isolamento utilizadas em máquinas elétricas e os respectivos limites de temperatura estão definidos conforme NBR 5116 e são apresentados na tabela 10.

Tabela 10 - Composição da Temperatura em função da classe de isolamento

\begin{tabular}{|c|c|c|c|c|c|}
\hline Classe de Isolamento & A & $\mathrm{E}$ & B & $\mathrm{F}$ & $\mathrm{H}$ \\
\hline Temperatura ambiente ${ }^{\circ} \mathrm{C}$ & 40 & 40 & 40 & 40 & 40 \\
\hline Elevação da Temperatura ${ }^{\circ} \mathrm{C}$ & 60 & 75 & 80 & 100 & 125 \\
\hline Temperatura da classe ${ }^{\circ} \mathrm{C}$ & 100 & 115 & 120 & 140 & 165 \\
\hline $\begin{array}{l}\text { Diferença entre o ponto mais quente e a } \\
\text { temperatura média } \mathrm{em}^{\circ} \mathrm{C}\end{array}$ & 5 & 5 & 10 & 15 & 15 \\
\hline Temperatura limite da classe ${ }^{\circ} \mathrm{C}$ & 105 & 120 & 130 & 155 & 180 \\
\hline
\end{tabular}

Fonte: ecatalogweg.net

O motor aplicado neste projeto tem classe de isolamento $\mathrm{H}$ e fator de serviço igual a 1 . Como será aproveitada a estrutura pré-existente do Pálio com o radiador, o eletroventilador e o termoestato que irá acionar o eletroventilador a uma temperatura aproximada de $90{ }^{\circ} \mathrm{C}$, isso garante que o motor elétrico trabalhará em uma condição intermediária ao limite previsto na sua classe de isolamento. Em adição, os sensores de temperatura, PT-100, instalados na armadura e no enrolamento do motor elétrico serão integrados ao Inversor de Frequência, o que permite programar um alarme para proteger o motor de sobreaquecimentos, caso alguma parte do sistema de arrefecimento apresente problemas.

\subsection{EXECUÇÃO DA CONVERSÃO}

Nesta etapa houve a necessidade de definir-se de que forma seria construída a estrutura de acoplamento do motor elétrico no veículo. A estrutura ficou definida da seguinte forma: 
Transmissão: Optou-se por aproveitar a caixa de transmissão já existente no veículo para que não fosse necessário buscar no mercado alguma solução ou mesmo trabalhar no desenvolvimento de nova caixa;

Embreagem: Apesar de aproveitar-se a caixa de transmissão do veículo, foi feita a opção de usar um sistema de acoplamento direto no eixo piloto da caixa de transmissão sem usar a embreagem. O detalhe importante é que, neste caso, não será usado o kit de embreagem. O acoplamento servirá apenas para o ensaio no laboratório em uma única marcha por meio do Ciclo SAE J227a, em duas das quatro modalidades C e D.

Foram desenhadas e usinadas uma flange (figura 8) e um distanciador (figura 9), em aço 1045, que servem de apoio para toda a estrutura do motor elétrico a ser conectada a caixa de transmissão.

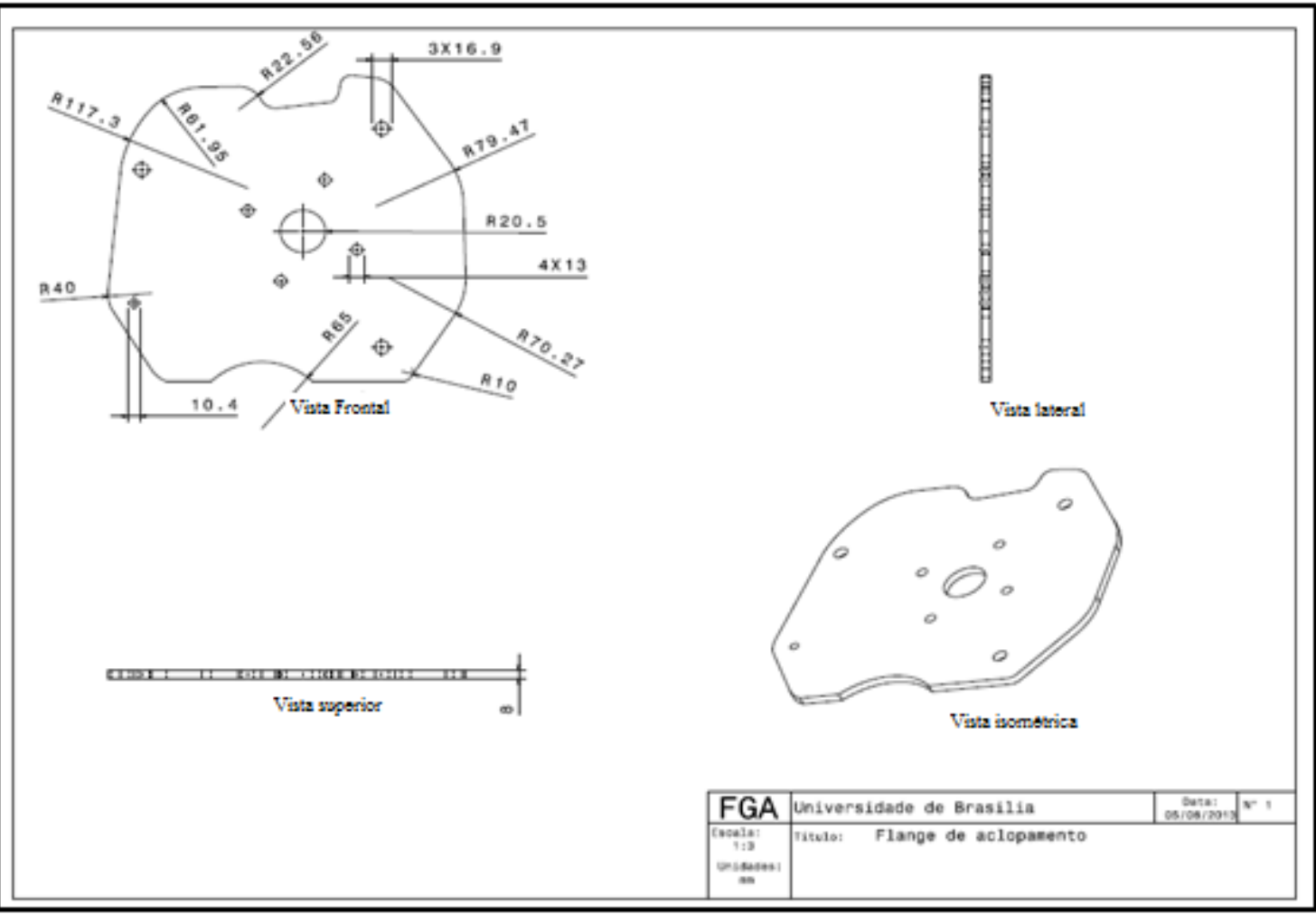

Figura 13 - Detalhamento da flange

Fonte: O autor, 2013. 


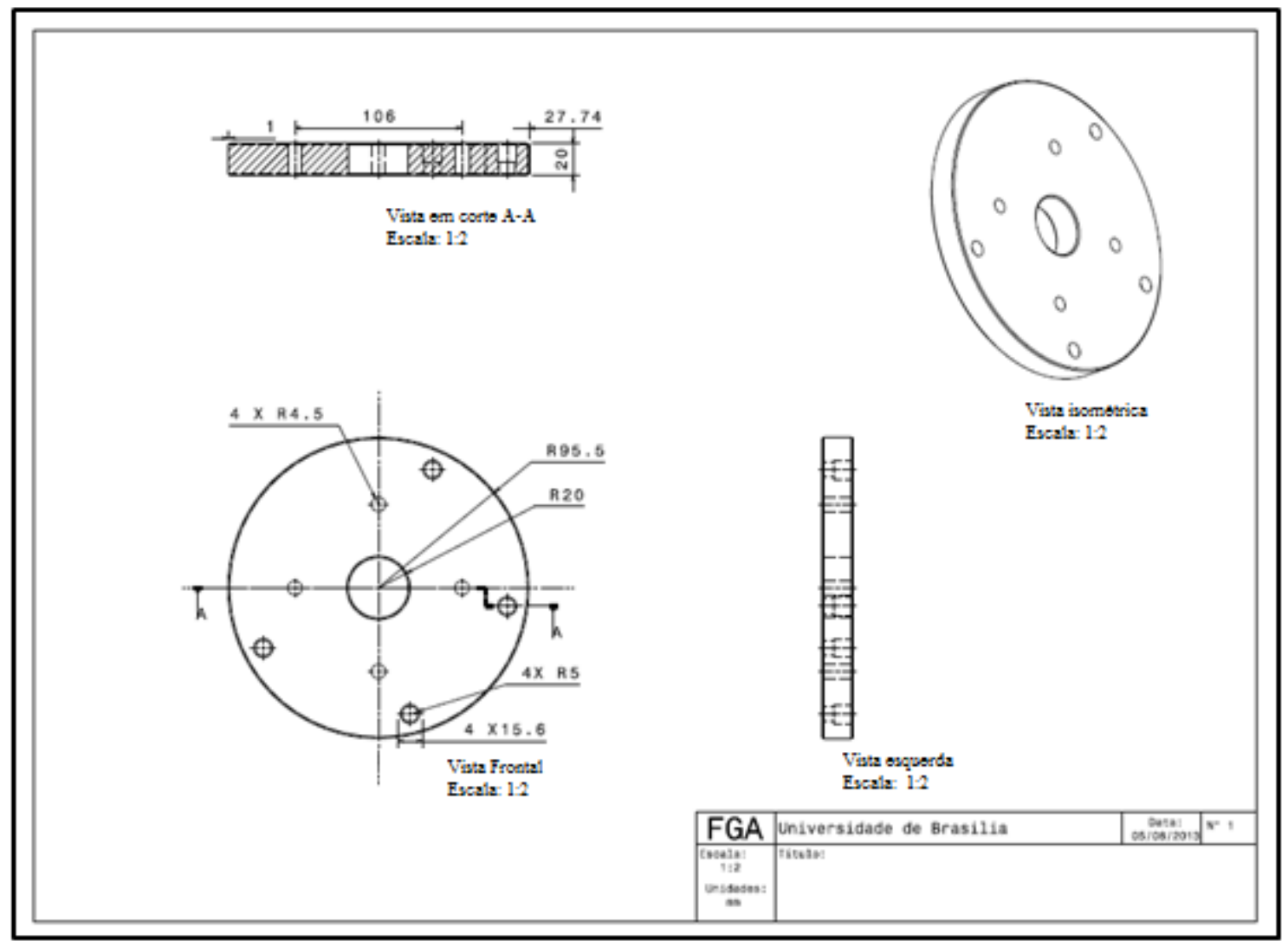

Figura 14 - Detalhamento do distanciador Fonte: O autor, 2013.

A figura 10 apresenta o desenho das peças desenvolvidas para a fixação do conjunto e acoplamento.

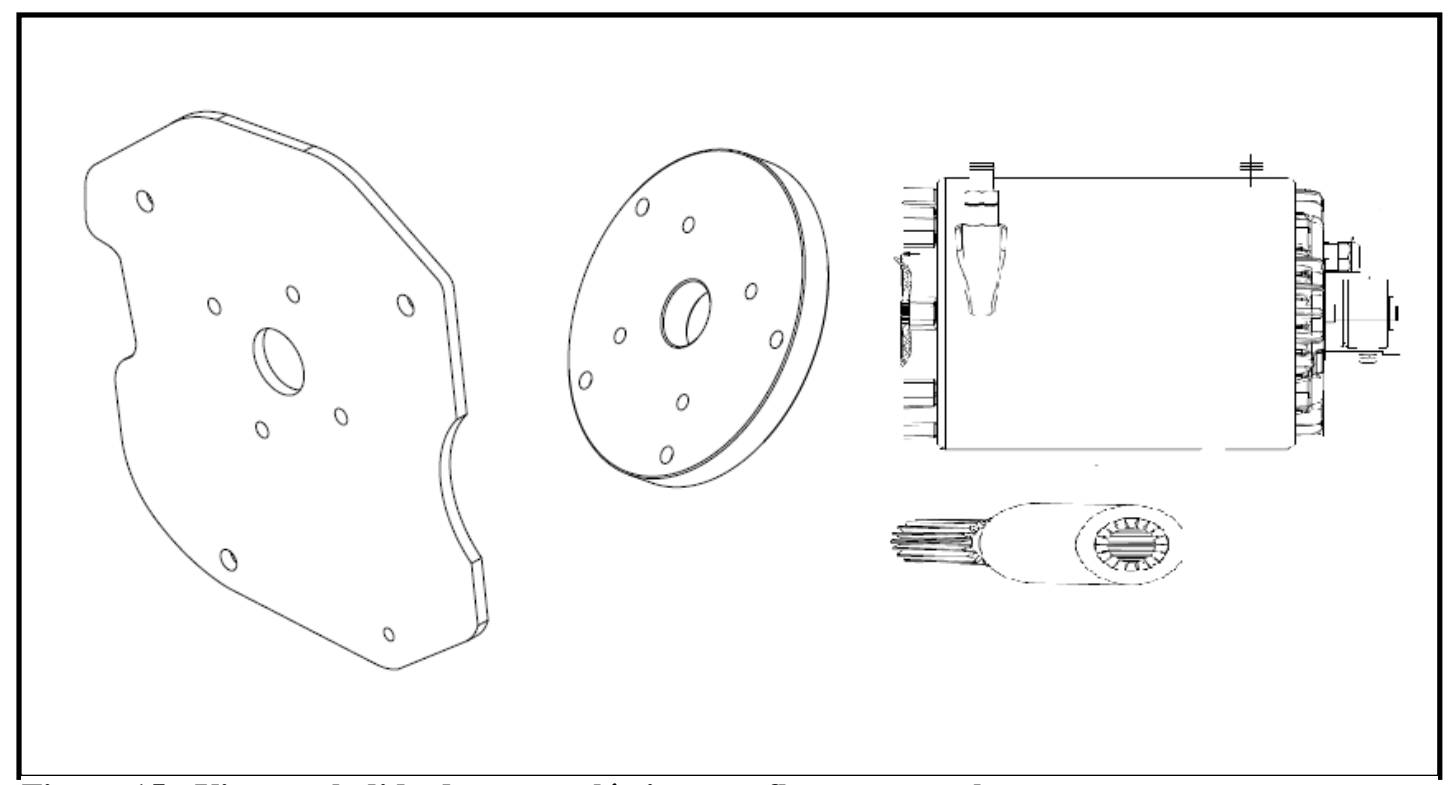

Figura 15 - Vista explodida do motor elétrico com flanges e acoplamento

Fonte: O autor, 2013. 
Para o acoplamento foi usinado um eixo em aço 1045 (figura 11) com as dimensões do furo do eixo do motor elétrico e também do eixo piloto da caixa de transmissão.

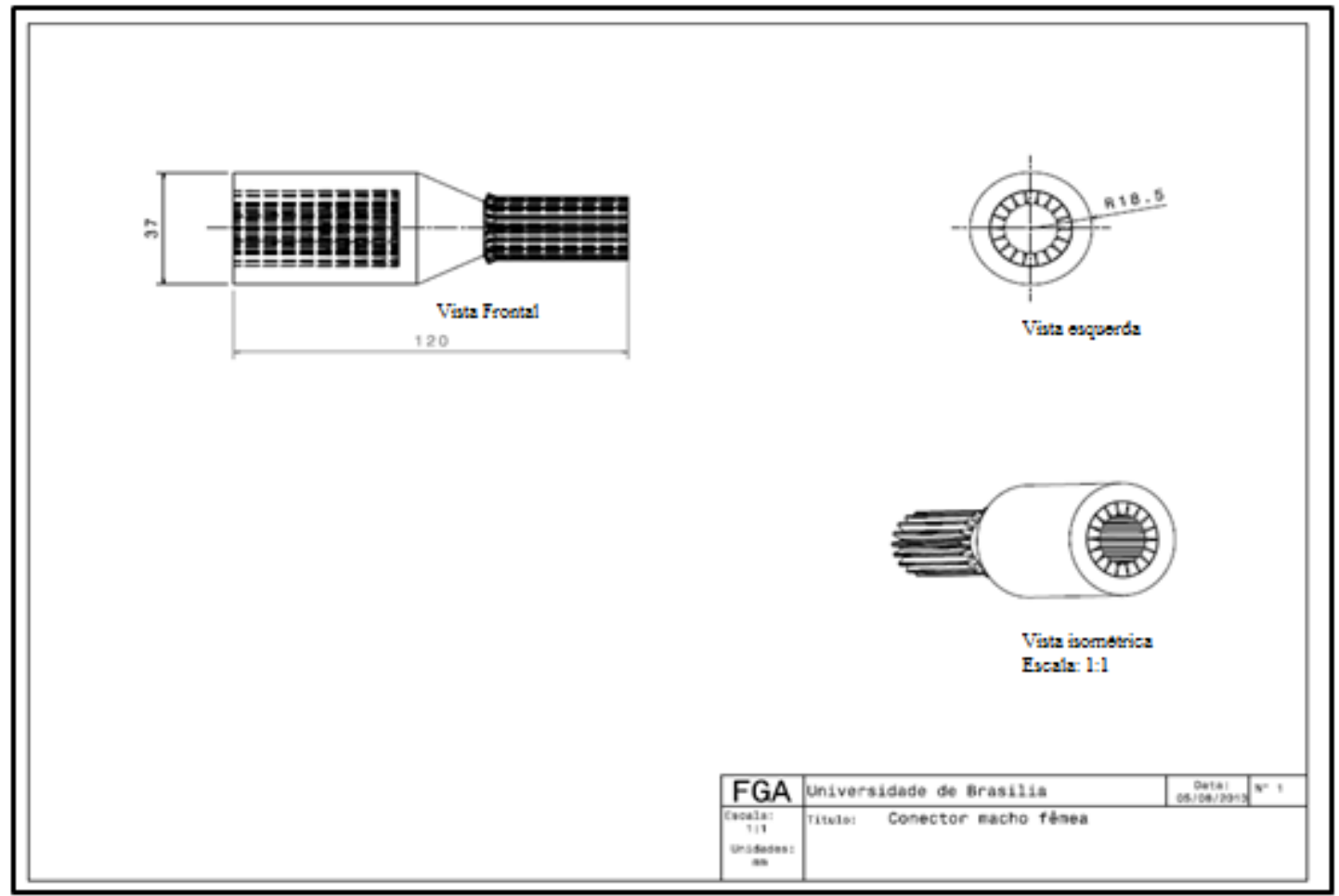

Figura 16 - Detalhamento do acoplamento

Fonte: O autor, 2013.

As peças e o processo de intalação pode ser verificado nas figuras 12 e 13 .

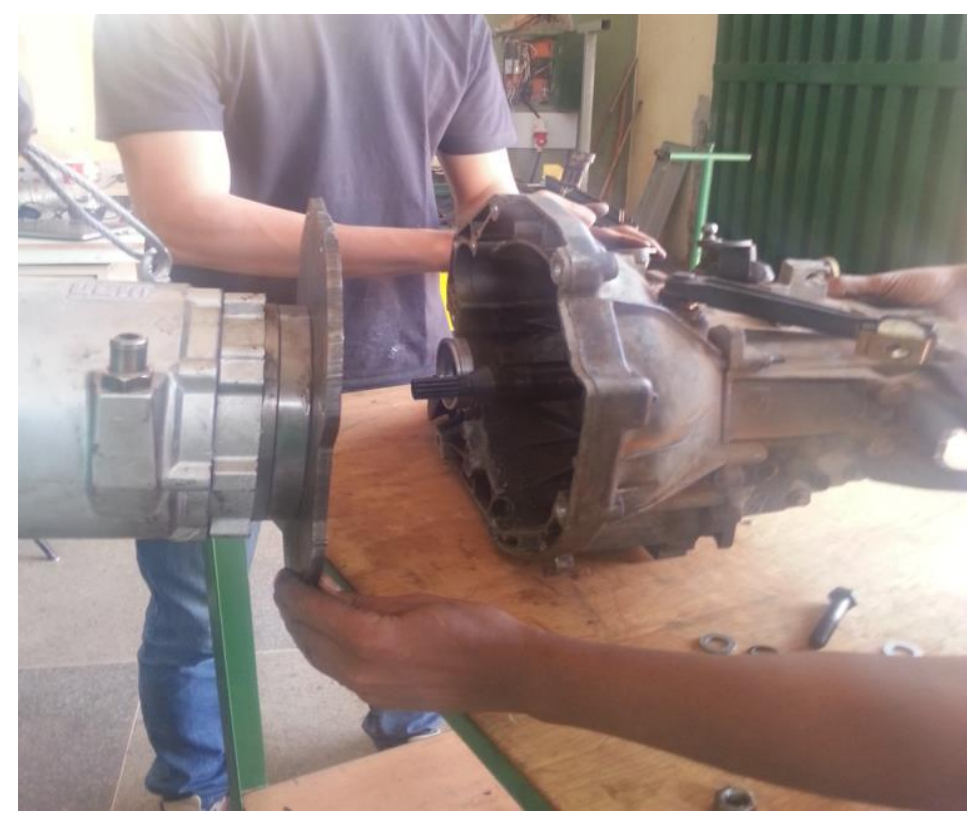

Figura 17 - Conjunto motor, flange, acoplamento e câmbio sendo montados Fonte: O autor, 2013. 


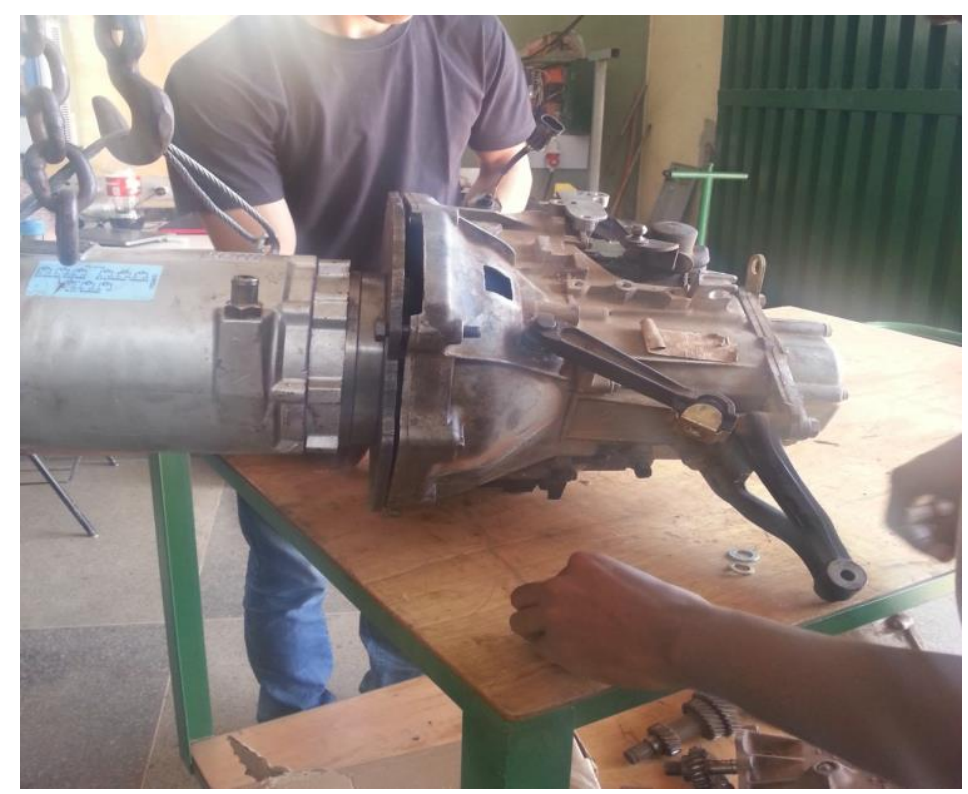

Figura 18 - Conjunto sendo fixado

Fonte: O autor, 2013.

Neste capítulo foram relatados os passos seguidos para a definição do motor elétrico a ser utilizado na tração do veículo, levando em consideração o fato de já se dispor do veículo, isso representou uma vantagem pois, do contrário seria necessária a avaliação de uma série de outras condições para transpor essa etapa, conforme recomendados por (Costa, 2012).

Cabe destacar os ganhos de espaço e redução massa consideráveis pelo simples uso de um motor refrigerado a água. Para se ter uma estimativa do ganho, a relação peso/potência nos dias atuais em motores de indução é da ordem de $5,7 \mathrm{~kg} / \mathrm{kw}$, enquanto nesse motor a relação é de aproximadamente $2,6 \mathrm{~kg} / \mathrm{kw}$. 


\section{PROJETO E EXECUÇÃO DA BANCADA}

Dentro da estrutura da plataforma, a bancada tem um papel muito importante, o de reunir todos os componentes necessários para reproduzir o banco de baterias, sistemas de proteção e toda a parte de controle e potência, sem que nenhum desses componentes e sistemas esteja instalado no veículo.

A bancada é composta por um quadro de comando elétrico que recebe tensão da rede e conecta o transformador rebaixador trifásico de $380 / 220 \mathrm{~V}$ de $30 \mathrm{kw}$ por meio de dispositivos de conecção e proteção. O conjunto dispõe também de um inversor de frequência e resistores de freio interconectados ao quadro de comandos elétricos. O projeto obedece as normas NBR 9050 e a NR 12.

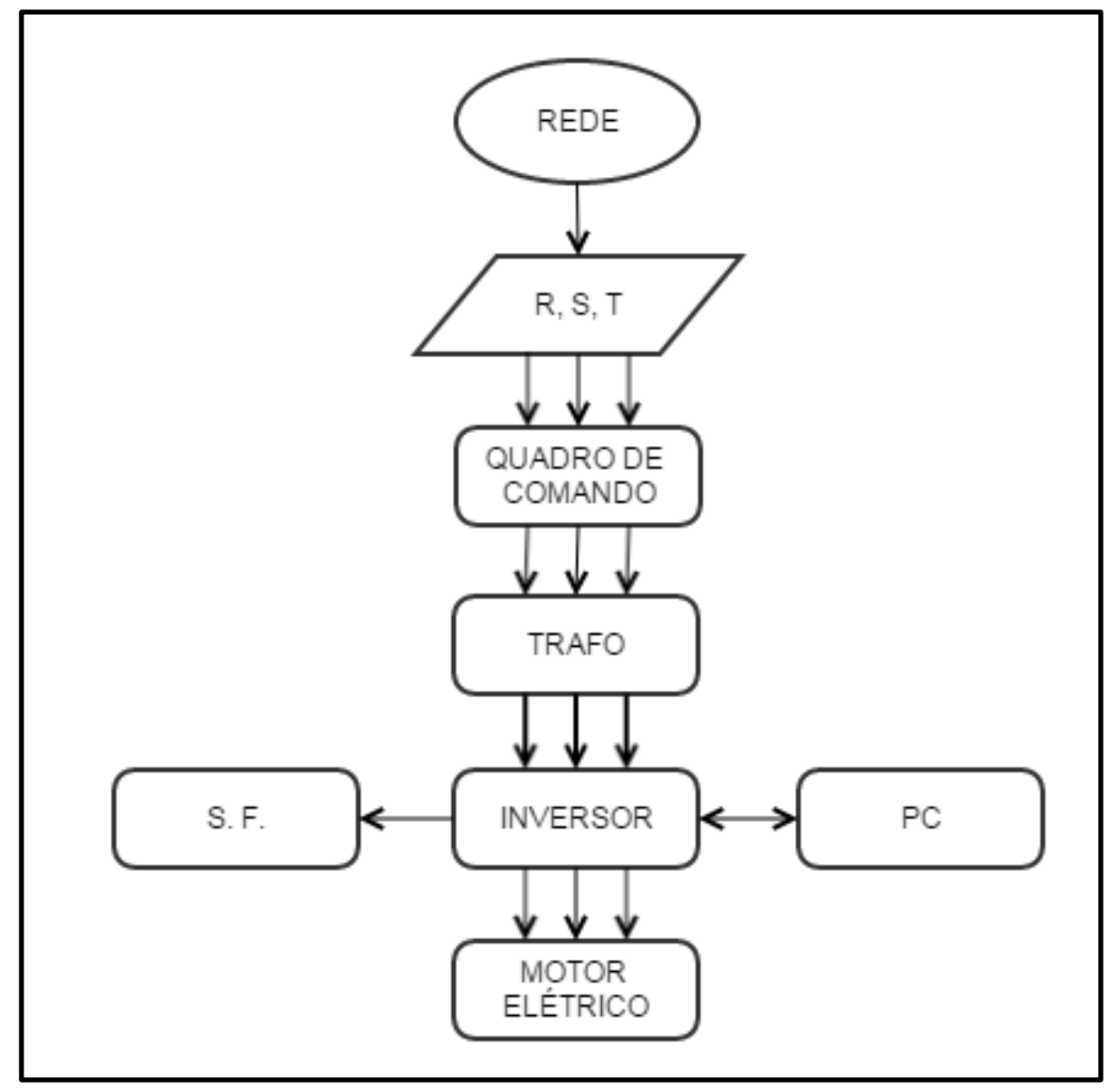

Figura 19 - Diagrama dos componentes da banca de ensaios Fonte: O autor, 2013. 
No diagrama da figura 14 podem-se identificar de forma esquemática os elementos que compõem a bancada:

- Trafo - O transformador recebe tensão de 380 volts trifásico da rede elétrica e a rebaixa para 220 volts trifásico. Está conectado ao Quadro de Comando Elétrico onde fica os sistemas de proteção e as conexões que alimentam o Inversor de Frequência;

- Quadro de comandos elétricos - Concentra os componentes de controle e segurança relativos ao primário e ao secundário do Transformador;

- Inversor de Frequência - Responsável pelo envio de alimentação do Motor Elétrico. Recebe a alimentação do secundário do Transformador através do Quadro de Comando Elétrico e pode ser acessado tanto pela sua Interface Homem Máquina (IHM) como pelo computador;

- S.F. - Sistema de Freio. Funciona interligado ao Inversor de Frequência e pode ser usado para freiar o motor elétrico. Dissipa energia elétrica por efeito Joule; e

Além dos componentes ilustrados na figura 14, o dinamômetro dispõe de um controle dinâmico, equipamento usado para inserir resistência por meio do freio magnético que foi instalado a parte da bancada, por questões de mobilidade.

\subsection{SISTEMA ELÉTRICO DA BANCADA}

O projeto elétrico foi desenvolvido de modo a promover segurança e confiabilidade na operação. Assim, foram introduzidos no seu projeto diversos equipamentos tais como seccionadoras, contatores, fusíveis e outros equipamentos elétricos integrados neste sentido.

A figura 15 apresenta o trifilar do sistema elétrico da bancada. 


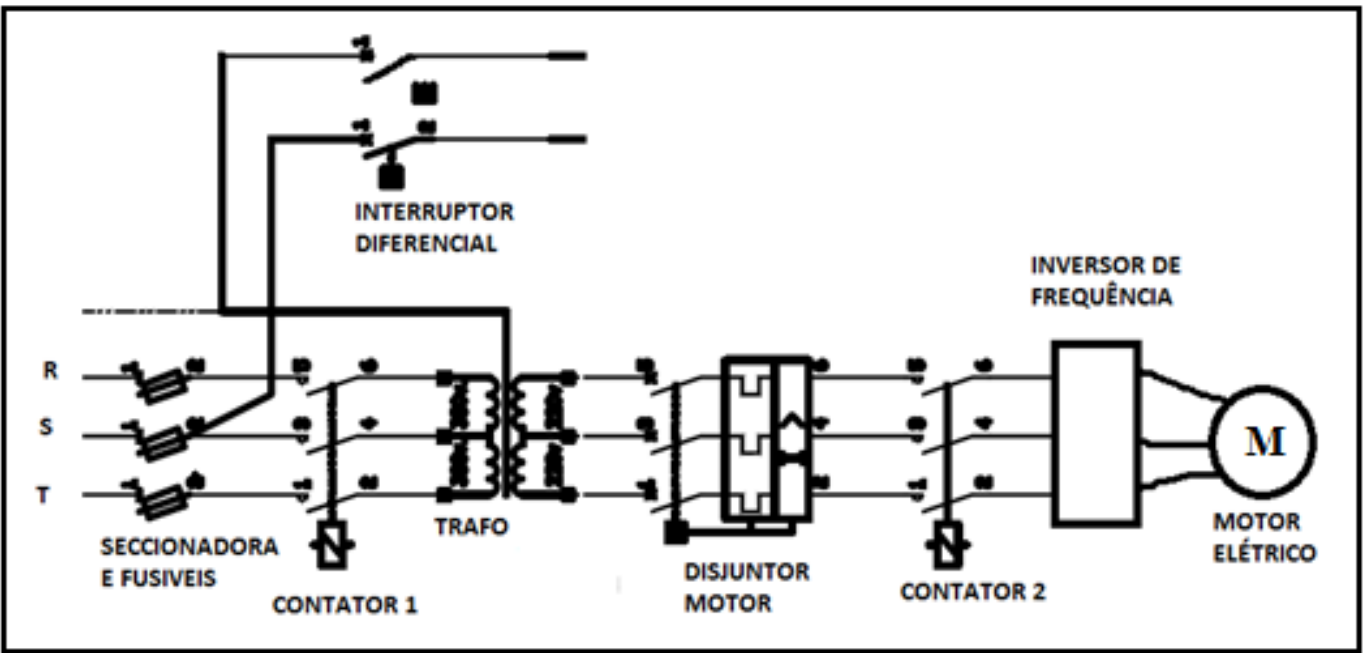

Figura 20 - Trifilar das proteções da bancada de ensaios

Fonte: O autor, 2013.

\subsection{QUADRO DE COMANDO}

O quadro de comando apresentado na figura 16 dispõe de componentes como: chave seccionadora tripolar, fusíveis ultra-rápidos, potenciômetro e indicadores luminosos de operação. Além dos equipamentos necessários para a realização dos testes no motor, existem também os equipamentos responsáveis pela proteção, comando e conexão da bancada, que são a chave seccionadora, o contator, o disjuntor em caixa, disjuntores motor e tomadas industriais que usam interruptor diferencial para proteção. 


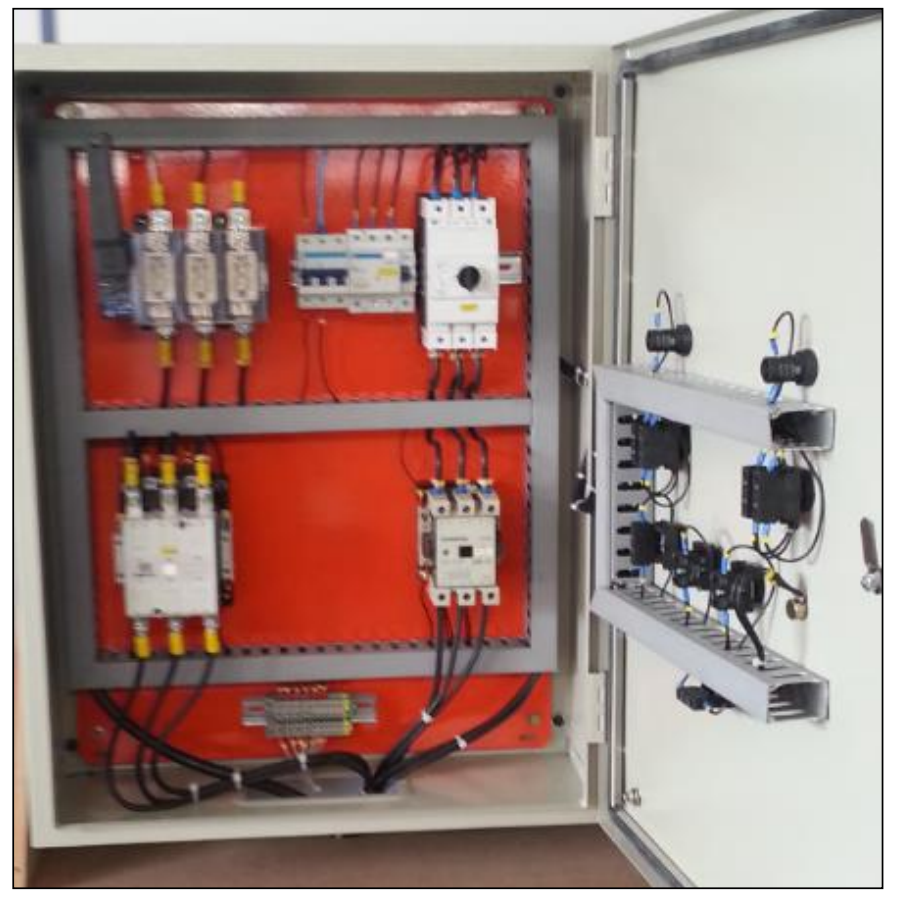

Figura 21 - Quadro de comando elétrico

Fonte: O autor, 2013.

\subsection{TRANSFORMADOR}

Os transformadores são utilizados para realizarem a elevação ou a redução dos níveis de tensão sendo em alguns casos de extrema importância para a funcionalidade dos componentes de um sistema. No caso da bancada de testes, para que os equipamentos funcionem de maneira adequada é necessário utilizar um transformador rebaixador de 380/220 Volts trifásico.

Como a bancada de testes realizará ensaios com motores de potência elevada, como o motor elétrico de $22 \mathrm{~kW}$ o transformador tem $30 \mathrm{~kW}$ de potência (vide figura 17). 


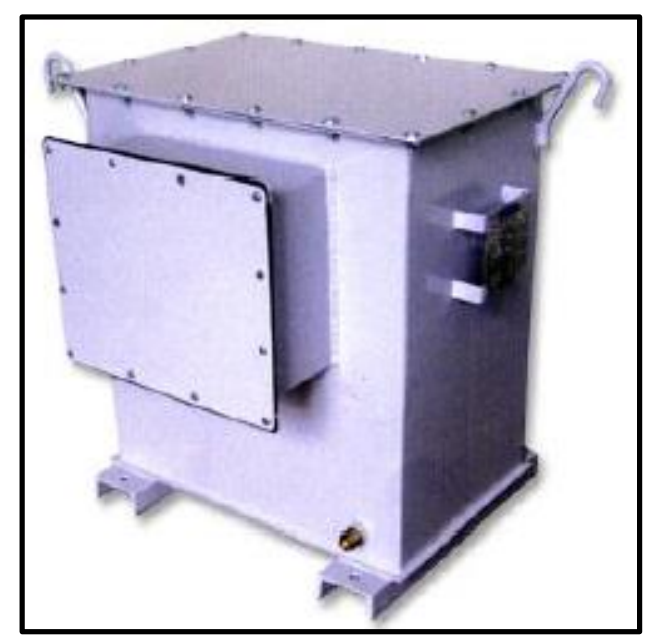

Figura 22 - Transformador da bancada de ensaios

\subsection{INVERSORES DE FREQUÊNCIA}

O Inversor de Frequência é o principal equipamento da bancada, sendo por meio dele que a partida e o controle do motor elétrico são realizados. O controle realizado pelo inversor ocorre a partir de variações de frequência e tensão no barramento do motor, que é feito com o uso de transistores, possibilitando que o sinal de saída determine a velocidade e o sentido de rotação desejada para do motor elétrico. Além disso, o inversor atenua a corrente de pico ocasionada pela partida do motor, o que evita um superdimensionamento dos condutores do sistema de alimentação do carro elétrico. O diagrama típico de um inversor de frequência é apresentado na figura 18. 


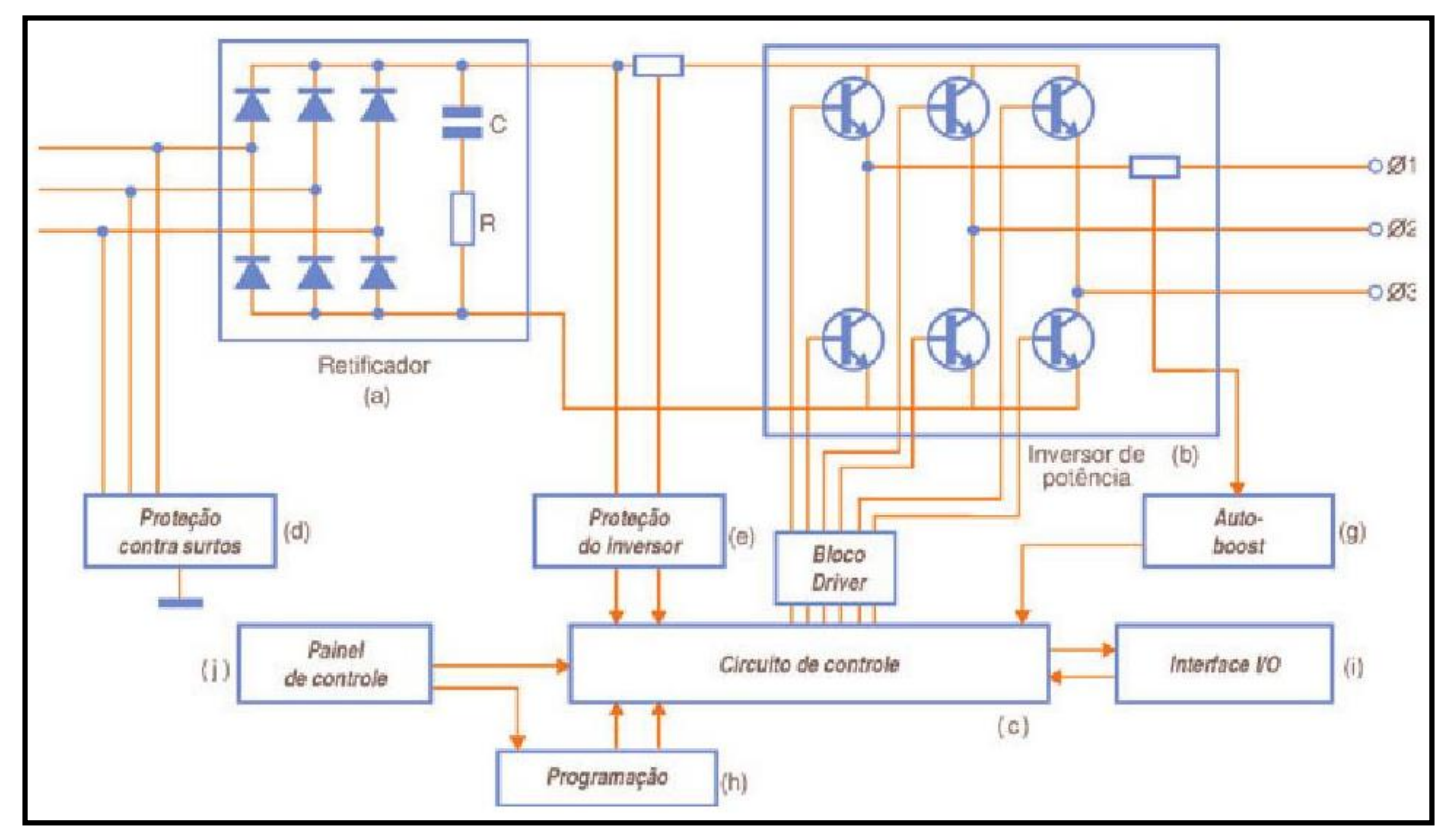

Figura 23 - Diagrama de um inversor de frequência típico

Fonte: Mecatrônica Atual

O modelo de Inversor de Frequência utilizado para o projeto foi o CFW 110105 T2 da empresa WEG. Esse inversor é alimentado com tensão de 220 Volts trifásico, sendo que a corrente máxima de funcionamento é de 105 Amperes. O controle desse inversor pode ser feito através de um comando local, através de uma Interface Homem Máquina (IHM) ou a partir de um comando remoto, que pode ser realizado com o uso de chaves e de um potenciômetro. O monitoramento dos parâmetros controlados pelo inversor pode ser realizado por essa IHM ou então a partir do software Super Drive G2. O uso do comando remoto do inversor permite que o controle seja realizado a partir de componentes típicos em automóveis, como a um pedal de acelerador dotado de potenciômetro no lugar do potenciômetro do inversor e uma chave de acionamento do motor, mas para isso é preciso realizar algumas adequações. Com o referido software pode-se acessar todas as funcionalidades do comando remoto, além de permitir identificação online do drive conectado, edição e transferência de parâmetros entre o drive e o Computador, monitoração gráfica de parâmetros e comunicação, importação e visualização de variáveis armazenadas na função Trace do drive. A figura 19 mostra uma imagem da tela do Super Drive G2. 


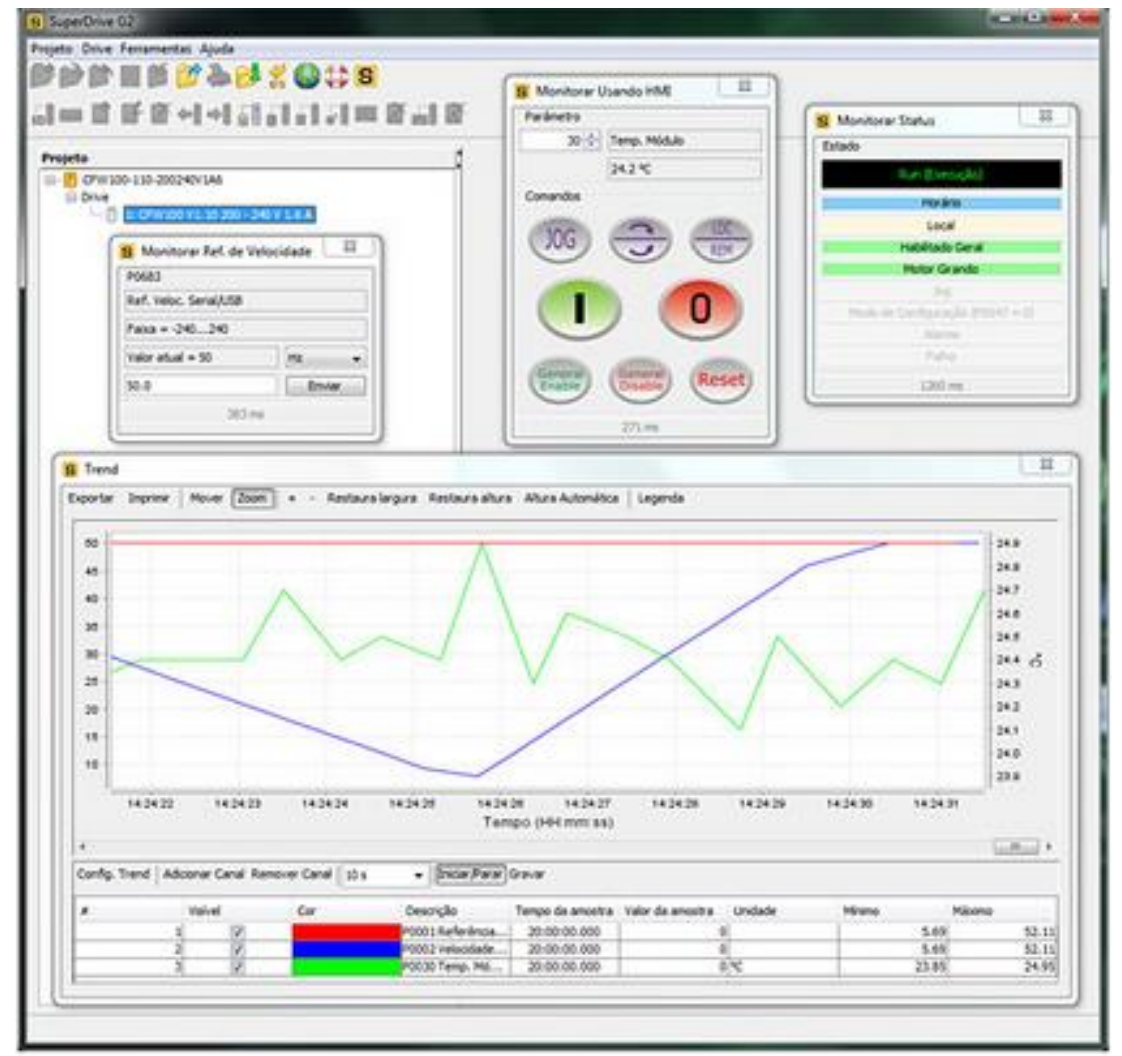

Figura 24 - Tela do software Super Drive G2

Fonte: Weg.net

O inversor de frequência CFW-11 é um produto de alta performance que permite o controle de velocidade e torque de motores de indução trifásicos. A característica central deste produto é a tecnologia "Vectrue", a qual apresenta as seguintes vantagens:

- controle escalar (V/f), V V W ou controle vetorial programáveis no mesmo produto;

- o controle vetorial pode ser programado como "sensorless" (o que significa motores padrões, sem necessidade de encoder) ou como controle vetorial com encoder no motor;

- o controle vetorial "sensorless" permite alto torque e rapidez de resposta, mesmo em velocidades muito baixas ou na partida;

- o controle vetorial com encoder possibilita alto grau de precisão no acionamento, para toda faixa de velocidade ;

- função "frenagem ótima" para o controle vetorial, permitindo a frenagem controlada do motor, eliminando, em algumas aplicações, o uso do resistor de frenagem; 
- a função "autoajuste" para o controle vetorial permite ajuste automático dos reguladores e parâmetros de controle, a partir da identificação (também automática) dos parâmetros do motor e da carga utilizada. (Manual do Inversor CFW 11)

A figura 20 mostra uma foto da bancada com todos os componentes apta a ser usada nos ensaios.

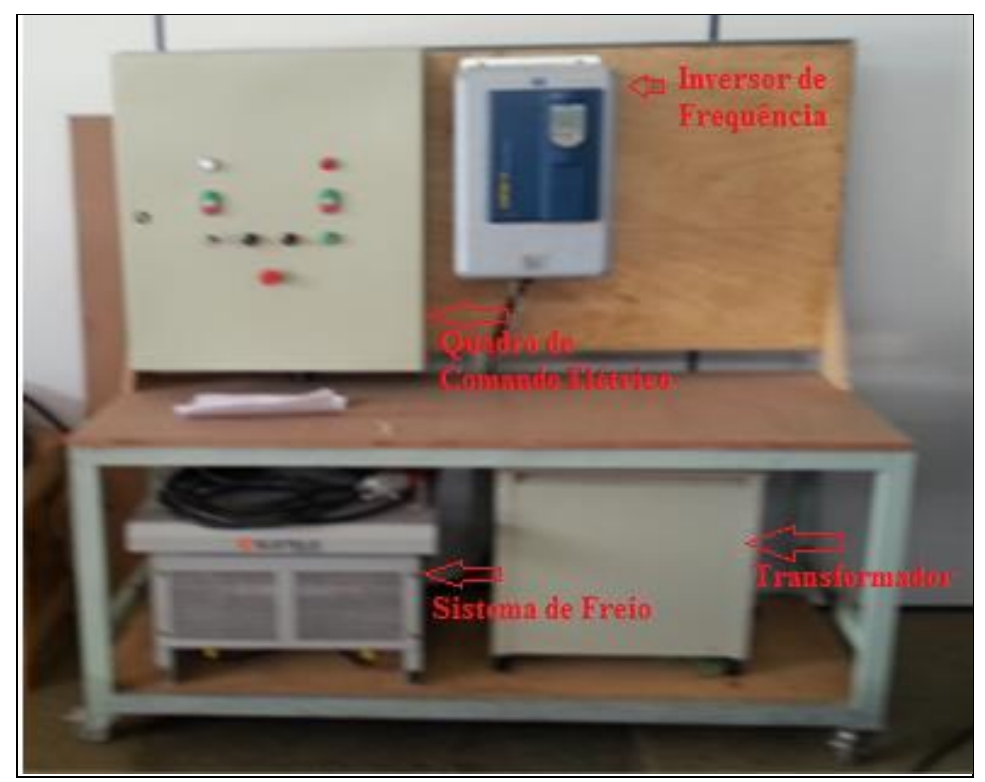

Figura 25 - Foto da bancada elétrica montada

Fonte: O autor, 2013. 


\section{INTEGRAÇÃO DO DINAMÔMETRO}

Finalizada a conversão e a construção da bancada, passou-se para a instalação do dinamômetro para permitir integrá-lo à plataforma. Cabe destacar que o equipamento estava armazenado há pelo menos quatro anos, pois foi adquirido para outro projeto de pesquisa e por motivos desconhecidos não chegou a ser usado.

Foi escolhido um local para coloca-lo em operação levando em conta critérios de segurança e acessibilidade, além de permitir o uso de pontos de fixação para as cintas de segurança que mantém o veículo afixado em cima da prancha.

\subsection{DINAMÔMETROS}

Com o advento das máquinas a vapor no século XVIII e, posteriormente, com o desenvolvimento de motores de combustão interna, surgiu a necessidade de medir-se os efeitos dinâmicos daquelas máquinas, tais como momento angular, torque, potência etc.

Em 1821, Gaspard Riche de Prony, um físico francês, desenvolveu o primeiro dispositivo com essa finalidade: o freio de Prony. Esse equipamento consistia de um dinamômetro de fricção, indubitavelmente eficiente para a época, e que foi insubstituível por quase um século. (VIANA, 2011).

Décadas se passaram até a introdução do freio hidráulico por Willian Froude, engenheiro naval, em 1877. Posteriormente, com o desenvolvimento de motores de corrente contínua, foi concebido em 1883 o dinamômetro de corrente contínua. (SHERIF, 1985 apud VIANA, 2011).

Apesar das contribuições sobre a teoria de dinamômetros de correntes parasitas serem formuladas pelo físico Francês Jean Bernard Leon Foucault, (1819-1868), o método somente foi implementado em um dispositivo por volta de 1928. Nesse período a medição de desempenho era voltada apenas para validação de motores de combustão interna. (SHERIF, 1985 apud VIANA, 2011).

Com a criação do sistema de transmissão, a análise de desempenho passou para o veículo como um todo e os testes tiveram que ser aprimorados. Discussões sobre seu desenvolvimento são citadas em relatórios da Sociedade de Engenharia Automotiva (SAE) datados de 1951, nos quais o foco da pesquisa era a medição de desempenho dos sistemas de 
freios veiculares. Nesses documentos foram descritos, em detalhes, o funcionamento e o processo de utilização do equipamento, que recebeu o nome de Dinamômetro de Inércia. (JOERGES; SHINN, 2001 apud VIANA, 2011).

Os dinamômetros de inércia eram usados para duas funções distintas: a medição de desempenho em sistemas de freios veiculares e a medição de desempenho de motores e sistemas de transmissão conjugados.

Em diversas referências bibliográficas os dinamômetros citados anteriormente são caracterizados como dinamômetros de absorção, cuja finalidade é absorver a energia gerada pelo motor. Existem ainda dinamômetros de transmissão descritos como transmissores de energia para o sistema.

Os dinamômetros podem ser classificados de diferentes formas, principalmente com relação aos seus modelos. (VIANA, 2011).

\subsubsection{Dinamômetro De Correntes De Foucault}

O princípio do funcionamento de um Dinamômetro de Corrente de Foucault, representado na Figura 21, está intrinsecamente ligado ao fenômeno de geração de correntes elétricas parasitas no interior de massas metálicas condutoras, imersas em campos magnéticos variáveis, denominadas Correntes de Foucault. (SOUZA, 2005 apud VIANA, 2011).

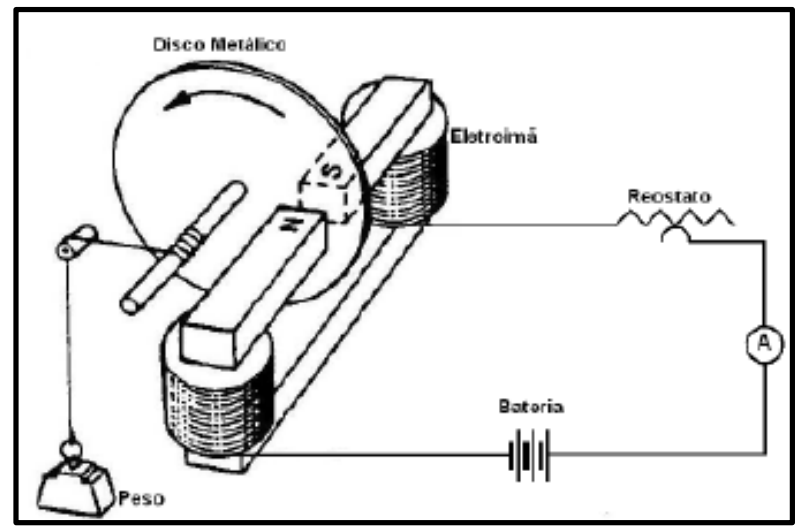

Figura 26 - Princípio de funcionamento do dinamômetro de Corrente de Foucault

Fonte: Haical, 2009.

Quando o sistema está desligado, livre da presença de corrente de alimentação nos ímãs, o disco metálico não encontra dificuldades em realizar o movimento. Porém, é freado no momento em que uma corrente parasita inicia sua circulação proporcionalmente a 
velocidade do disco. O fenômeno físico descrito nessa situação é definido pela Lei de Lenz, que é enunciada resumidamente na seguinte forma: "Qualquer corrente induzida tem um sentido tal que o campo magnético que ela gera se opõe à variação do fluxo magnético que a produziu." (HAICAL, 2009; SOUZA, 2005 apud VIANA, 2011).

A figura 21 representa o princípio de funcionamento de um dinamômetro de corrente contínua. Quando o eletroíma é alimentado por uma corrente elétrica, ele induz um campo magnético ao redor do disco metálico. Esse campo gera as correntes de Foucault no disco que por sua vez, gera campos magnéticos opostos aos primeiros induzidos, freando o sistema. A variação da corrente produz a variação de torque no dinamômetro. A medição desse torque é feita transferindo-se o valor para o instrumento por meio de uma alavanca.

A larga utilização desse dinamômetro está relacionada com a produção de torques elevados em baixas rotações, com a rapidez na resposta às variações de carga e com a sua grande robustez. (VIANA 2011).

\subsubsection{Dinamômetros De Corrente Alternada}

O dinamômetro de corrente alternada tem como característica a geração de energia elétrica em seus terminais na realização de procedimentos de teste em equipamentos, razão pela qual é descrito a partir do princípio de funcionamento de um gerador elétrico. Essa energia é absorvida por uma carga variável, que pode ser uma cuba eletrolítica ou um banco de resistores.

Para a realização de testes mais precisos é necessária a correção dos instrumentos a fim de compensar perdas no rendimento do gerador. Os benefícios dessas máquinas são a utilização do dinamômetro como motor para acionamento do equipamento em teste, o tamanho reduzido e o baixo custo. (HAICAL, 2009 apud VIANA, 2011).

\subsubsection{Dinamometros de Corrente Contínua}

Da mesma maneira que os dinamômetros de corrente alternada, os dinamômetros de corrente contínua acionam ou freiam o equipamento em teste, funcionando como motor 
elétrico ou como gerador. A partir da força aplicada em uma célula de carga por um braço de alavanca conectado à carcaça do gerador e do comprimento deste mesmo braço é possível calcular o torque. (VIANA 2011).

\subsection{DINAMOMETRO DA PLATAFORMA}

O dinamômetro DYNOmite Dynamometer AC refrigerado a ar automotivo que foi usado nos ensaios é de origem americana e é do tipo AC (correntes de Foucault). Ele mede a carga de controle, em microsegundos, além disso aplica automaticamente os fatores de correção SAE para temperatura do ar, pressão barométrica e umidade relativa.

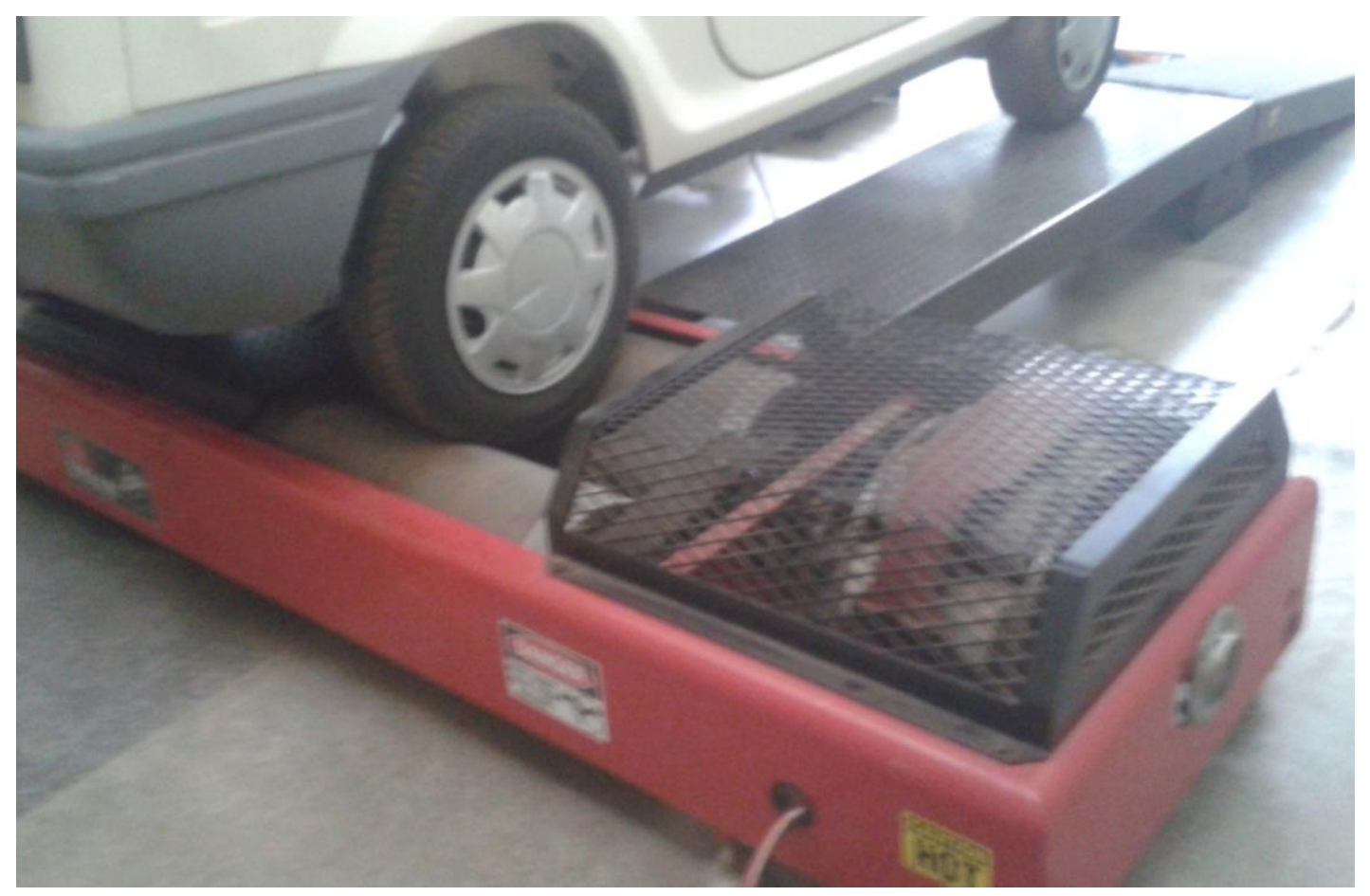

Figura 27 - Dinamômetro no laboratório

Fonte: O autor, 2013.

Um computador, por meio do programa DYNO-MAX, apresenta os dados adquiridos no monitor e faz registro real de Potência, Torque, RPM, tempo decorrido podendo fazer até 1000 leituras por segundo em cada canal.

Permite também simular as condições de condução por meio do programa e do PC utilizando a função " road load simulation " que simula a arrancada do veículo, resistência do 
ar, o atrito de rolamento, etc. sendo necessário que seja fornecido dados do veículo como o peso e dados de arrasto. Dispõe de uma biblioteca com diversos modelos de veículos que utilizam motores a combustão interna sendo capaz de fazer correções em função para características ambientais onde acontece o ensaio como altitude, temperatura ambiente, humidade e densidade do ar.

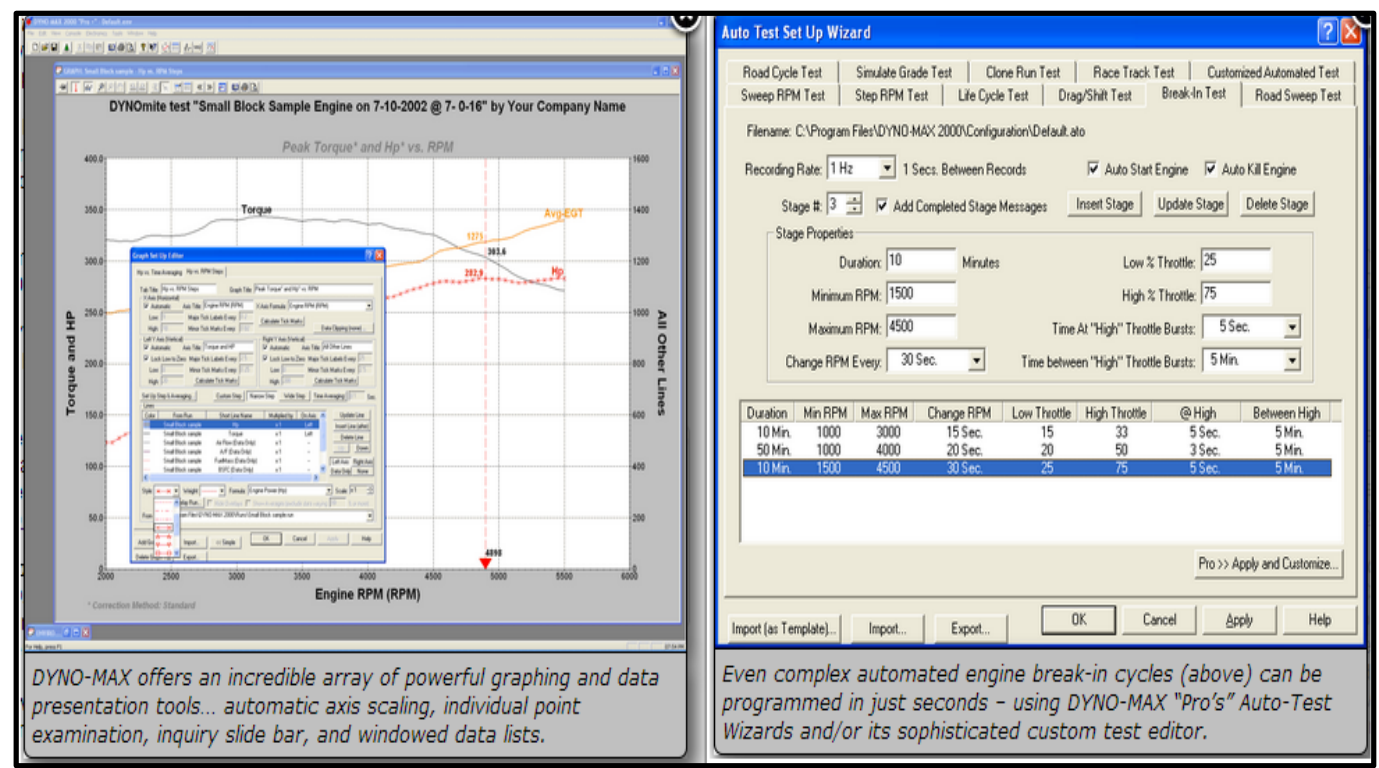

Figura 28 - Tela do software DYNO MAX

Fonte: site DYNOmite Dynamometer

O dinamômetro é composto de transdutores que monitoram a frequência de rotação dos rolos e o torque que são usados para determinar a potência em diversos regimes de ensaio. Para os ensaios deste trabalho foi utilizada a instrumentação do dinamômetro para levantar as curvas de torque e potência do veículo a ser ensaiado.

O diagrama de blocos apresentado na figura 24 demonstra os passos para a coleta de informações no sistema utilizando o software do equipamento na ilustração A e os passos necessários para coleta de dados durante o ensaio na ilustração B. 


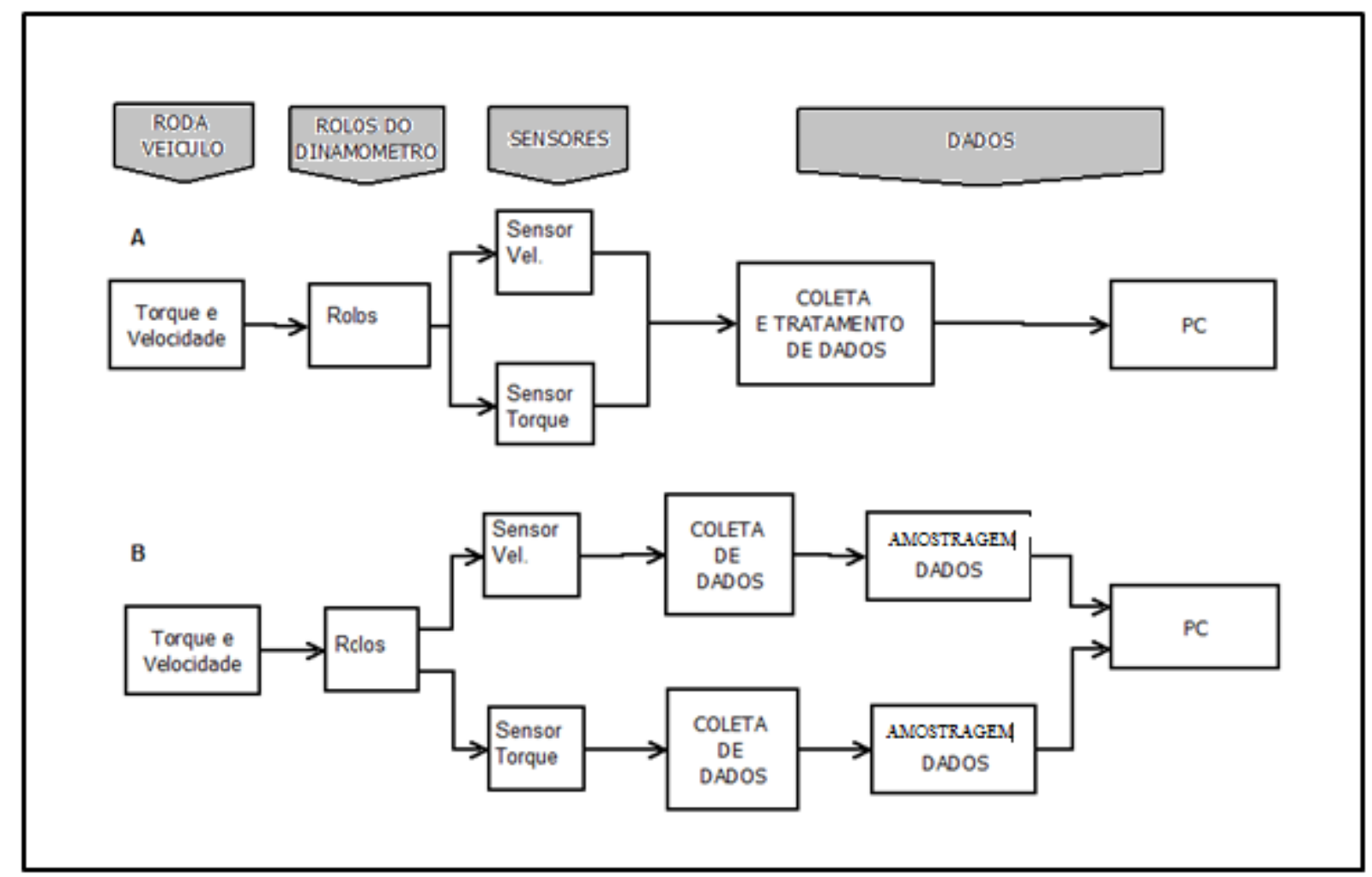

Figura 29 - Diagrama de blocos do funcionamento do Dinamômetro (A) com software (B) caminho alternativo

Fonte: O autor, 2013.

Os dados do dinamômetro são oriundos dos transdutores sendo que o primeiro é uma célula de carga tipo straing gage e o segundo um sensor de rotação indutivo (vide ilustração figura 30). Foi necessário fazer a calibragem de ambos para obter-se maior confiabilidade na coleta dos dados. Straing gage é um componente que mede a variação de resistência elétrica proporcional a deformação da bitola de um corpo e que normalmente atua numa ponte tipo Wheastone no lugar do resistor variável. Na figura 31 pode-se observar a célula de carga usada que é da marca Total Comp e tem capacidade de medir até $680 \mathrm{kgf}$, com resolução de 3 $\mathrm{mV} / \mathrm{V}$ e um erro da ordem de $0,03 \%$. Para fazer as leituras foi utilizado um mostrador da marca MK modelo 2030. 


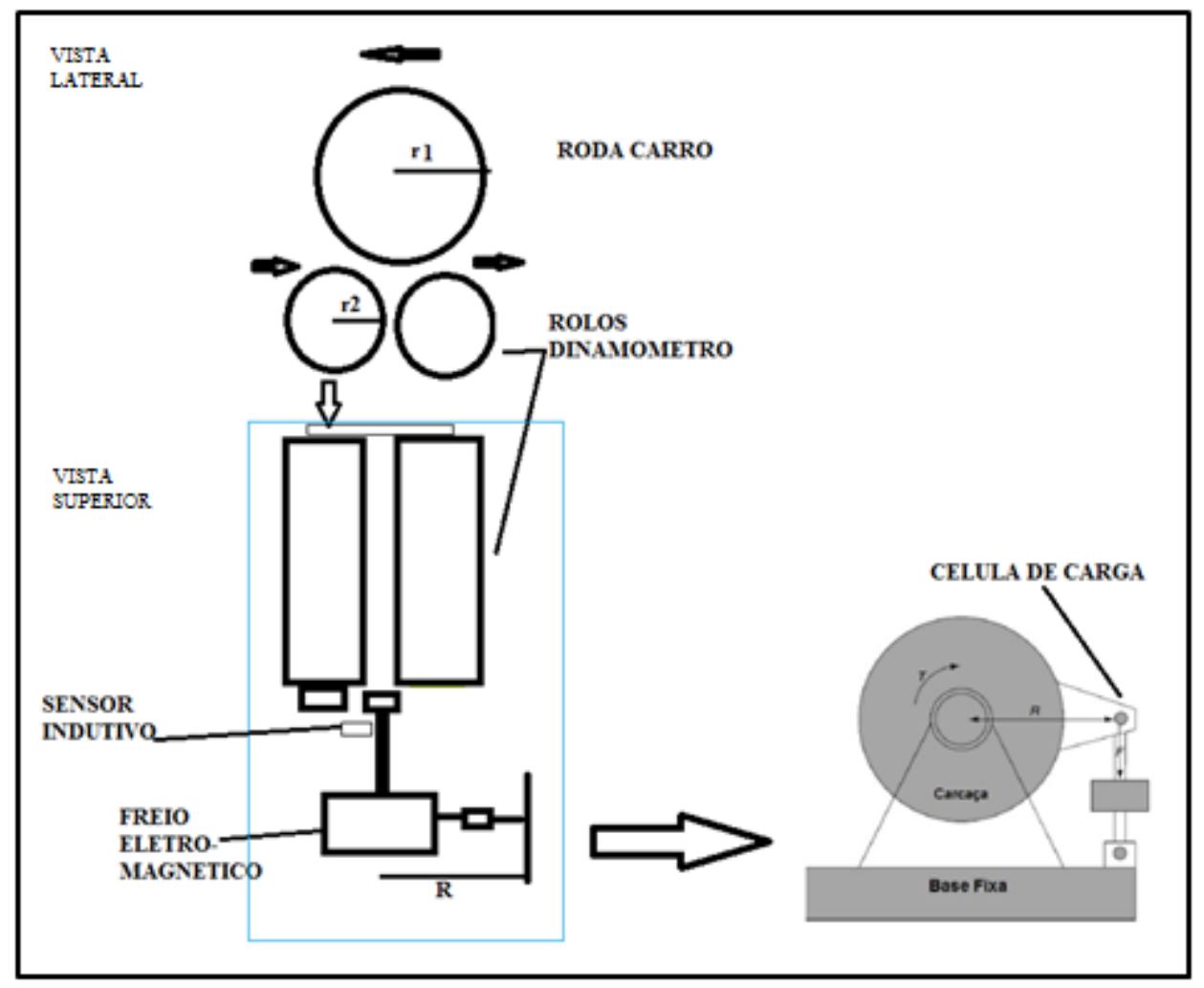

Figura 30 - Esquemático da instrumentação no dinamômento

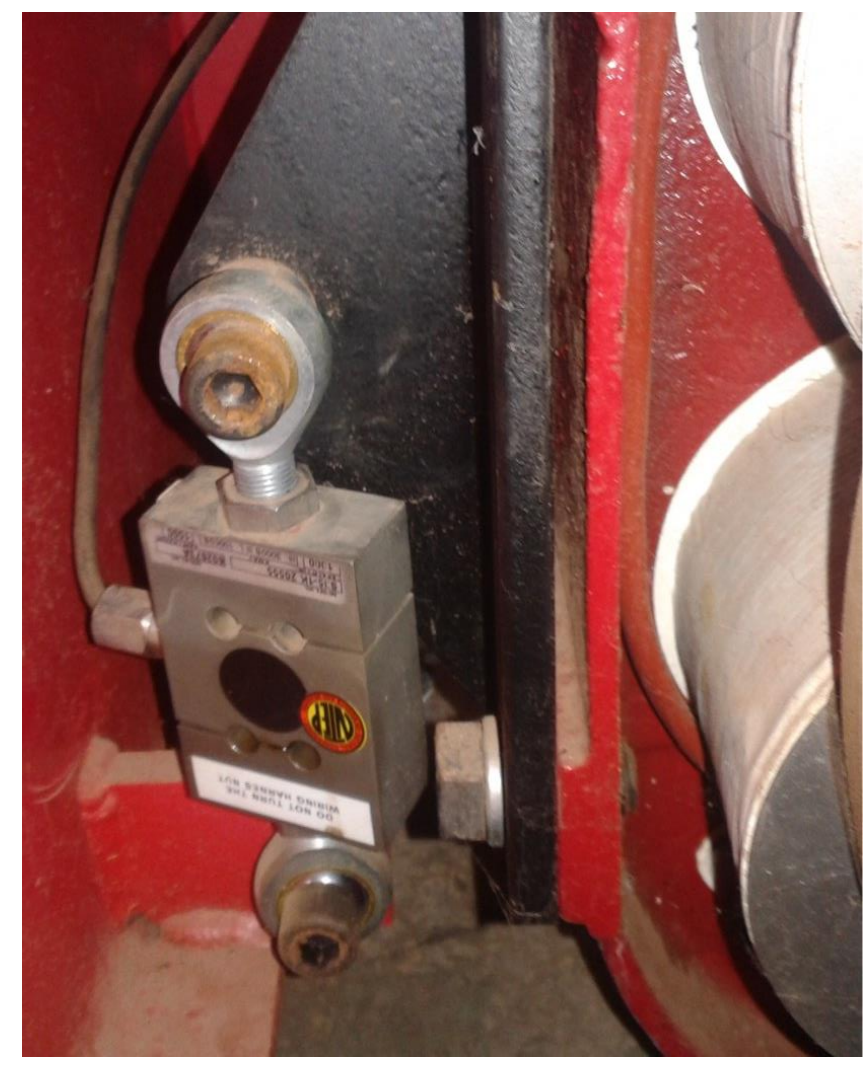

Figura 31 - Célula de carga do dinamômetro Fonte: O autor, 2013. 
Para medir a velocidade no dinamômetro o sensor indutivo, mostrado na figura 26, foi instrumentado e calibrado. Junto com ele foi utilizado um mostrador da marca Wika.

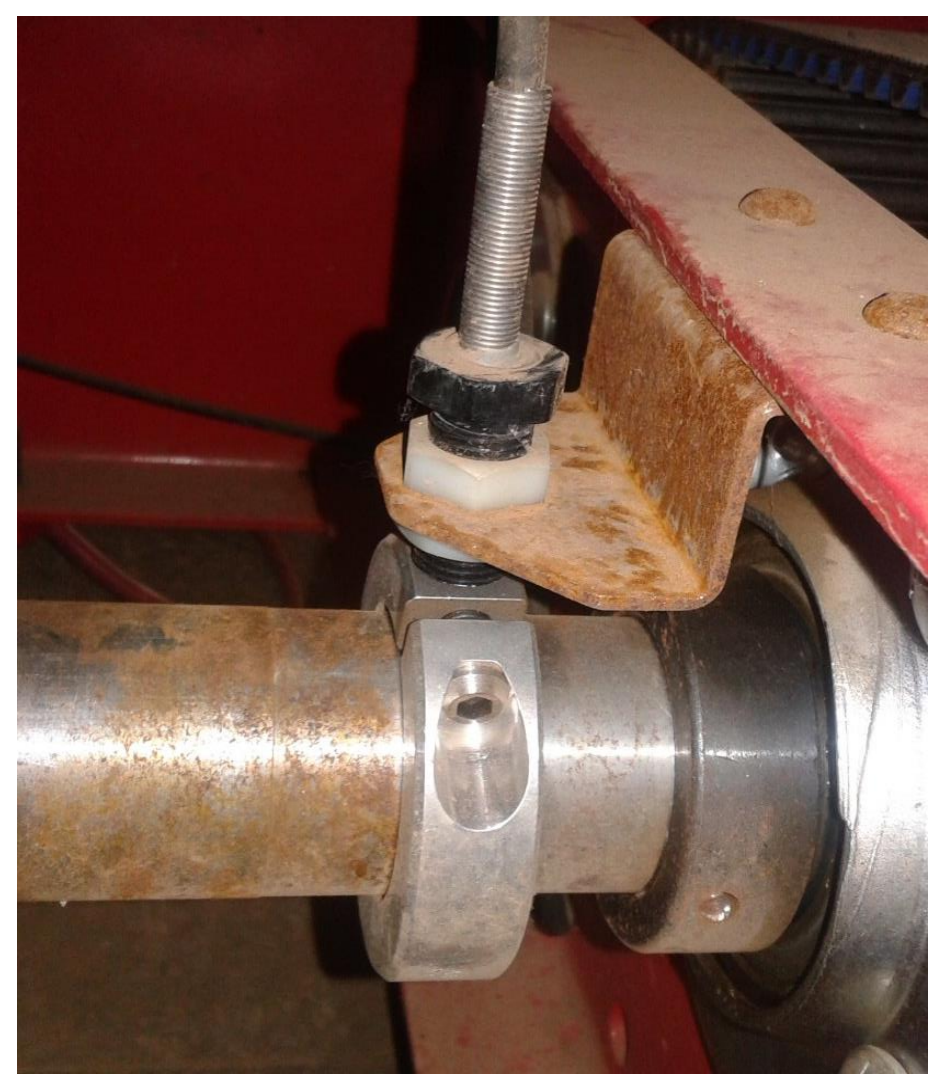

Figura 32 - Sensor indutivo do dinamômetro

Fonte: O autor, 2013.

Apesar da impossibilidade de se usar toda a funcionalidade do dinamômetro com o software do fabricante do equipamento, foram feitos ajustes, calibrações e inseridos fatores de correção necessários para a realização dos experimentos de modo a garantir uma boa precisão na medidas 


\section{ENSAIO E ANÁLISE DOS DADOS}

Nesta etapa foi implementada a integração da proposta utilizando os instrumentos, quadros e programas da plataforma (vide figura 33). Os ensaios foram feitos em ambiente controlado de modo a avaliar a funcionalidade dos equipamentos, o comportamento do veículo convertido e as requisições de energia do veículo para o dimensionamento e a escolha da tecnologia das baterias. Para a realização dos ensaios foram efetuados testes em três etapas distintas: (i) análise do comportamento da temperatura do motor elétrico refrigerado a água; (ii) levantamento de torque e potência do veículo convertido; e (iii) ciclos de condução.

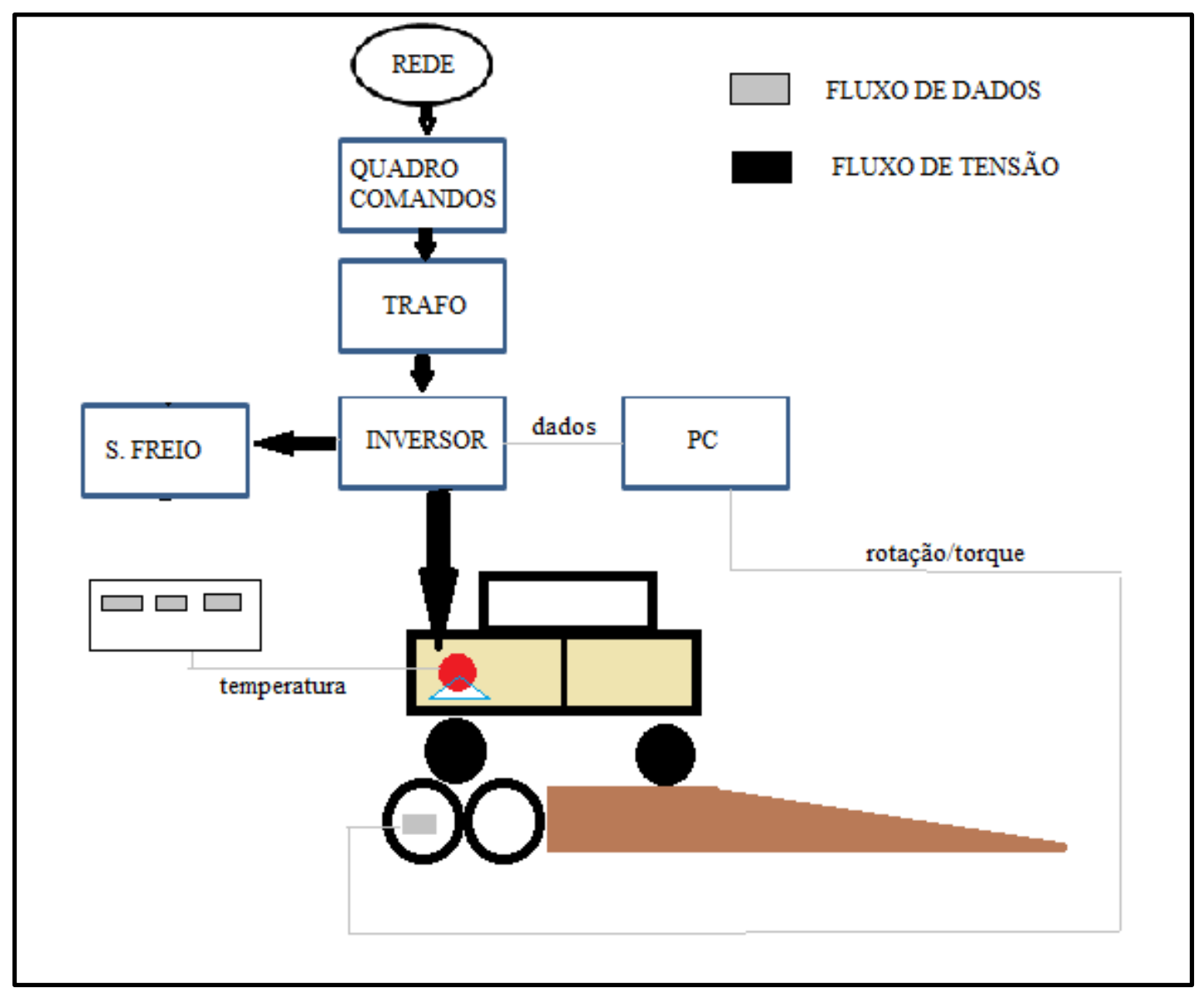

Figura 33 - Diagrama da plataforma de ensaios Fonte: $\mathrm{O}$ autor, 2013.

\subsection{MONITORAMENTO DA TEMPERATURA}

Antes de apresentar os dados colhidos é importante tecer algumas considerações sobre a disposição dos sensores de temperatura, são do tipo PT-100 e vem instalados de fábrica. 
São nove sensores distribuídos entre parte frontal, enrolamento e parte traseira do motor elétrico o que permite realizar a leitura e supervisão de forma precisa da temperatura do motor, conforme esquema apresentado pela figura 34.

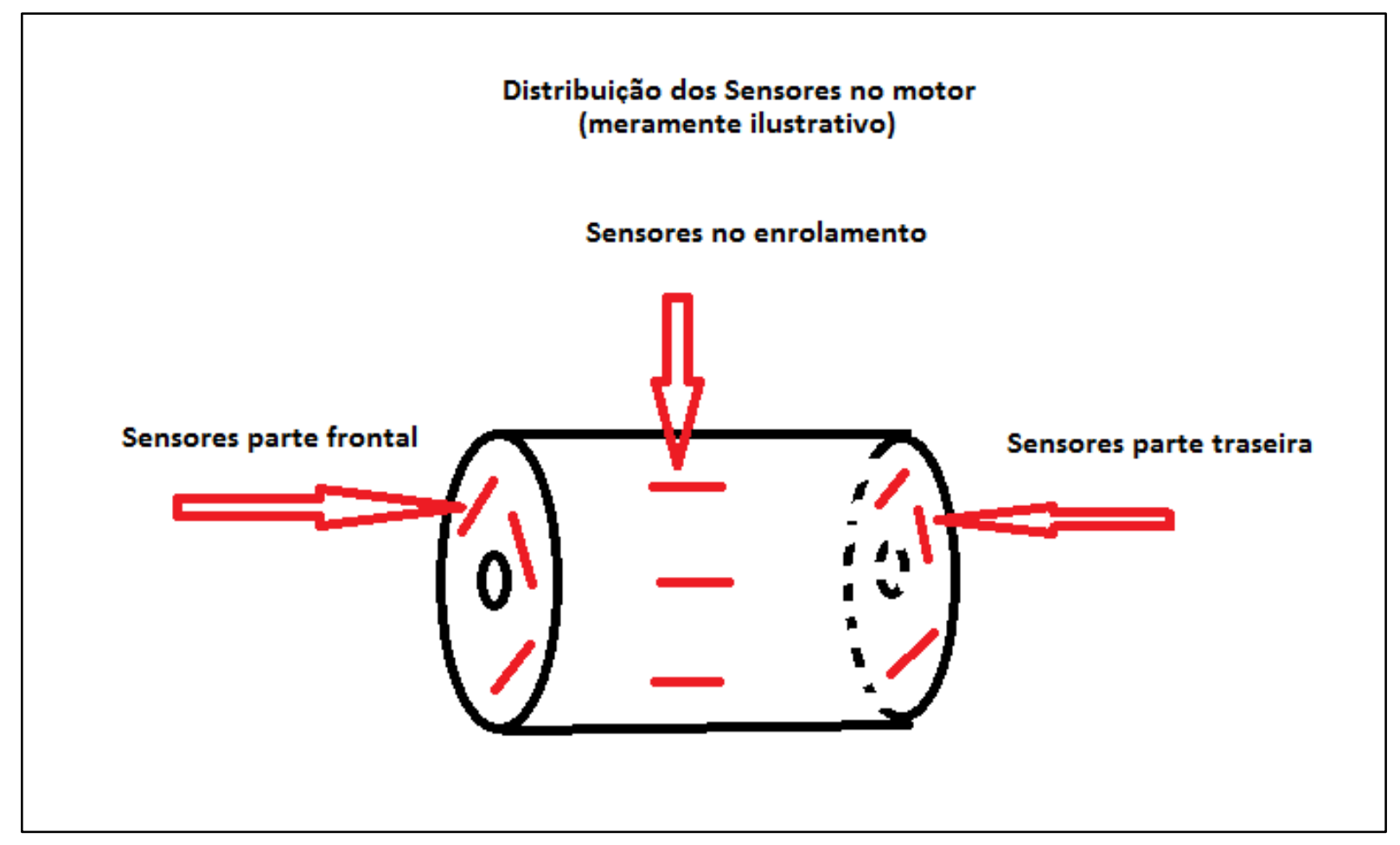

Figura 34 - Ilustração da disposição dos sensores

Fonte: $\mathrm{O}$ autor, 2013.

Para avaliar a elevação da temperatura foi realizado um ensaio onde o motor foi energizado (partindo do repouso em temperatura ambiente) até atingir a rotação de $1600 \mathrm{rpm}$, atingindo a velocidade de aproximadamente $20 \mathrm{~km} / \mathrm{h}$, por um período de aproximadamente 25 minutos, supondo um percurso regular e sem aclive.

Como para cada região distinta existem três sensores, optamos por usar a média das medidas de cada conjunto de sensores pois na grande maioria das vezes não houve diferença considerável nas leituras observadas.

O gráfico apresentado na figura 35 demonstra a elevação da temperatura em graus Celsius desde o início e seu decaimento por mais 35 minutos com o motor desligado. 


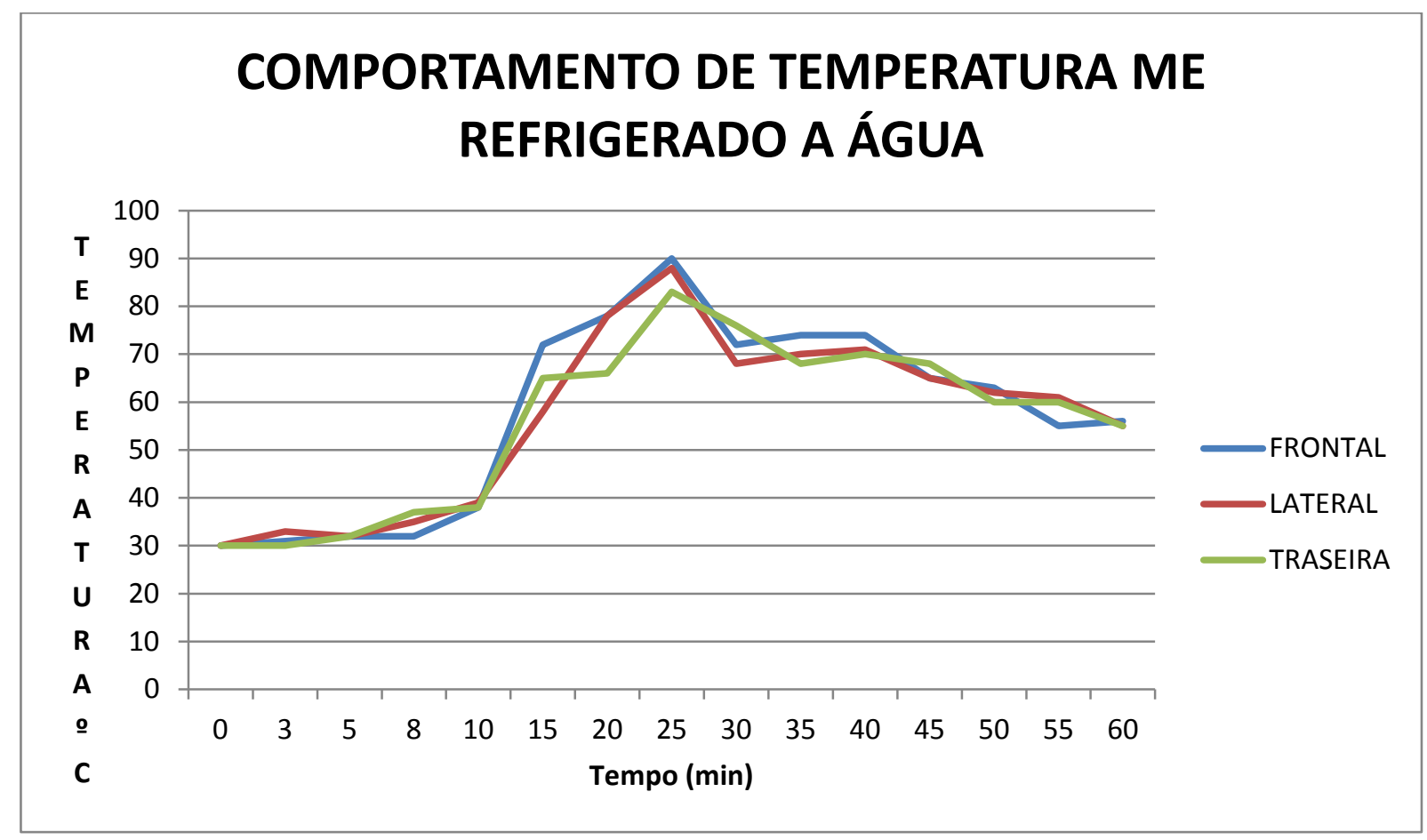

Figura 35 - Grafico da elevação da temperatura durante o ensaio

Fonte: O autor, 2013.

Durante o ensaio não houve a circulação do fluído de arrefecimento, neste caso, conforme orientação do fabricante do motor elétrico, foi aplicado o mesmo fluído de arrefecimento usado em radiadores de veículos com motores a combustão interna, aditivos de radiador (que têm etilenoglicol,(álcool) em sua composição) que previnem o congelamento, o superaquecimento e a corrosão.

O objetivo foi avaliar o aumento de temperatura e a estratégia mais adequada para gerenciamento do trabalho da bomba elétrica de circulação do fluido de arrefecimento.

Nesse ensaio foram utilizados mostradores multifuncionais da marca Wika, por meio dos quais foram lidas as informações de temperatura do motor elétrico. As leituras de dados mostraram que, em alguns momentos, alguns valores eram inconsistentes por não terem um comportamento regular de forma ascendente, o que acreditamos ser possivelmente proveniente de interferência eletromagnética no sistema.

Nesse ensaio foi possível observar que é de suma importância que se faça uso de um termoestato com acionamento na faixa de $90{ }^{\circ} \mathrm{C}$ e usar as funções do inversor para leitura e 
supervisão da temperatura para que sejam criadas proteções para prevenir o superaquecimento do motor elétrico.

A ascensão da temperatura aconteceu de forma rápida, ficando patente que a parte frontal do motor aquece mais que a região do enrolamento e do mancal traseiro do motor elétrico.

\subsection{ANALISE DE TORQUE E POTENCIA NO DINAMÔMETRO}

Fazendo-se uso dos transdutores disponíveis no dinamômetro e de equipamentos para leitura procedeu-se uma sequência de três ensaios nas mesmas condições no veículo para levantar os valores máximos de torque e potência do veículo convertido no dinamômetro. No ensaio optou-se por variar a rotação máxima do motor em degraus de $500 \mathrm{rpm}$ até atingir 3000 conforme apresentado na tabela 11. Lembrando que a rotação nominal desse motor elétrico é de $2930 \mathrm{rpm}$, o ultimo estágio deste ensaio foi executado de forma breve A frenagem magnética foi determinada numa faixa limite suportável pela estrutura do sistema, a figura 36 apresenta o comportamento de torque e potência no ensaio.

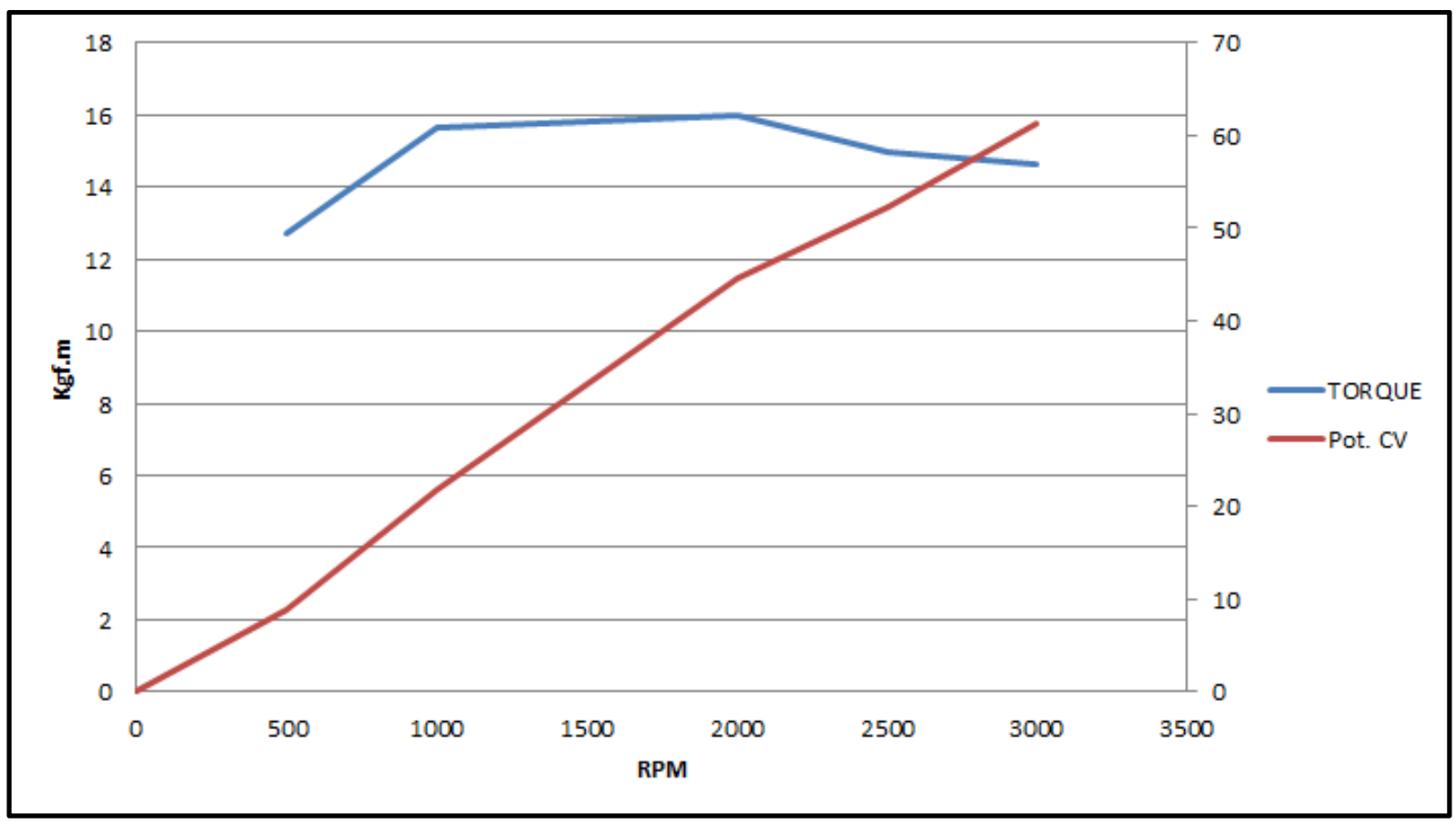

Figura 36 - Curva de Torque e Potência do veículo Fonte: O autor, 2013. 
Tabela 11 - Dados do ensaio de torque e potência do veículo

\begin{tabular}{|l|l|l|l|l|}
\hline RPM & TORQUE Kgfm & Pot. CV & Pot. NM & Pot. KW \\
\hline 0 & & 0 & & \\
\hline 500 & 12,7 & 8,866 & 124,5 & 6,521 \\
\hline 1000 & 15,67 & 21,88 & 153,7 & 16,09 \\
\hline 1500 & 15,84 & 33,18 & 155,3 & 24,4 \\
\hline 2000 & 16,01 & 44,71 & 157 & 32,88 \\
\hline 2500 & 14,98 & 52,29 & 146,9 & 38,46 \\
\hline 3000 & 14,64 & 61,32 & 143,6 & 45,1 \\
\hline
\end{tabular}

Fonte: $\mathrm{O}$ autor, 2013.

\subsection{CICLO DE ENSAIOS}

O grande entrave dos veículos elétricos é a capacidade de armazenar a energia e este aspecto influi diretamente na sua autonomia. Em qualquer caso, essa questão é crítica no projeto de um veículo elétrico. Dessa forma, nos cálculos e testes a autonomia de um veículo é sempre um elemento complexo.

Para que os veículos sejam testados, os ciclos de ensaio dever ser projetados de forma a simular, da forma mais realística possível, as condições as quais vão ser submetidos. A forma mais simples de testar um veículo é supor que a sua velocidade será constante, que na verdade é uma situação hipotética, pois o veículo é submetido a condições adversas relativas ao pavimento, arrasto aerodinâmico entre outras. Entretanto, esse teste é importante pois serve de linha de base para comparação. A segunda forma de testar o veículo seria definir um perfil de velocidade de maneira a simular uma condição mais real de teste, sendo que existe um grande número de variações definidas por normas. (Larminie, 2003)

Conforme pode ser observado, as formas de testar os veículos são chamadas de ciclos de ensaios. De modo a serem o mais próximo da realidade, tais ciclos devem representar diversas condições ambientais e isso afeta os diversos componentes do sistema, o que torna os cálculos ainda mais complexos. 
Para facilitar a condução de ciclos mais complexos atualmente existem programas que conseguem simular perfis de utilização do veículo. Esses ciclos de condução têm sido desenvolvidos principalmente para viabilizar os testes relativos a emissões veiculares. Um dos mais conhecidos e que é baseado em fluxos reais de tráfego em Los Angeles é o LA-4. Após esse ciclo foram desenvolvidos outros como o Federal Urban Driving Schedule (FUDS). O FUDS é um ciclo que dura cerca de 1500 segundos, em que para cada segundo é definida uma diferente velocidade. Existe também uma versão simplificada de SFUDS (Simplified FUDS) que dura apenas 360 segundos. É importante frisar que tais ciclos simulam velocidade máxima, frenagens e outros comportamentos normais durante o uso de um veículo. Existem também ciclos de simulação de condução fora de cidades e ou condução em estrada. Apesar de amplamente utilizado, este ciclo tem uma velocidade máxima pouco realista para a condução em estrada, e o novo padrão US06 agora está se tornando mais amplamente usado. (LARMINE, 2003).

$\mathrm{Na}$ cena europeia os ciclos tendem a ser bastante simples com períodos de aceleração e velocidade constante. Um com particular interesse é o ECE 15 (Urban Driving Cycles) o qual é útil para testar o desempenho de veículos de pequeno porte, tais como carros elétricos com bateria. Em testes de emissão na europa isso tem que ser combinado os ciclos de condução extra-urbano (EUDC, Extra-urban driving cycles), que adotam uma velocidade máxima de $120 \mathrm{~km} / \mathrm{h}$.

Atualmente, o padrão mais amplamente usado na Ásia é o japonês ciclo Modo 10-15. Como os ciclos Europeus, esses envolvem períodos de velocidade constante e aceleração. Ele não é diferente de uma combinação do 15 ECE com o ciclo de condução extra urbana européia o (EUDC). No Japão esses padrões têm velocidades máximas na região de 100 km/h para diversos tipos de veículos elétricos, incluindo o veículo de entrega elétrico e a scooter com motor elétrico, mas não é uma velocidade real pois muitas vezes não pode ser atingido, em alguns casos é necessário ensaiar esses veículos em outros ciclos.

Um padrão bastante antigo, que foi desenvolvido especificamente para veículos elétricos na década de 1970, é o J227a cronograma de condução SAE. Tem quatro versões, com diferentes velocidades. Cada ciclo é bastante curta no tempo, e consiste de uma fase de aceleração , uma fase de velocidade constante, numa fase acostamento e uma travagem de 
fase, seguido por um tempo fixo. A fase de acostamento, onde a velocidade não é especificada, mas o esforço de tração é zero, é um pouco de um incômodo para modelo. $\mathrm{O}$ perfil geral de é mostrado na Figura 37, e os detalhes de cada uma das quatro variantes neste ciclo são apresentados na tabela 12.

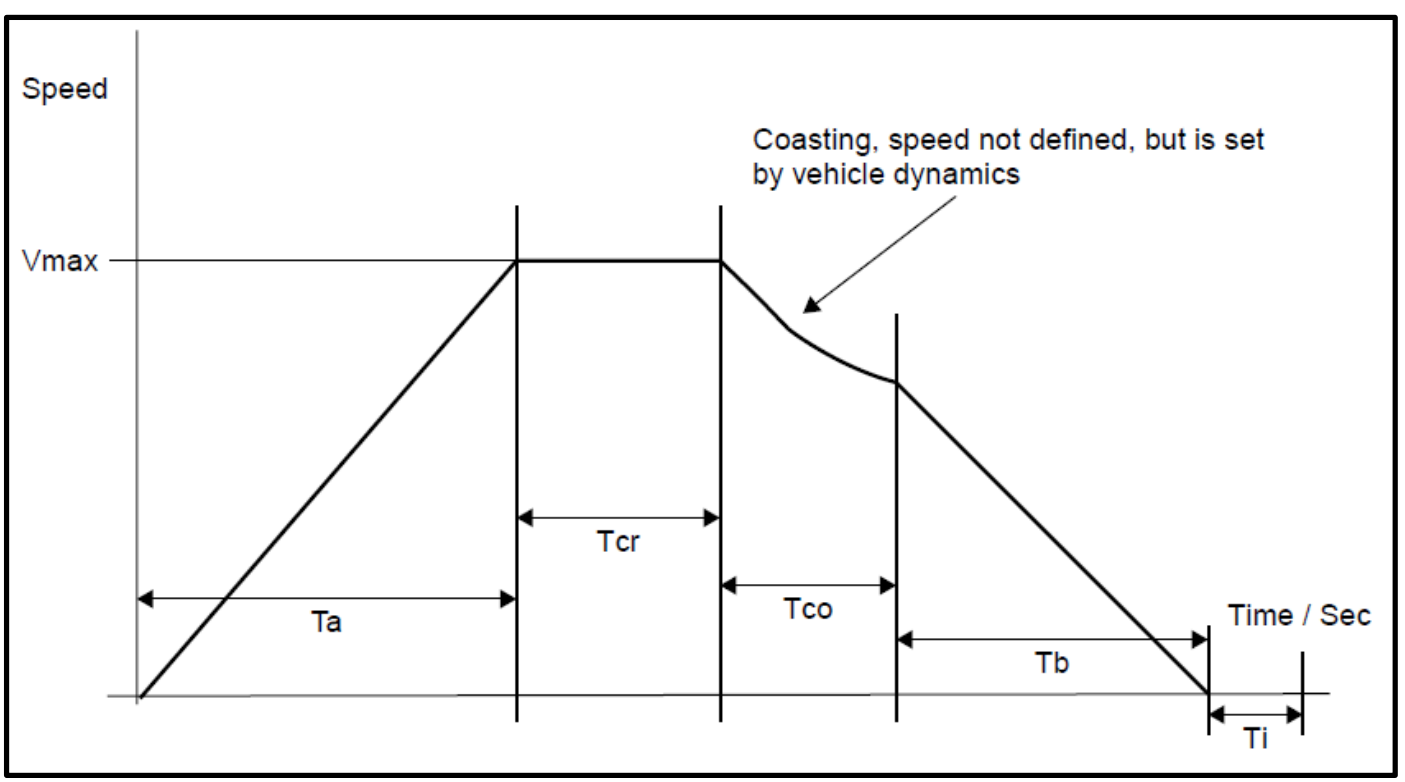

Figura 37 - Ciclo de condução SAE J227a

Fonte: Larmine, 2003.

O ciclo mais utilizada é SAE J227a -C, que é particularmente adequado para veículos urbanos de pequeno porte como scooters elétricos e outros veículos elétricos. O ciclos A e B são por normalmente usados para veículos de entrega para fins especiais. Outro programa digno de nota para veículos de baixa velocidade é o Europeu ECE- 47 que é utilizado para o teste de emissões de ciclomotores e motocicletas com capacidade inferior a $50 \mathrm{~cm} 3$, mas também é amplamente utilizado para a faixa de simulação de eléctrico scooters. O ciclo SAEJ227a pode ser um pouco complicado para executar a simulação, pelo fato da velocidade não ser especificada em todos os momentos. (LARMINE, 2003) 
Tabela 12 - Tempos do SAE J227a

\begin{tabular}{|c|c|c|c|c|c|}
\hline PARÂMETRO & UNIDADE & CICLO A & CICLO B & CICLO C & CICLO D \\
\hline Vel. Máxima & $\mathrm{Km} / \mathrm{h}$ & 16 & 32 & 48 & 72 \\
\hline $\begin{array}{c}\text { T. de } \\
\text { Aceleração } \\
\text { (Ta) }\end{array}$ & $\mathbf{S}$ & 4 & 19 & 18 & 28 \\
\hline $\begin{array}{l}\text { T. Cruzeiro } \\
\text { (Tc)r }\end{array}$ & $\mathbf{S}$ & $\mathbf{0}$ & 19 & 20 & 50 \\
\hline $\begin{array}{c}\text { T. } \\
\text { Acostamento } \\
\text { (Tco) }\end{array}$ & $\mathbf{S}$ & 2 & 4 & 8 & 10 \\
\hline $\begin{array}{c}\text { T. de } \\
\text { Frenagem } \\
\text { (Tb) }\end{array}$ & $\mathbf{S}$ & 3 & 5 & 9 & 9 \\
\hline $\begin{array}{c}\text { T. Ocioso } \\
\text { (Ti) }\end{array}$ & $\mathbf{S}$ & 30 & 25 & 25 & 25 \\
\hline T. Total & $\mathbf{S}$ & 39 & 72 & 80 & 122 \\
\hline
\end{tabular}

Fonte: Larmine, 2003

Há muitos outros ciclos de ensaios que podem ser encontrados na literatura e algumas empresas têm a sua própria metodologia de condução. Acadêmicos, às vezes, propõem mudanças na tentativa de replicar uma condução real. Há ciclos locais, que refletem os padrões de uma cidade específica e que reproduz as suas condições singulares. Um exemplo digno de nota é Ciclo de Nova Iorque, que tem particularmente longos períodos de ausência de movimento e acesso a velocidades médias, refletindo o estado de suas vias. Esse ciclo é por vezes usado quando são simulados veículos elétricos/híbridos, com motor de combustão interna (ICE - Internal Combustion Engine). Entretanto, no caso dos ciclos americanos, os quais consistem de uma velocidade específica de cada vez, é mais conveniente para usar dados de arquivos baixados de sites da web. Estes podem ser facilmente encontrados na internet através de sites de busca. (Larmine, 2003) 


\subsubsection{Coleta de Dados}

O ensaio foi executado na plataforma utilizando o Ciclo SAE J227a C e D. Apesar de haverem quatro diferentes ciclos, optou-se pelos dois últimos pelo fato de terem períodos de aceleração e desaceleração mais longos, ou seja, mais coerentes com um regime de direção usual de um veículo urbano. Além disso, adotou-se uma rotina para a execução do ensaio de modo a melhorar a confiabilidade e garantir repetibilidade do processo. $\mathrm{O}$ fluxo da rotina de ensaio é apresentado na figura 38.

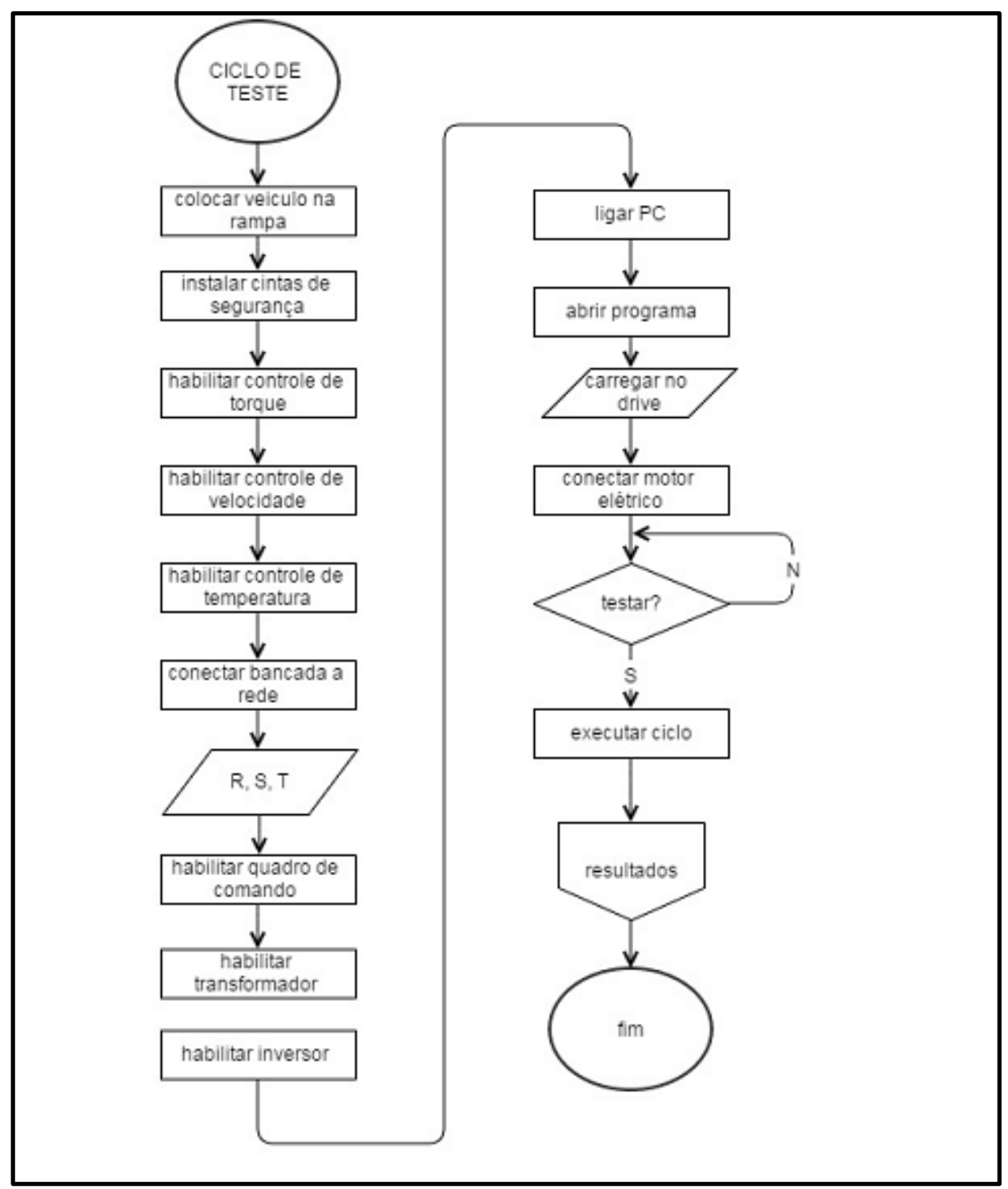

Figura 38 - Fluxograma da rotina de ensaios

Fonte: O autor, 2013 
Para a realização do ensaio, algumas premissas tiveram de ser definidas como que,, a aplicação do veículo seria doméstica, para uso em centro urbano, os trajetos aleatórios, uma velocidade máxima em torno de $70 \mathrm{Km} / \mathrm{h}$ e a lotação de pelo menos dois passageiros.

Para reproduzir o perfil de velocidades recomendado nos Ciclos SAE J227a, cada ensaio aconteceu três vezes, observando os detalhes recomendados e as condições de contorno que a Plataforma poderia oferecer. Para garantir maior precisão nos tempos determinados no Ciclo todo o processo foi feito usando funcionalidades do CFW 11, por meio de programação. O Tempo de Acostamento do Ciclo, (Tco) não apresenta qual velocidade deverá ser seguida e, por isso, optou-se por somar o tempo de acostamento com o tempo de frenagem numa única rampa de desaceleração.

Foram acompanhados por meio do programa Super Drive G2 os parâmetros de:

- Velocidade do Motor (rpm);

- Corrente do Motor (ampéres);

- Tensão de Saída (volts);

- Torque do Motor (percentual);

- Contador de Consumo (Kwh); e

- Potência de Saída (Kw).

\subsubsection{Ensaio do Veículo, Ciclo SAE J227a-C:}

Neste ensaio foram usados os parâmetros do Ciclo SAE J227a-C, obedecendo os limites de velocidade máxima e respectivos tempos conforme apresentado na tabela 13.

Tabela 13 - Parâmetros do Ciclo

\begin{tabular}{|c|c|}
\hline PARÂMETROS & Valores \\
\hline Velocidade Máxima & $48 \mathrm{Km} / \mathrm{h}$ \\
\hline T. de Aceleração (Ta) & $18 \mathrm{~s}$ \\
\hline T. Cruzeiro (Tc)r & $20 \mathrm{~s}$ \\
\hline T. Acostamento (Tco) & $8 \mathrm{~s}$ \\
\hline T. de Frenagem (Tb) & $9 \mathrm{~s}$ \\
\hline T. Ocioso (Ti) & $25 \mathrm{~s}$ \\
\hline T. Total & $80 \mathrm{~s}$ \\
\hline
\end{tabular}


A figura 39 reúne todos os parâmetros observados através do software do inversor durante este ensaio no motor elétrico. São eles rotação, corrente, tensão, torque e energia consumida.

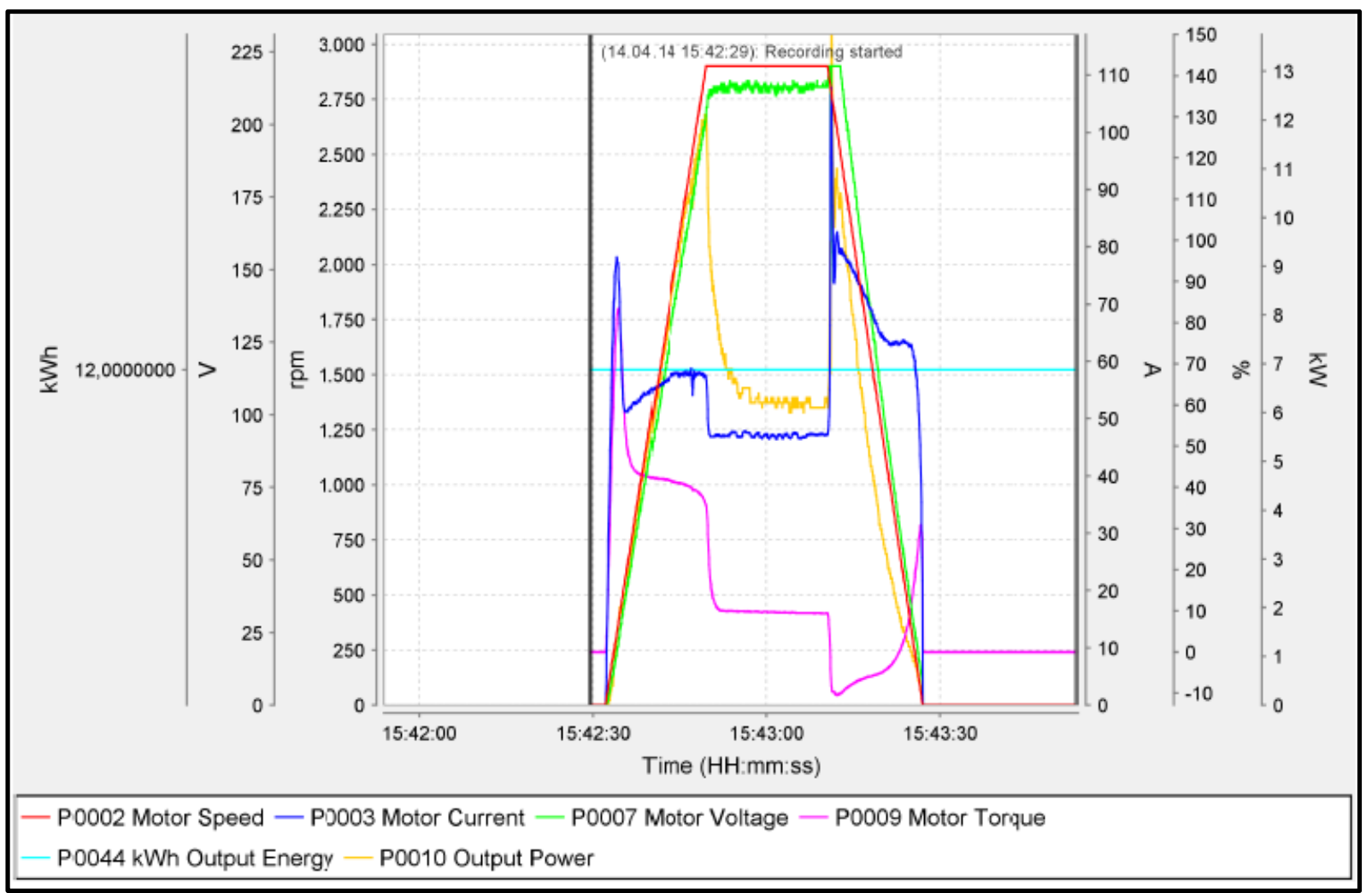

Figura 39 - Ciclo C SAE j227a - todos os parâmetros

Fonte: Super Drive G2 
A figura 40 destaca o comportamento do torque no motor elétrico e sua respectiva rotação. Durante a partida do motor o torque (linha rosa) atinge pouco mais que $80 \%$ da sua capacidade, em seguida tem uma queda em forma de degrau até estabilizar abaixo de $20 \%$. No instante da desaceleração do motor elétrico ele tem um pico negativo em alguns segundos um pico negativo e um rápido pico positivo caindo para o valor nulo.

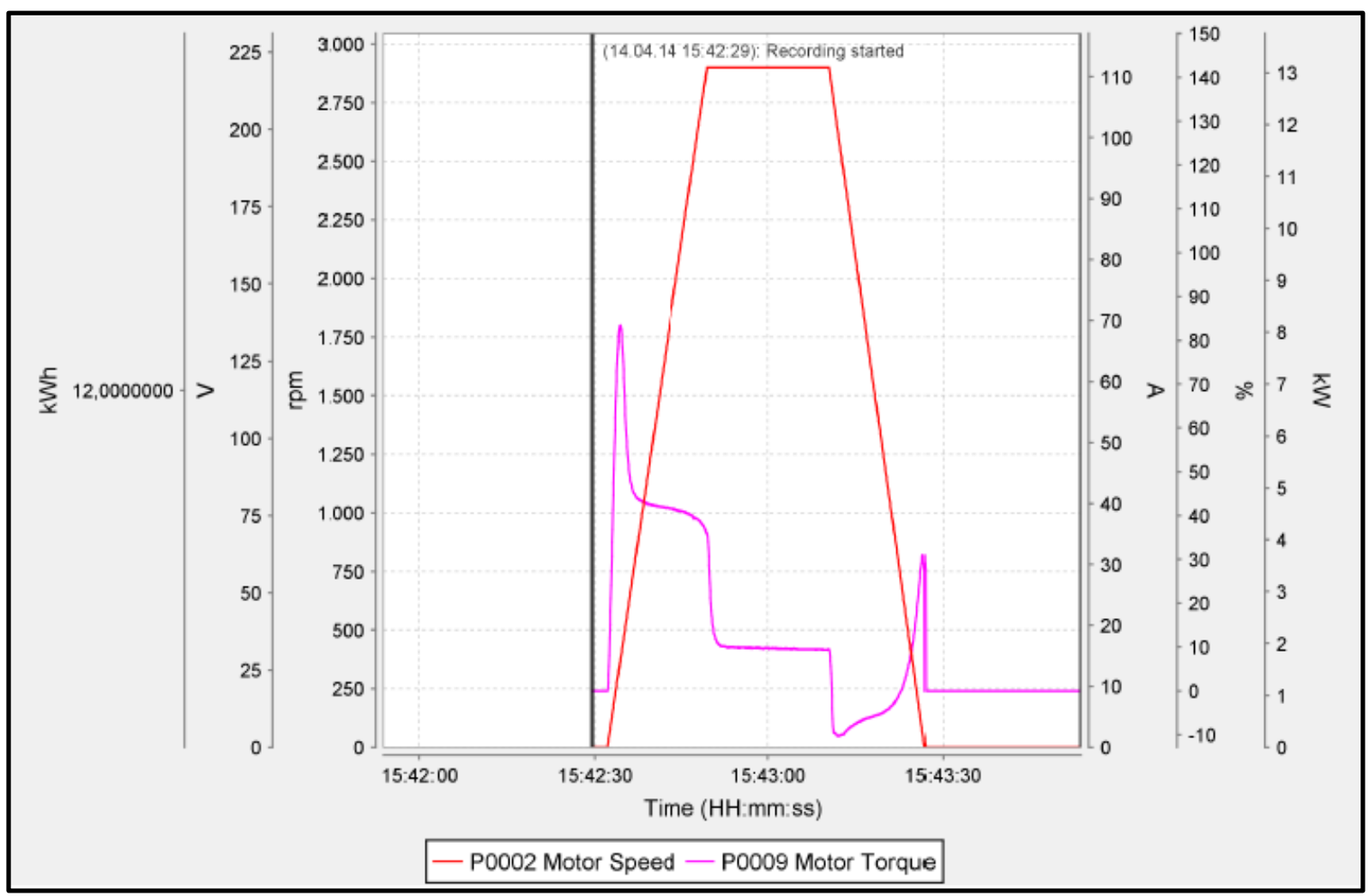

Figura 40 - Ciclo C SAE J227a - Velocidade e Torque no Motor

Fonte: Super Drive G2

A figura 41 demonstra o comportamento da tensão e da corrente elétrica durante o ensaio. A curva de corrente (linha vermelha) tem um rápido pico de aproximadamente $70 \mathrm{~A}$ durante a partida do motor com oscilações em queda até o segundo 22 do ensaio quando a corrente se estabiliza próximo de 50 A. No instante em que o motor começa a desacelerar acontece outro rápido pico, dessa vez de 100 A quando ele inicia uma queda que em aproximadamente 15 segundos atinge o valor nulo. A tensão tem um comportamento aproximadamente linear entre a partida e o regime estacionário, destaque para dois rápidos 
picos, um descendente seguido de uma ascendente no segundo 45 do ensaio, instante em que o motor inicia a desaceleração.

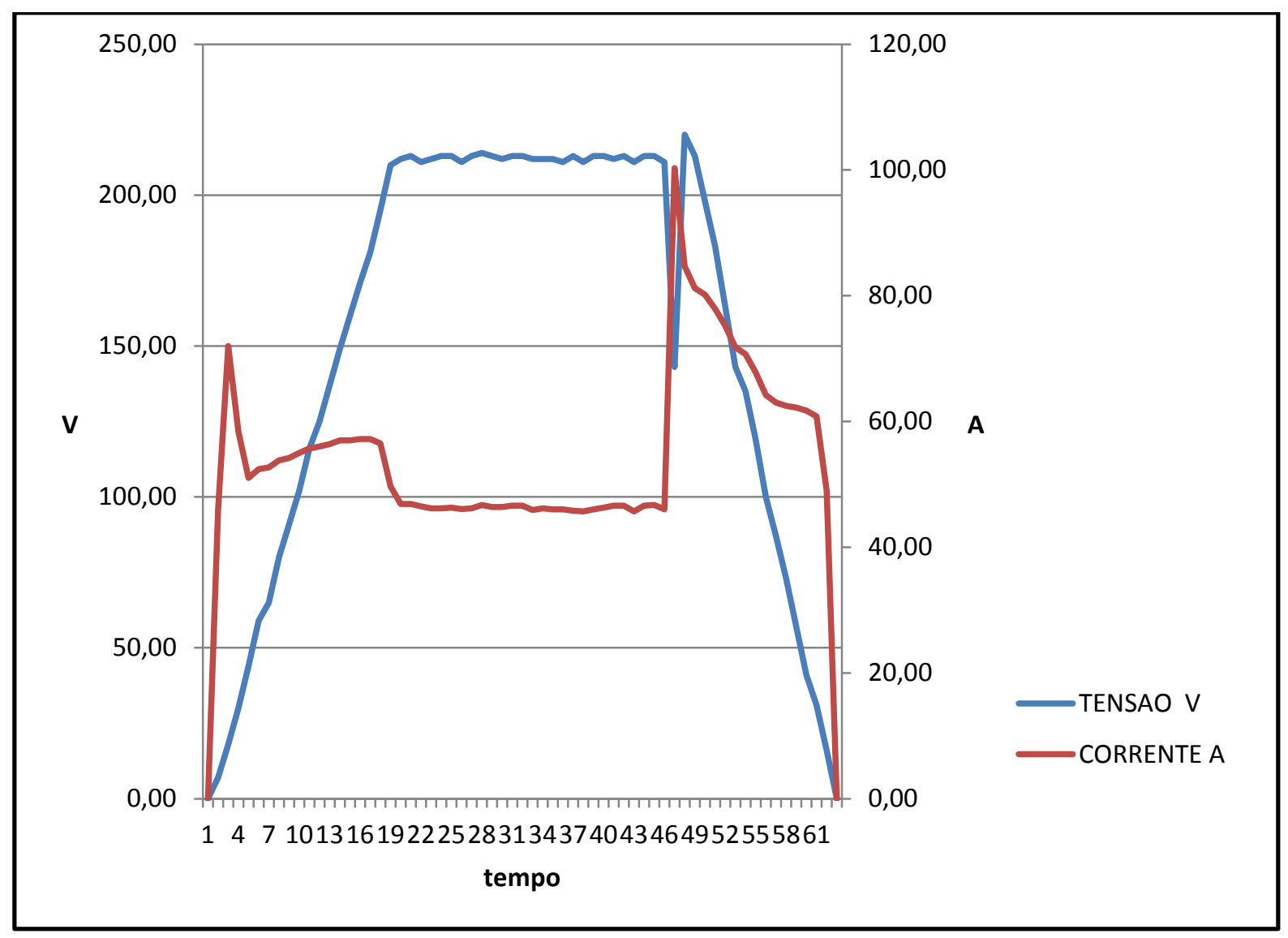

Figura 41 - Ciclo C SAE J227a - Tensão e Corrente no Motor

Fonte: O autor, 2013.

A figura 42 demonstra a potência elétrica no motor a cada segundo, sendo que o valor é resultado do produto da tensão pela corrente elétrica durante o ensaio. Destaque para o instante (segundo 45 do ensaio) em que o motor começa a desacelera e há uma elevação dos valores de tensão e de corrente. 


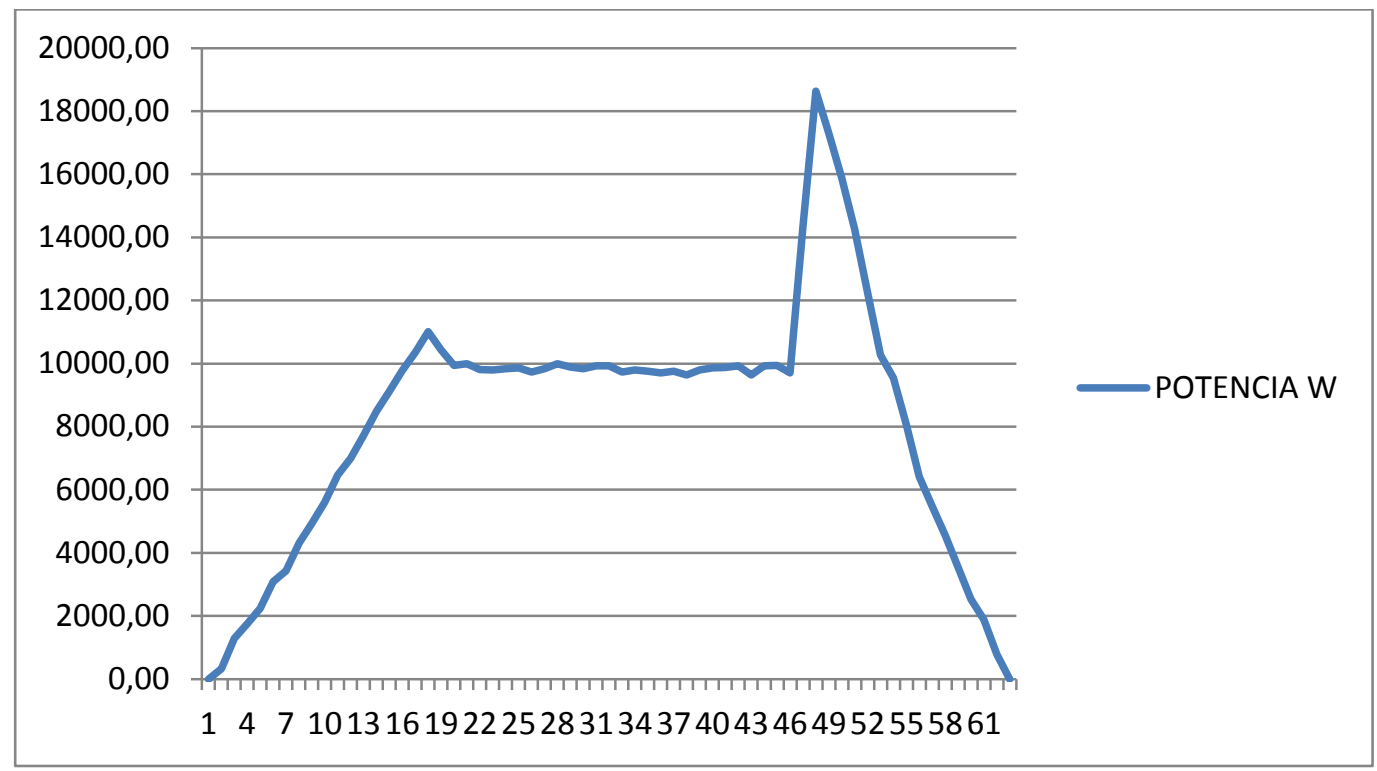

Figura 42 - Ciclo C SAE J227a - Potência de saída no Motor

Fonte: O autor, 2013.

Já a figura 43 demonstra a potência elétrica consumida a cada segundo, bem como demonstra a integração dos valores a cada segundo no ciclo de ensaio.

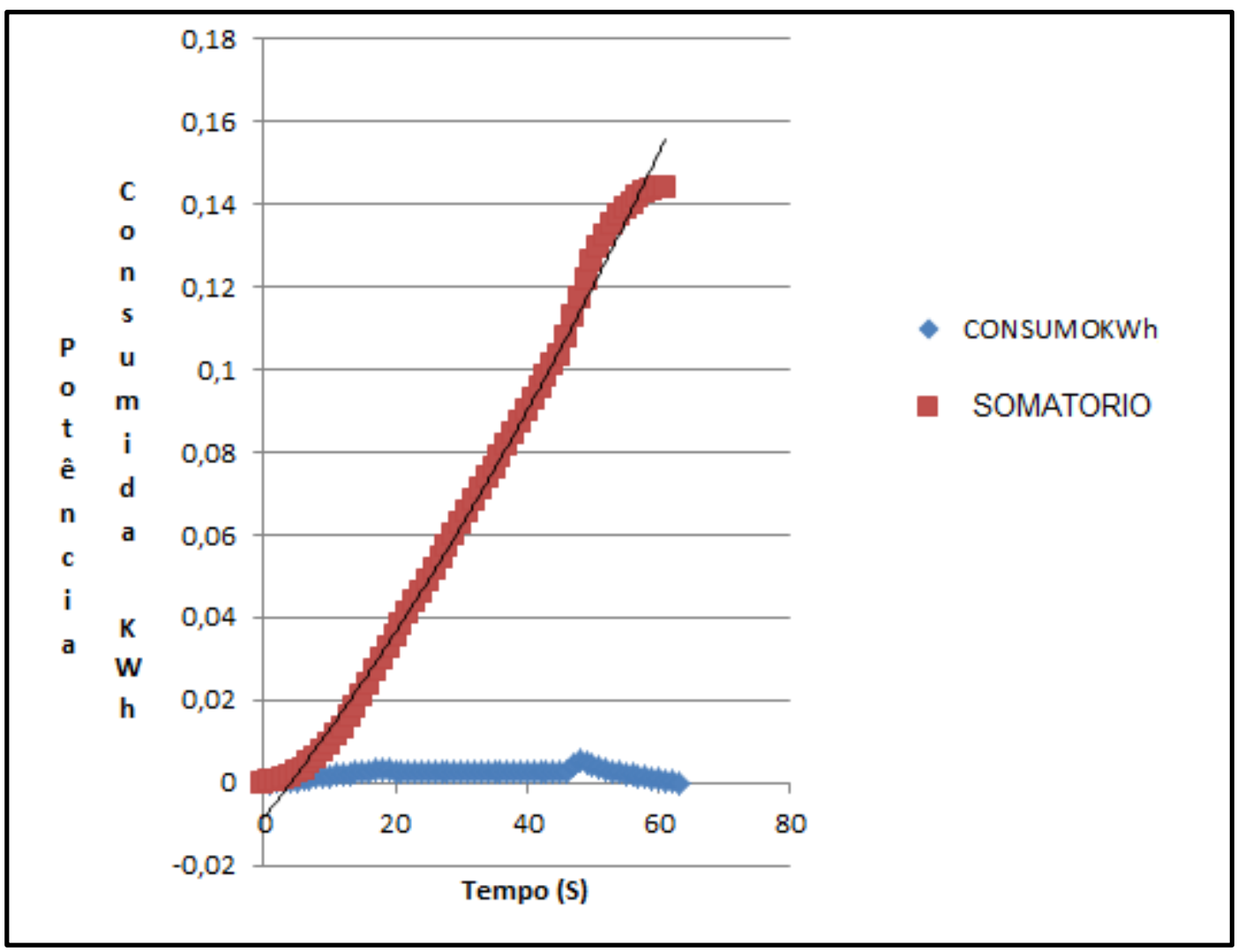

Figura 43 - Ciclo C SAE J227a - Potência consumida no Motor em Kwh

Fonte: O autor, 2013. 
$\mathrm{Na}$ tabela 14 estão dispostos os valores obtidos durante o ciclo de ensaio com informações do programa disponível no inversor, do monitoramento da temperatura do motor elétrico e das informações da instrumentação do dinamômetro.

\section{Tabela 14 - Dados obtidos no Ciclo C}

\begin{tabular}{|l|l|c|c|c|}
\hline Dados & Unidade & Mínimo & Média em Regime & Máximo \\
\hline Velocidade do Motor & RPM & 0 & 2900 & 2.900 \\
\hline Corrente do Motor & Ampere & 0 & 46 & 105,07 \\
\hline Tensão no Motor & Volt & 0 & 213 & 231 \\
\hline Torque no Motor & $(\%)$ & $-12,85$ & 8,5 & 80,9 \\
\hline Potência de Saída & $\mathrm{KW}$ & 0 & 10 & 18 \\
\hline Potência na Roda & $\mathrm{Nm}$ & 0 & 125 & 75 \\
\hline Temp Mancal Diant & ${ }^{\circ} \mathrm{C}$ & 23 & 54 & 56 \\
\hline Temp Estator & ${ }^{\circ} \mathrm{C}$ & 23 & 31 & 48 \\
\hline Temp Mancal Tras & ${ }^{\circ} \mathrm{C}$ & 23 & 31 & 75 \\
\hline
\end{tabular}

Fonte: O autor, 2013.

Neste ciclo a velocidade máxima solicitada foi de $48 \mathrm{~km} / \mathrm{h}$, o que permitiu utilizar a terceira marcha. As leituras demonstraram o bom desempenho do equipamento sem que as variáveis observadas tivessem comportamento acima dos limites recomendados pelo fabricante.

A potência elétrica total consumida durante o ensaio foi de $0,144 \mathrm{KWh}$ para um intervalo de pouco mais que um minuto e a distância percorrida foi de aproximadamente 528 metros. Levando em conta as velocidades praticadas em ambientes urbanos, em torno de 60 $\mathrm{km} / \mathrm{h}$, este ensaio demonstra ser importante avaliar o conjunto fazendo uso das demais marchas da caixa de câmbio, a serem demonstrados no item 6.3.3.

\subsubsection{Ensaio do Veículo, CICLO SAE J227a-D}

Neste ensaio foram usados os parâmetros do Ciclo SAE J227a-D, obedecendo os limites de velocidade máxima e respectivos tempos conforme a tabela 15. 
Tabela 15 - Parâmetros do Ciclo

\begin{tabular}{|c|c|}
\hline PARÂMETROS & Valores \\
\hline Velocidade Máxima & $72 \mathrm{Km} / \mathrm{h}$ \\
\hline T. de Aceleração (Ta) & $28 \mathrm{~s}$ \\
\hline T. Cruzeiro (Tc)r & $50 \mathrm{~s}$ \\
\hline T. Acostamento (Tco) & $10 \mathrm{~s}$ \\
\hline T. de Frenagem (Tb) & $9 \mathrm{~s}$ \\
\hline T. Ocioso (Ti) & $25 \mathrm{~s}$ \\
\hline T. Total & $122 \mathrm{~s}$ \\
\hline
\end{tabular}

Fonte: Larminie, 2003

A figura 44 reúne todos os parâmetros observados através do programa do inversor durante o ensaio no motor elétrico. São eles rotação, corrente, tensão, torque e energia consumida.

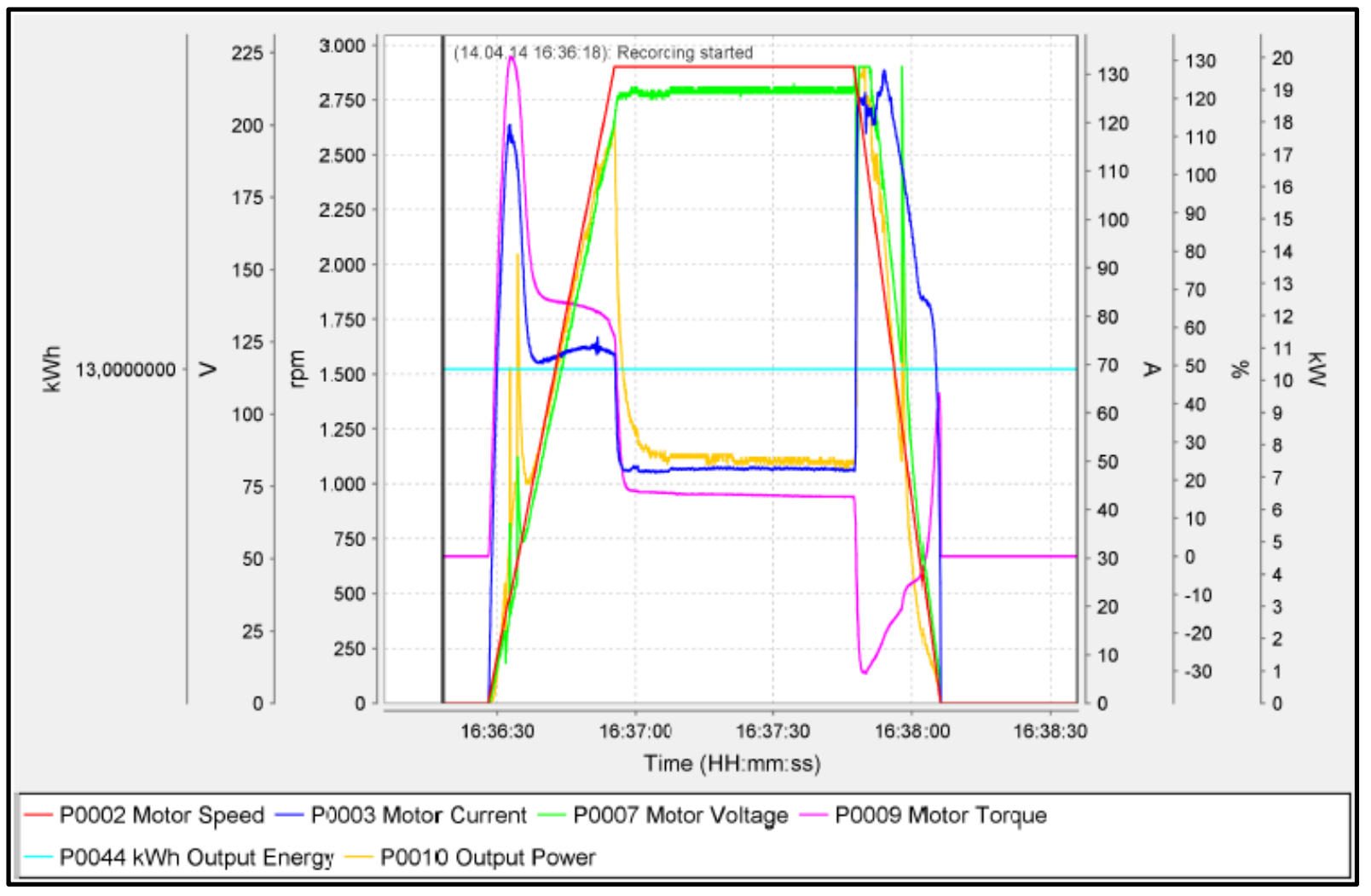

Figura 44 - Ciclo D SAE J227a - Todos os parâmetros

Fonte: Super Drive G2 
A figura 45 apresenta as curvas de torque e rotação do motor elétrico durante o ensaio utilizando o Ciclo SAE J227a-D. Ela é um recorte da figura 44 e demostra o comportamento do torque (linha rosa) e da rotação (linha vermelha). Pode-se perceber no instante da partida do motor que o torque é bem elevado, a medida que a velocidade aumenta o torque decai para um valor baixo, em seguida tem um pico negativo num intervalo pequeno seguido de um pico positivo. O pico negativo se explica pelo fato da velocidade da carga (veículo) ser maior que o campo girante no instante em que o motor começa a desacelerar.

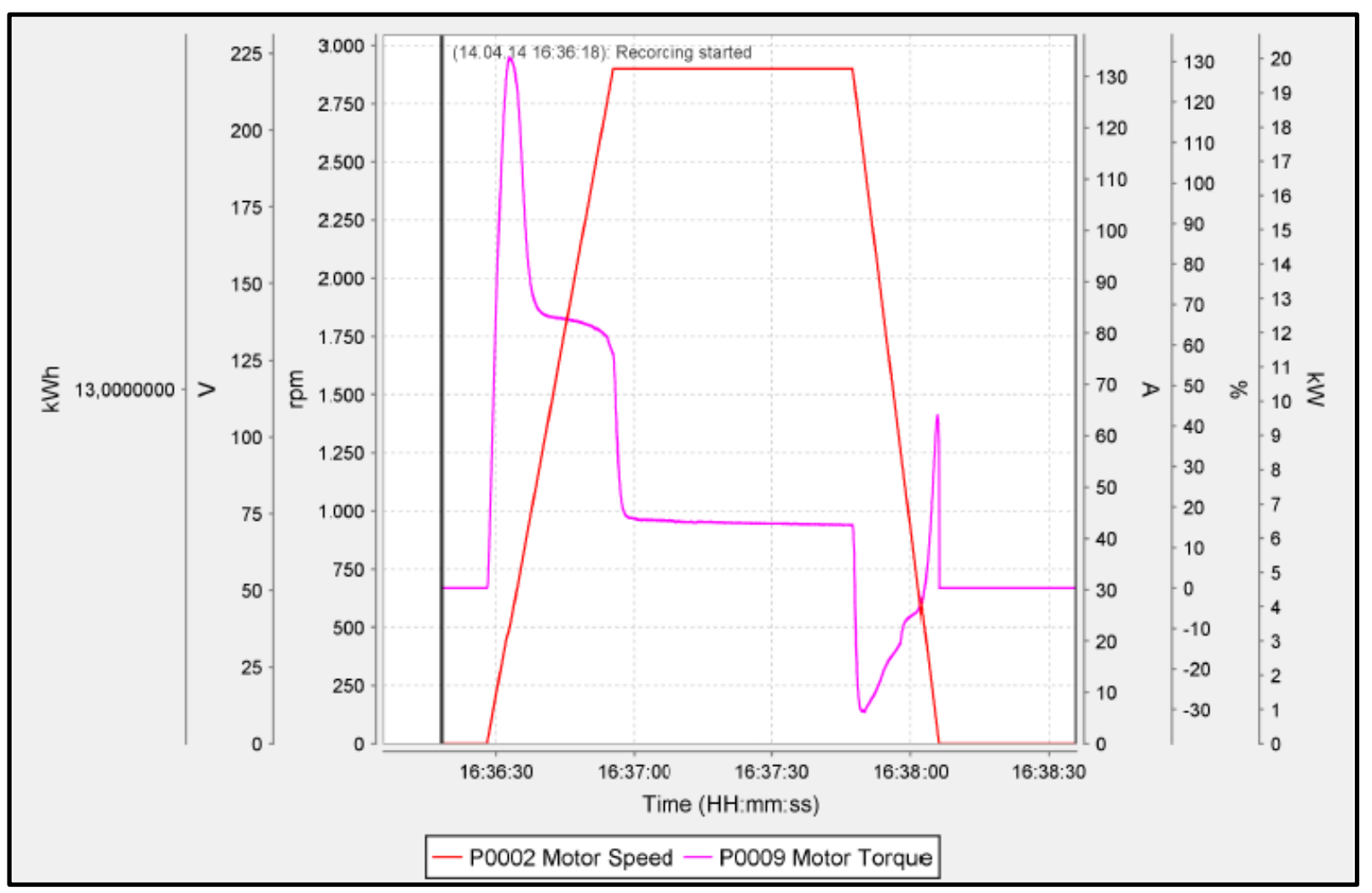

Figura 45 - Ciclo D SAE J227a - Velocidade e Torque no Motor

Fonte: Super Drive G2

A figura 46 demonstra o comportamento da tensão e da corrente elétrica durante o ensaio. As duas curvas, corrente, A (vermelho) e tensão,V (azul) tem comportamentos distintos durante o ensaio. A corrente no momento da partida tem crescimento rápido nos primeiro 5 segundos, em seguida tem dois degraus de queda até manter sua estabilidade abaixo da corrente nominal do motor, 84 A. Volta a subir no instante em que o motor começa a desacelerar e tem uma queda aproximadamente linear nos últimos 10s de funcionamento do 
motor. A tensão tem um crescimento aproximadamente linear no momento da partida até atingir o estado estacionário. No instante em que o motor começa a desacelerar ele tem uma pequena elevação seguida de queda até a velocidade nula. Cabe destacar que a amplitude da tensão manteve-se por todo o ensaio dentro do limite de amplitude, o que é garantido pelo inversor de frequência.

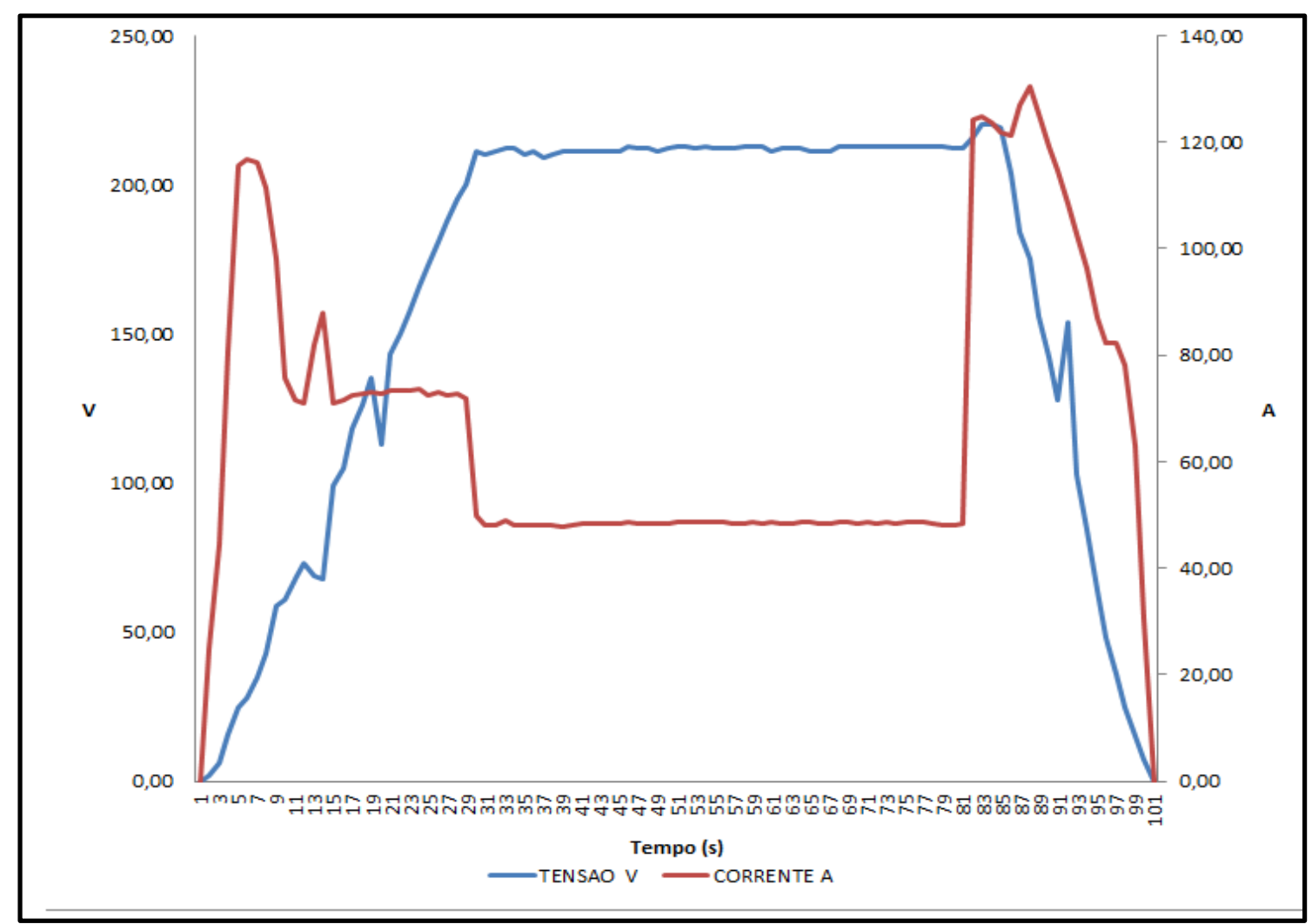

Figura 46 - - Ciclo D SAE J227a - Tensão e Corrente no Motor

Fonte: O autor, 2013.

A figura 47 apresenta os valores, a cada segundo, da potência elétrica consumida que é resultado do produto a cada segundo dos valores de tensão e corrente. Destaque para o instante em que o motor começa a desacelera e há uma elevação dos valores de tensão e de corrente. 


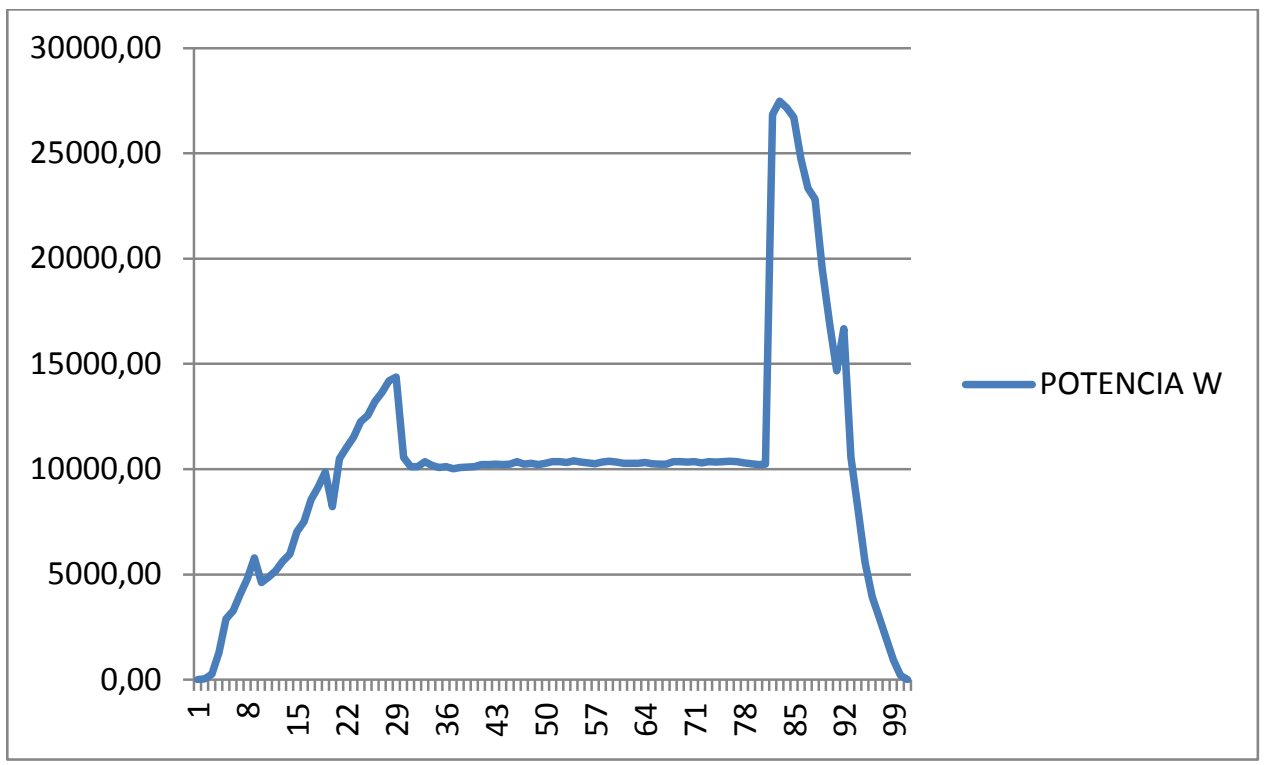

Figura 47 - Ciclo D SAE J227a - Potência de saída no Motor

Na figura 48 são apresentadas as curvas de potência elétrica instantânea a cada segundo e o somatório destes valores. A curva vermelha é a integral do consumo.

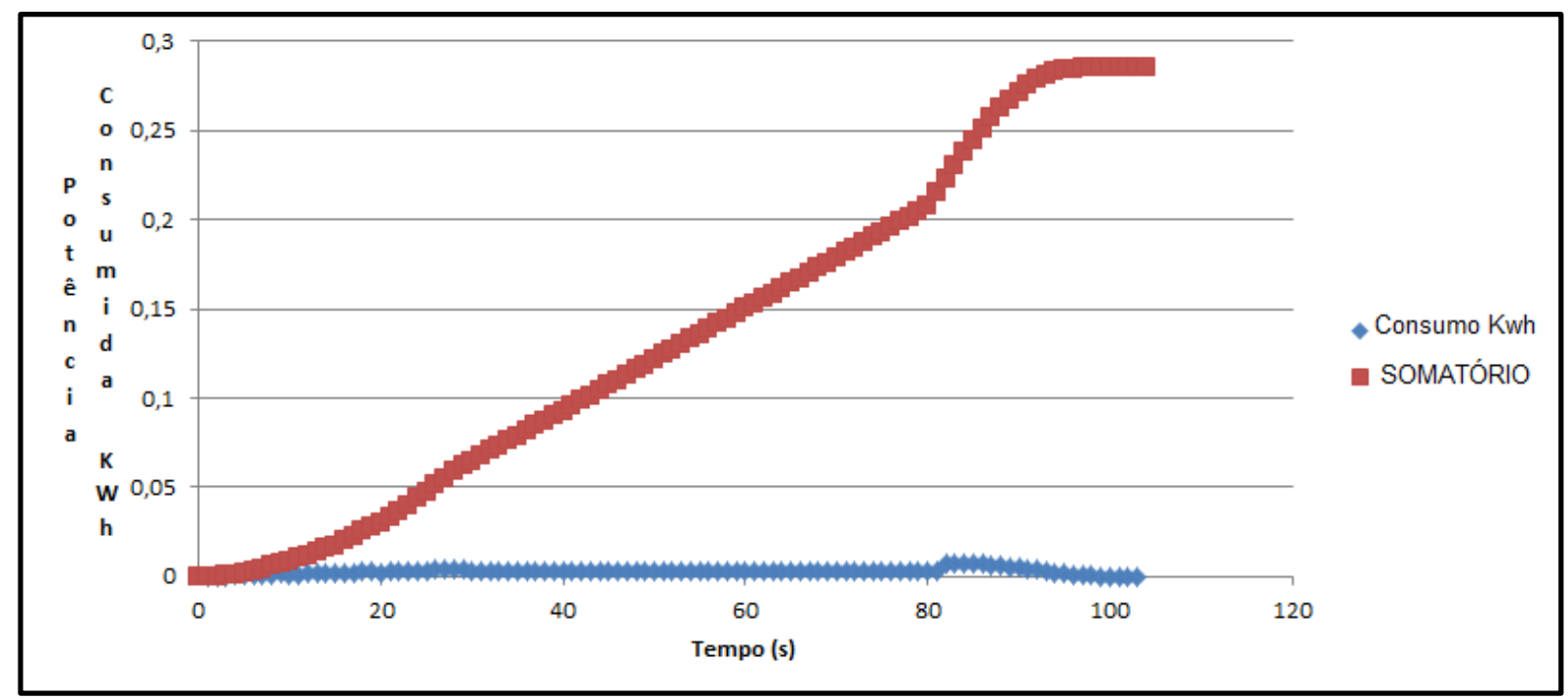

Figura 48 - Ciclo D SAE J227a - Potência consumida no Motor

Na tabela 16 estão dispostos os valores obtidos durante o ensaio através do Ciclo SAE J227a-D com informações do programa do inversor, do monitoramento da temperatura do motor elétrico e das informações da instrumentação do dinamômetro. 
Tabela 16 - Dados obtidos no Ciclo D

\begin{tabular}{|l|l|c|c|c|}
\hline Dados & Unidade & Mínimo & Média em Regime & Máximo \\
\hline Velocidade do Motor & RPM & 0 & 2900 & 2900 \\
\hline Corrente do Motor & Amper & 0 & 48,6 & 130 \\
\hline Tensão no Motor & Volts & 0 & 212 & 220 \\
\hline Torque no Motor & $(\%)$ & -30 & 16,3 & 130 \\
\hline Potência de Saída & $\mathrm{Kw}$ & 0 & 7,5 & 19,7 \\
\hline Potência na Roda & $\mathrm{Nm}$ & 0 & 130 & 85 \\
\hline Temp Mancal Diant & ${ }^{\circ} \mathrm{C}$ & 31 & 54 & 66 \\
\hline Temp Estator & ${ }^{\circ} \mathrm{C}$ & 30 & 45 & 43 \\
\hline Temp Mancal Tras & ${ }^{\circ} \mathrm{C}$ & 30 & 35 & 85 \\
\hline
\end{tabular}

Fonte: O autor, 2013.

Neste ciclo a velocidade máxima solicitada foi de $72 \mathrm{~km} / \mathrm{h}$, o que permitiu usar a quinta marcha. As leituras demonstraram o bom desempenho do equipamento com a ocorrência de uma pico de corrente de aproximadamente 130 amperes, mas dentro com uma duração aceitável de acordo com os limites definidos pelo fabricante.

Para avaliação do comportamento das variáveis observadas é importante destacar três momentos distintos nos ensaios: a rampa de aceleração, o funcionamento em estado estacionário e a rampa de desaceleração.

Durante a rampa de aceleração que foi de um instante t0 até a velocidade máxima que o ciclo determina, picos de corrente e torque tiveram destaque, o que chama a atenção para experimentar outras funcionalidades do inversor de frequência de modo a atenuar estas curvas que irão refletir em mais autonomia de energia, uma vez que a proposta inicial da conversão é que o veículo tenha aplicação urbana o que certamente implica em várias paradas e saídas em um curto espaço de tempo e também mais conforto na condução do veículo.

Durante o funcionamento em estado estacionário, com velocidade máxima constante, todo o conjunto tem um comportamento muito satisfatório com destaque para o rápido aumento de temperatura na parte do mancal motriz do motor elétrico, lembrando que o motor tem 9 sensores pt 100, sendo três junto ao mancal motriz, três junto ao estator e três juntos ao mancal traseiro. Por razões diversas, neste trabalho não será possível finalizar todo o sistema de arrefecimento, foi feito apenas um monitoramento da temperatura do motor através de seus 
sensores o que não comprometeu o funcionamento do motor, pois os ciclos de ensaio foram em torno de 2 minutos cada.

Já no funcionamento em rampa de desaceleração, o inversor que havia sido programado para garantir que o motor saísse de uma velocidade máxima para a velocidade nula, houve detecção de picos de corrente e torque acompanhados de picos de tensão próximos aos valores do funcionamento em estado estacionário, neste instante o torque passa a ser negativo, o que significa que a máquina elétrica deixou de ser um motor e passou a ser um gerador. $\mathrm{O}$ inversor permite implementar a frenagem regenerativa de modo a melhorar a autonomia do sistema. O mesmo comportamento foi observado no ciclo SAE J227a-C, mostrado no item 6.3.2.

O consumo de potência durante o ensaio no ciclo D foi de $0,285 \mathrm{KWh}$ e a distância percorrida foi de aproximadamente 1586 metros o que demonstra que para percorrer $50 \mathrm{~km}$ seriam necessários aproximadamente $9 \mathrm{Kwh}$. De acordo com Borba (2008), os veículos no Brasil rodam diariamente, em média, entre 25 e $50 \mathrm{~km}$, assim as informações até aqui obtidas na plataforma seriam úteis para se propor o uso de um banco de baterias (com ou sem o auxílio de um super capacitor), contabilizar o uso da frenagem regenerativa, de um sistema de ar condicionado e de outros sistemas acessórios. 


\section{CONCLUSÕES E SUGESTÕES}

\subsection{CONCLUSÕES}

Os primeiros ensaios da plataforma objetivaram avaliar a funcionalidade da estrutura sem aprofundamento em detalhes específicos relativos à conversão, à programação, ao comportamento dinâmico do motor, do veículo ou do dinamômetro. Entretanto cabem tecer alguns comentários sobre o motor, o inversor, o comportamento térmico do motor e o torque no motor elétrico baseado nos ensaios realizados.

$\mathrm{O}$ motor refrigerado a água, um protótipo do fabricante, que no caso aproveitou o sistema de arrefecimento original do veículo, se mostrou confiável e eficiente, ou seja, este tipo de motor parece ser bastante adequado aos veículos elétricos, se comparados com outros sem esse tipo de refrigeração.

O monitoramento da temperatura é feito através dos 09 sensores tipo PT-100 distribuídos, entre mancal dianteiro, mancal traseiro e enrolamento. Nos ensaios realizados, pôde-se observar uma elevação de temperatura rápida nas três partes monitoradas com nítida diferença no mancal dianteiro, que é o mancal motriz. Isto indica a necessidade de um aprofundamento maior para compreender suas causas e implementar melhoras ao conjunto.

Os ensaios com os ciclos SAE J227a para veículos elétricos permitiram obter dados mais qualitativos da operação do veículo convertido.

Os resultados do ensaio do ciclo J226a D mostra que o consumo de energia foi de 0,285 KWh para uma distância percorrida de aproximadamente 1586 metros. Para percorrer $50 \mathrm{~km}$ seriam necessários aproximadamente $9 \mathrm{Kwh}$. A comparação deste consumo com modelos similares já convertidos demonstra que há espaço para aperfeiçoamento.

O inversor usado é bastante robusto e tem uma grande variedade de funcionalidades. Explorar mais profundamente as potencialidades de programação abre a perspectiva de melhorar os resultados. Outra possibilidade é o uso de frenagem regenerativa, isto pode ser observado na variação da corrente no instante em que a velocidade do motor sai do regime estacionário e o torque passa a ser negativo, indicando que a velocidade da carga é maior que a do rotor. Neste instante há escorregamento negativo significando que o rotor da máquina gira na mesma direção do campo magnético girante do estator, mas com uma velocidade superior. Este é o momento em que a máquina elétrica passa a ser um gerador e pode-se 
aproveitar a frenagem regenerativa através do barramento DC do inversor. O aproveitamento da energia de frenagem regenerativa pode aumentar a autonomia do veículo elétrico.

Existem grandes desafios a serem vencidos na direção de se disseminar a informações sobre mobilidade elétrica, mas também existem oportunidades para a pesquisa e o desenvolvimento tecnológico.

A plataforma se insere num ambiente altamente propício, pois serve para avaliar desempenho e consumo de energia em veículos elétricos sob diversos aspectos. Essa funcionalidade terá papel fundamental na formação de estudantes de engenharia e no desenvolvimento de projetos acadêmicos para mobilidade elétrica.

A proposta da plataforma como um instrumento de avaliação e desenvolvimento, não pretende determinar o caminho definitivo para a solução de todos os problemas hoje existentes, mas propõe contribuir com desenvolvimento de alternativas para o futuro.

\subsection{SUGESTÕES PARA FUTUROS TRABALHOS}

Várias são as sugestões que poderão ser seguidas no intuito de aproveitar todas as possibilidades que a plataforma oferece.

A partir das informações levantadas nos ensaios pode-se dimensionar e instalar um banco de baterias no veículo com avaliação das diversas tecnologias de baterias como chumbo ácido, chumbo carbono, sódio, ions de lítio, bipolares e até mesmo, a implementação de outro sistema de transmissão.

Junto à plataforma é possível desenvolver uma bateria virtual por meio de ferramentas computacionais de modo a permitir a simulação da tecnologia, as dimensões e a potência dos acumuladores a serem usados no veículo convertido. Além disso, pode-se escolher o ciclo de ensaio a ser adotado.

Pode-se ainda, projetar um sistema de arrefecimento adequado às necessidades do motor refrigerado a água, com possíveis reduções de peso e diminuição do arrasto aerodinâmico através do redimensionamento da entrada de ventilação frontal e do projeto de um novo radiador. 
O inversor de frequência tem diversas funcionalidades que podem ser exploradas na plataforma. Por exemplo, o aproveitamento da frenagem regenerativa e a escolha de outras ferramentas de programação já disponíveis no equipamento, as quais poderão ser aplicadas tanto no veículo convertido neste trabalho, quanto em outros projetos.

É possível desenvolver toda uma estrutura de gerenciamento, coleta, tratamento, armazenamento e análise dos dados oriundos do dinamômetro.

Pode-se desenvolver um novo ciclo de ensaios para ser usado na plataforma que leve em conta questões especificas da região de Brasília em diferentes regimes de uso. 


\section{BIBLIOGRAFIA}

BASOTTI, M. R. Eletricidade; instalações industriais. Sapucaia do Sul: Centro de Educação Profissional SENAI de Eletromecânica, 2001.

BNDES, Veículos elétricos: aspectos básicos, perspectivas e oportunidades, Bernardo Hauch Ribeiro de Castro e Tiago Toledo Ferreira Data: 09/2010

BORBA, B. S. M. C., 2008. Metodologia de Regionalização do Mercado de Combustíveis Automotivos no Brasil. Tese de M.Sc., PPE/COPPE/UFRJ. Brasil.

BOTTURA, C. P.; BARRETO, G. Veículos Elétricos. Campinas: UNICAMP, 1989.

CARNEIRO, F. S. P. Projeto e desenvolvimento de um sistema de controle eletrônico de injeção direta GNV em veículos movidos à gasolina/álcool. Dissertação de Mestrado. Brasília: UnB, 2011.

CHAN, C. C.; BOUSCAYROL, A.; CHEN, K. Electric, hybrid, and fuel-cell vehicles: architectures and modeling. IEEE Transactions on Vehicular Technology, v. 59, n. 2, p. 589598, feb. 2010.

CHAN, C. C.; CHAU, K. T. An overview of power elwectronics in electric vehicles. IEEE Transactions on Industrial Electronics, v. 44, n. 1, p. 3-13, feb. 1997.

CORREIA, A. P. Processador embarcado em lógica reconfigurável para o controle de movimentação de veículo de passeio. Dissertação de Mestrado. Brasília: UnB, 2007.

COSTA, W. Metodologia para conversão de veículos equipados com motores a combustão interna para tração elétrica... Dissertação de Mestrado. Rio de Janeiro: UERJ, 2009.

DE PAULA, G. T. Análise e projeto de máquinas síncronas com ímã permanente.

Dissertação de Mestrado. São Carlos: EESC, 2011.

DYNOmite Dynamometer. Disponível em: http://www.land-and-sea.com/dyno-max-dataacquisition-software/dyno-max.htm Acesso em: 10/02/2014

EHSANI, M.; RAHMAN, K. M.; TOLYIAT, H. A. Propulsion system design of electric and hybrid vehicles. IEEE Transactions on Industrial Electronics, v. 44, n. 1, feb. 1997. 
EMADI, A.; LEE, Y. J.; RAJASHEKARA, K. Power electronics and motor drives in electric, hybrid electric, and plug-in hybrid electric vehicles. IEEE Transactions on Industrial Electronics, v. 55, Issue 6, p. 2237-2245, jun. 2008.

FITZGERALD, A.; KINGSLEY, C.; UMANS, S. Electric machinery. New York: MacGrawHill, 1991.

Finep 2013. Disponível em: http://www.finep.gov.br/imprensa/noticia.asp?cod_noticia=3135, acesso em 18/05/2014.

Fraunhofer IWES. Disponlivel em: 〈http://www.iwes.fraunhofer.de/de/profil.html〉 Acesso em: 20/02/2014.

GUEDES, M. V. Máquinas elétricas - Resenha Histórica. Cidade do Porto: Universidade do Porto, 2003.

H. Ben Brown, Illah Nourbakhsh, Chris Bartley, Jennifer Cross, Paul Dille, Josh Schapiro, Alex Styler; Robotics Institute, Carnegie Mellon University, Pittsburgh, Pennsylvania 15213 ChargeCar Community Conversions: Practical, Electric Commuter Vehicles Now!

HAICAL, R. C. Desenvolvimento de um sistema de controle de dinamômetros para testes em motores de combustão interna. Dissertação de Mestrado. Porto Alegre: UFRS, 2009. http://autocenter.blog.br/wp-content/uploads/2013/10/tracao-na-dianteira.jpg> acesso em $16 / 02.2015$ http://autocenter.blog.br/wp-content/uploads/2013/10/tracao-na-dianteira.jpg > acesso em $16 / 02.2015$

http://www.ufrrj.br/institutos/it/deng/varella/Downloads/IT154_motores_e tratores/apresenta/ sistema\%20de\%20arrefecimento.pdf > acesso em 16/02.2015

http://ecatalog.weg.net/files/wegnet/WEG-guia-de-especificacao-de-motores-eletricos50032749-manual-portugues-br.pdf. >. Acesso em: 1 mai. 2013.

INVERSOR de Frequência. WEG, [200-]. Disponível em:

$<$ http://ecatalog.weg.net/files/wegnet/WEG-cfw11t-inversor-de-frequencia-para-controle-de- 
motores-aplicados-em-veiculos-eletricos-10002020360-manual-portugues-br.pdf> . Acesso em: 1 mai. 2013.

James Larminie and John Lowry

KIEHNE, H. A. Battery technology handbook. 2. ed. [S.1.]: Marcel Dekker, 2003.

LARMINE,J, Lowry, J., Electric Vehicle Technology Explained, John Wiley \& Sons, Ltd, England, 2003.

LINEN, D.; THOMAS, R. The handbook of batteries. Oli3. ed. New York: MacGrawHill, 2004.

Mecatrônica Atual, http://www.mecatronicaatual.com.br/artigos/1213-os-inversores-defrequncia , acessado em $12 \mathrm{dez} 2013$.

MOHAN, N.; UNDELAND, T. M; ROBBINS, W. P. Robbins. Power electronics: converters, applications, and design. 3. ed. [S.1.]: Wiley, 2002.

NICOLAZZI, L.C., Rosa, E. da, Leal, L.C.M. Introdução à modelagem quase-estática de veículos automotores de rodas. Brasil: Publicação interna do GRANTE - Depto de Engenharia Mecâncica da UFSC. 2001.

PEREIRA, J. C. Dinamômetros hidráulicos. Perfectum, 4 abr. 1999. Disponível em: <http://www.perfectum.eng.br/energia/dinos1.html > . Acesso em: 20 fev. 2013.

PERES, L. A. P; HORTA, L. A. N.; LAMBERT-TORRES, G. Influências sobre os sistemas de energia com a introdução dos veículos elétricos na sociedade. In: CONGRESSO LATINOAMERICANO GERAÇÃO TRANSMISSÃO DE ENERGIA ELÉTRICA, 3. 1997, Campos do Jordão, SP. Anais... Campos do Jordão, SP, 1997.

PORTAL FATOR BRASIL, http://www.revistafatorbrasil.com.br/ver_noticia.php?not=56441 acesso em 12 dez. 2013.

Quim, Nelson - Desenvolvimento de uma Metodologia Aplicada ao Sistema de Arrefecimento Veicular. Dissertacao de Mestrado- Escola Politecnica da Universidade de Sao Paulo, Departamento de Engenharia Mecanica, Sao Paulo, 2007 
RENAULT 19 CLUB. Sistema de arrefecimento (figura). r19club, [200-]. Disponível em: <http://r19club.com/arrefecimento-do-motor/limpeza-do-radiador/>. Acesso em: $12 \mathrm{dez}$. 2013.

SHERIF, S. Gindy; Force and Torque Measurement, A Tecnology Overview Part II - Torque. Volume 9, Experimental Techniques, Julho 1985.

TOLIYAT, H. A.; KLIMAN, G. B. Handbook of electric motors. 2. ed. [S.1.: s.n.], 2004.

Velloso, J. P. R. (Coord.). (2010). Estratégia de implantação do carro elétrico no

Brasil. Rio de Janeiro: Instituto Nacional de Altos Estudos (INAE), Cadernos

Fórum Nacional 10.

VIANA, J. C. O. Plataforma de testes de desempenho veicular para dinamômetros inerciais em linguagem LAB VIEW. Santo André, SP: Faculdade de Tecnologia de Santo André, 2011. $\square 2003$ ISBN: 0-470-85163-5

WEG.NET. Disponível em: http://www.weg.net/br/Produtos-eServicos/Drives/Softwares/SuperDrive-G2-Software-de-Parametrizacao-de-Drives Acesso em: 15/12/2013.

XUE, X. D. et al. Selection of electric motor drives for electric vehicles. 2008, Australasian Universities Power Engineering Conference (AUPEC'08).Proceedings..., AUPEC, 2008. 
APENDICE A - PROJETO ELÉTRICO DA BANCADA

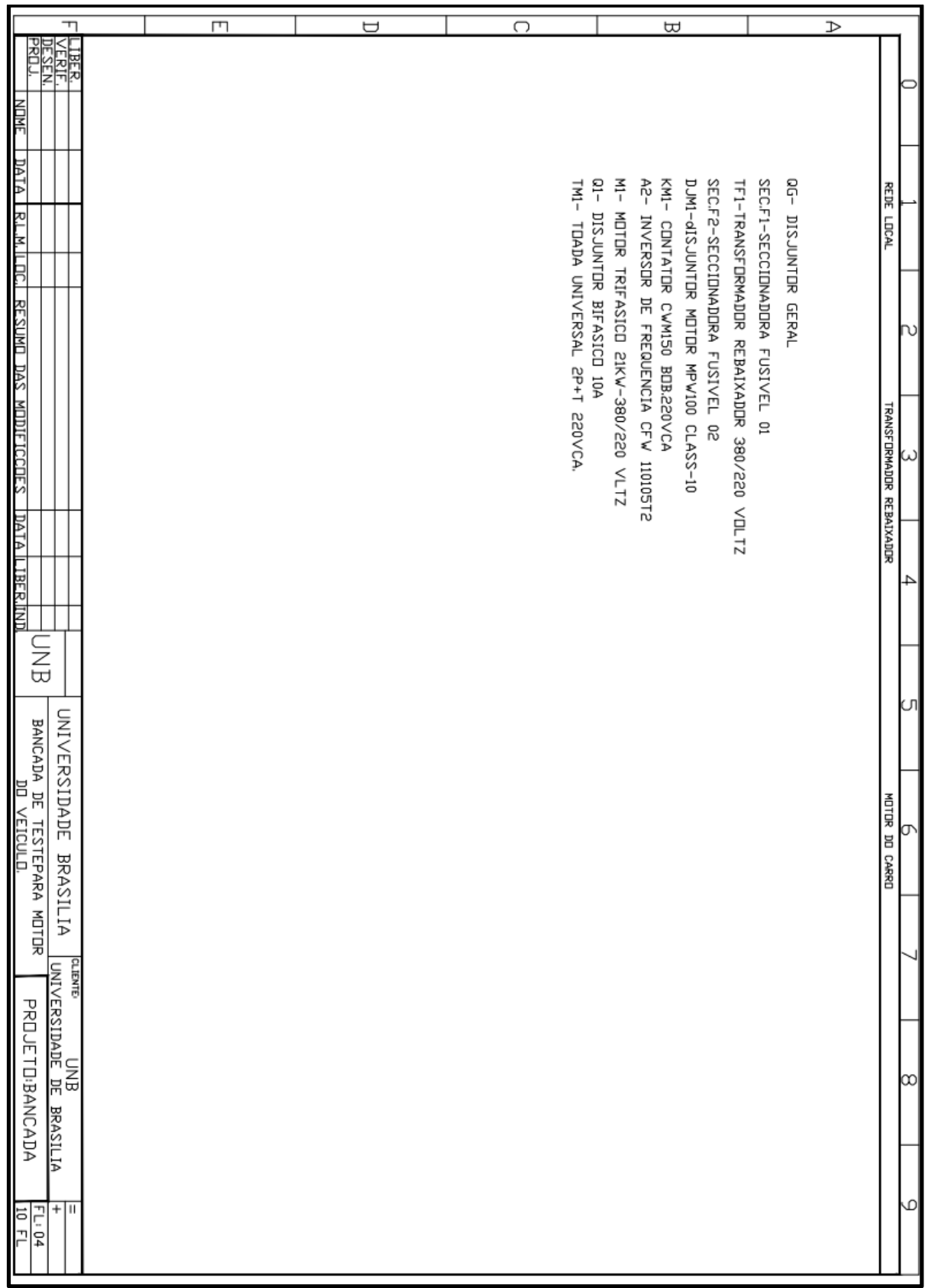




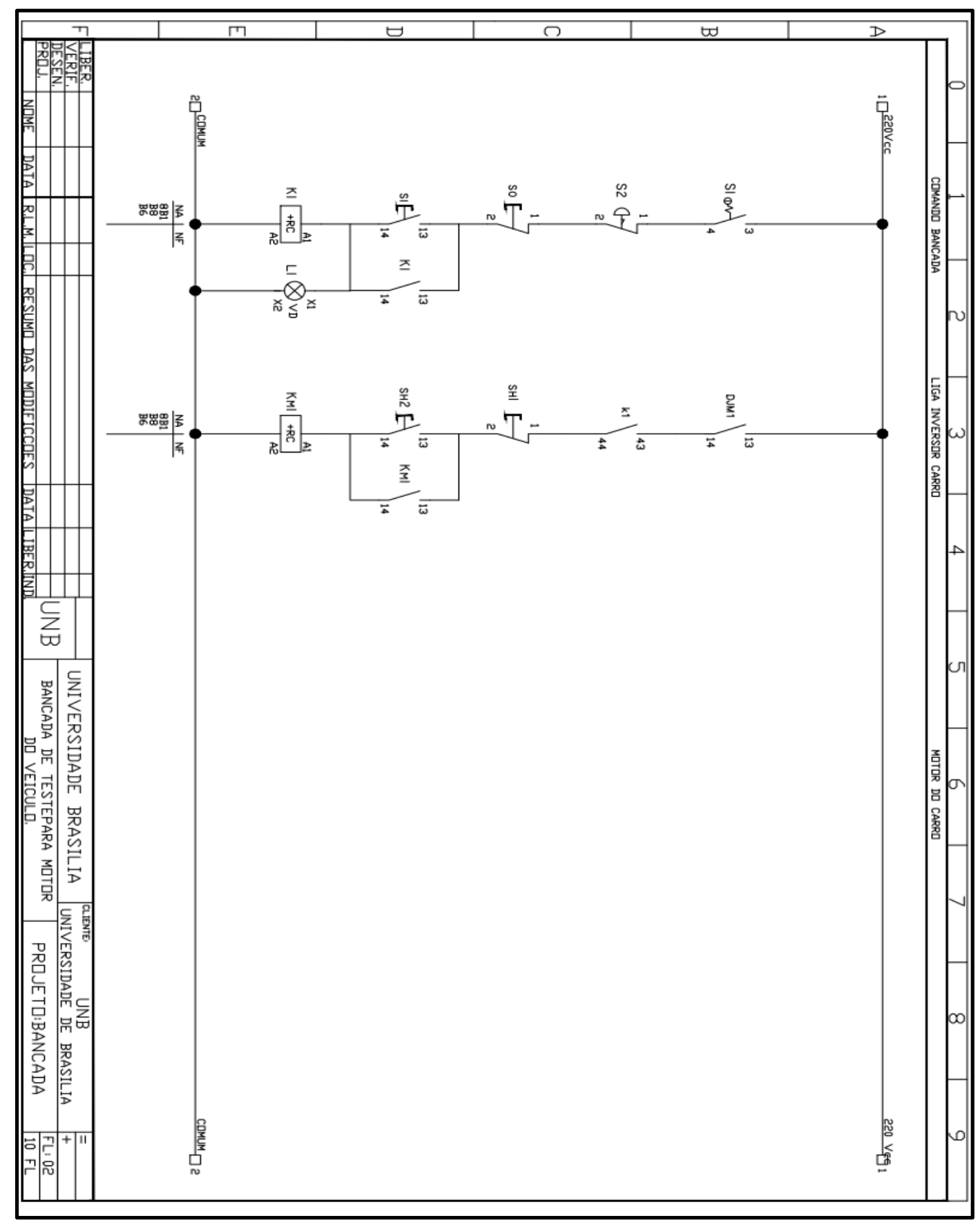




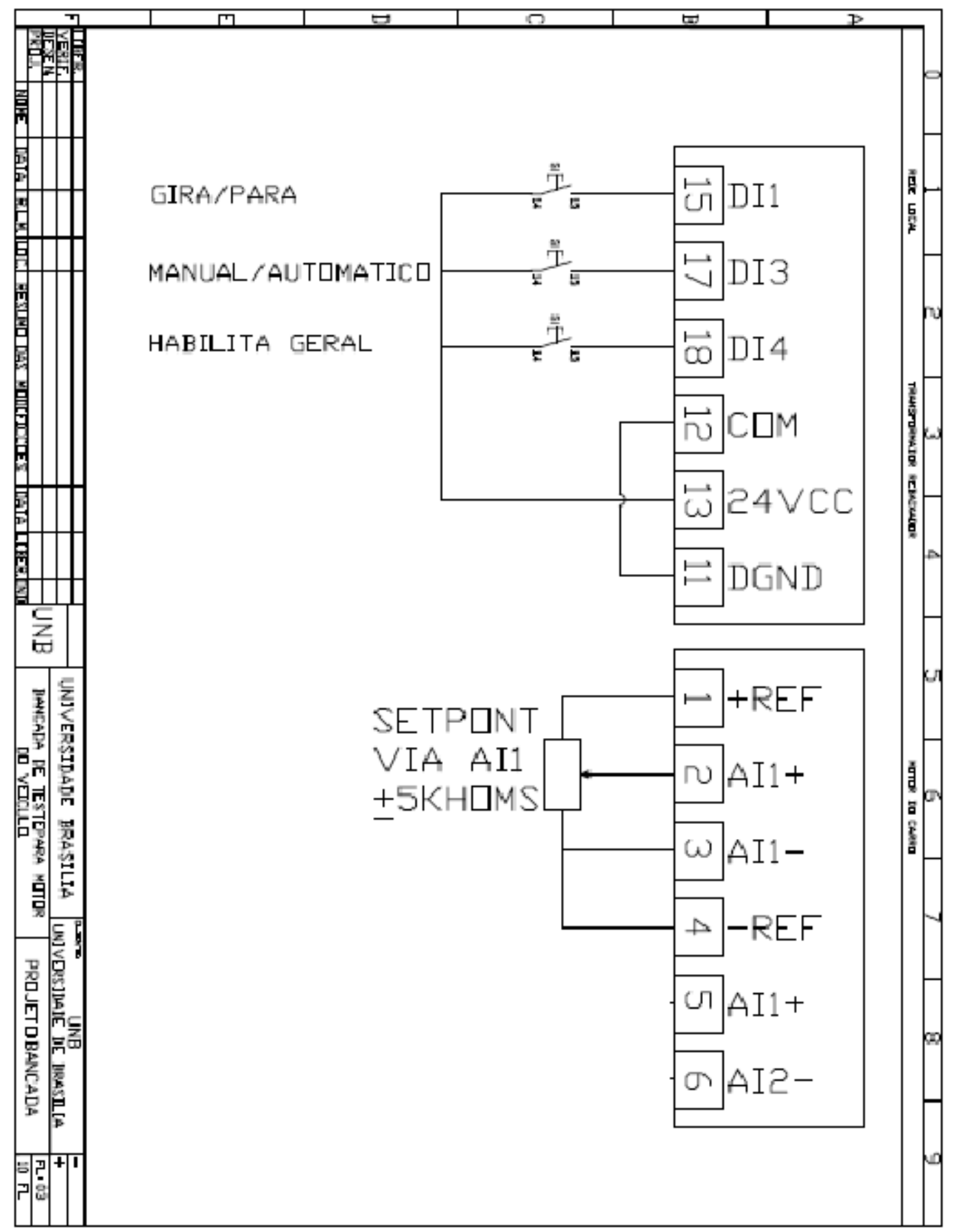




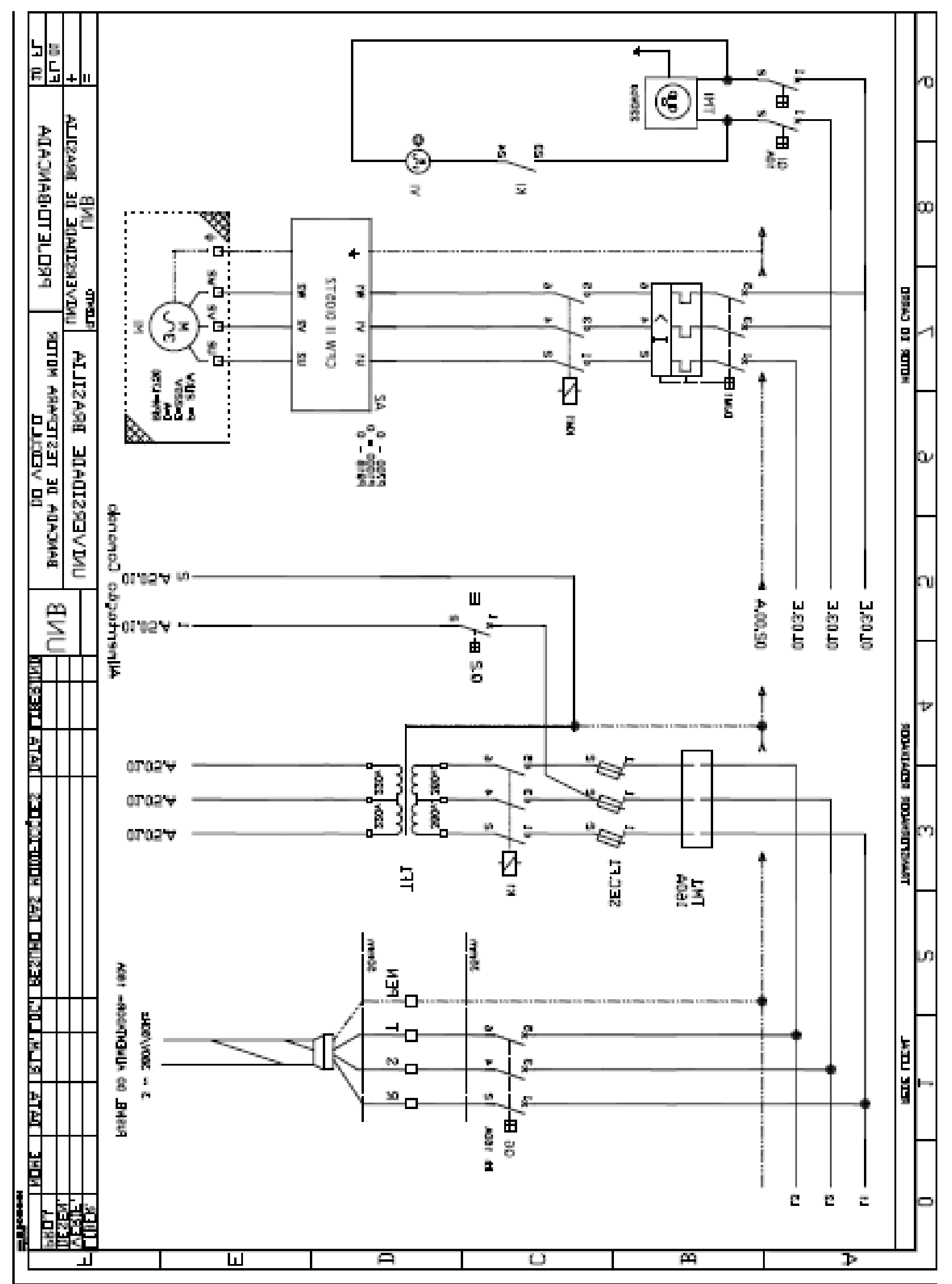


APENDICE B - PROJETO ESTRUTURAL DA BANCADA

VISTA FRONTAL ESTRUTURA

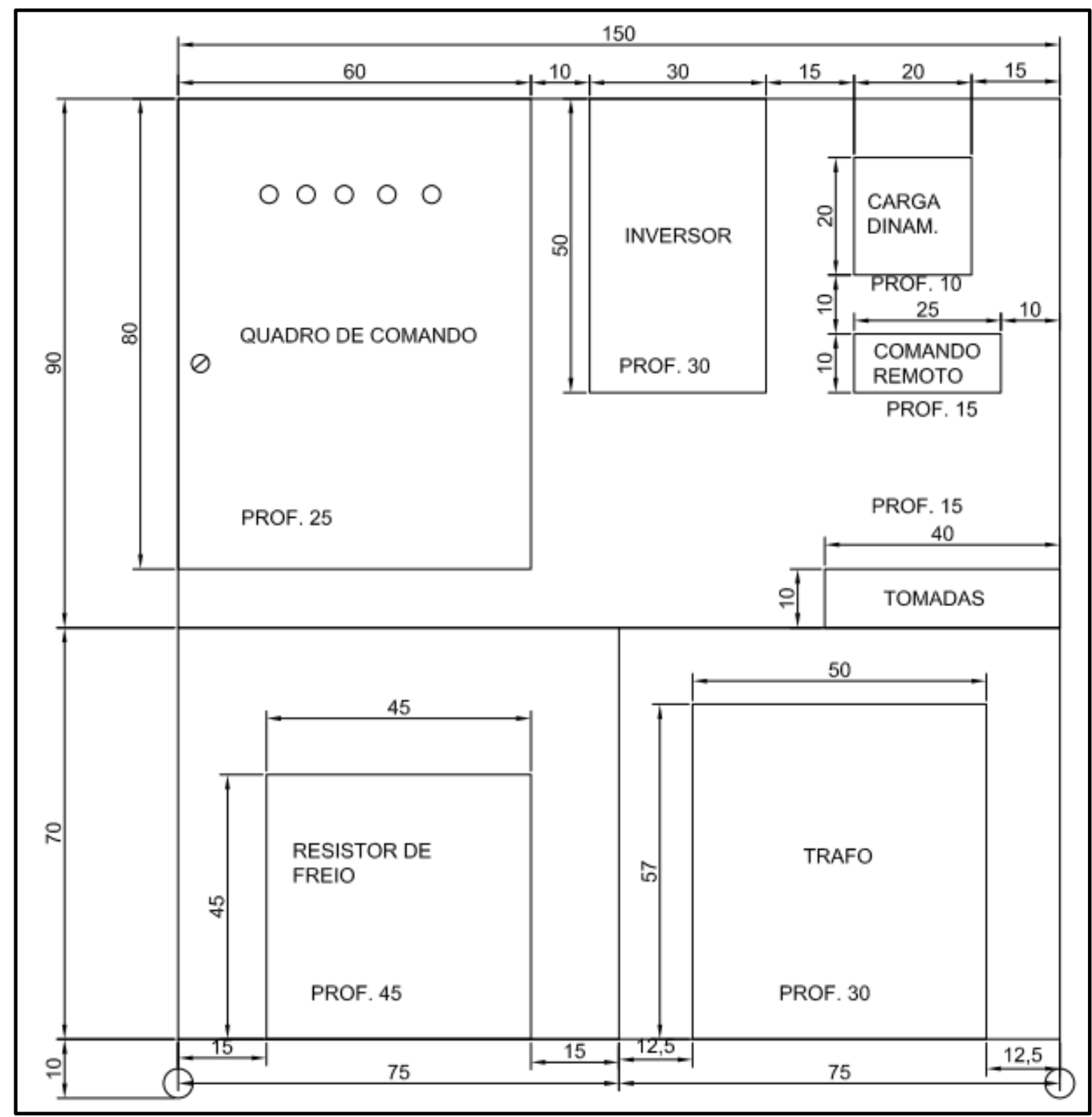


VISTA LATERAL ESTRUTURA

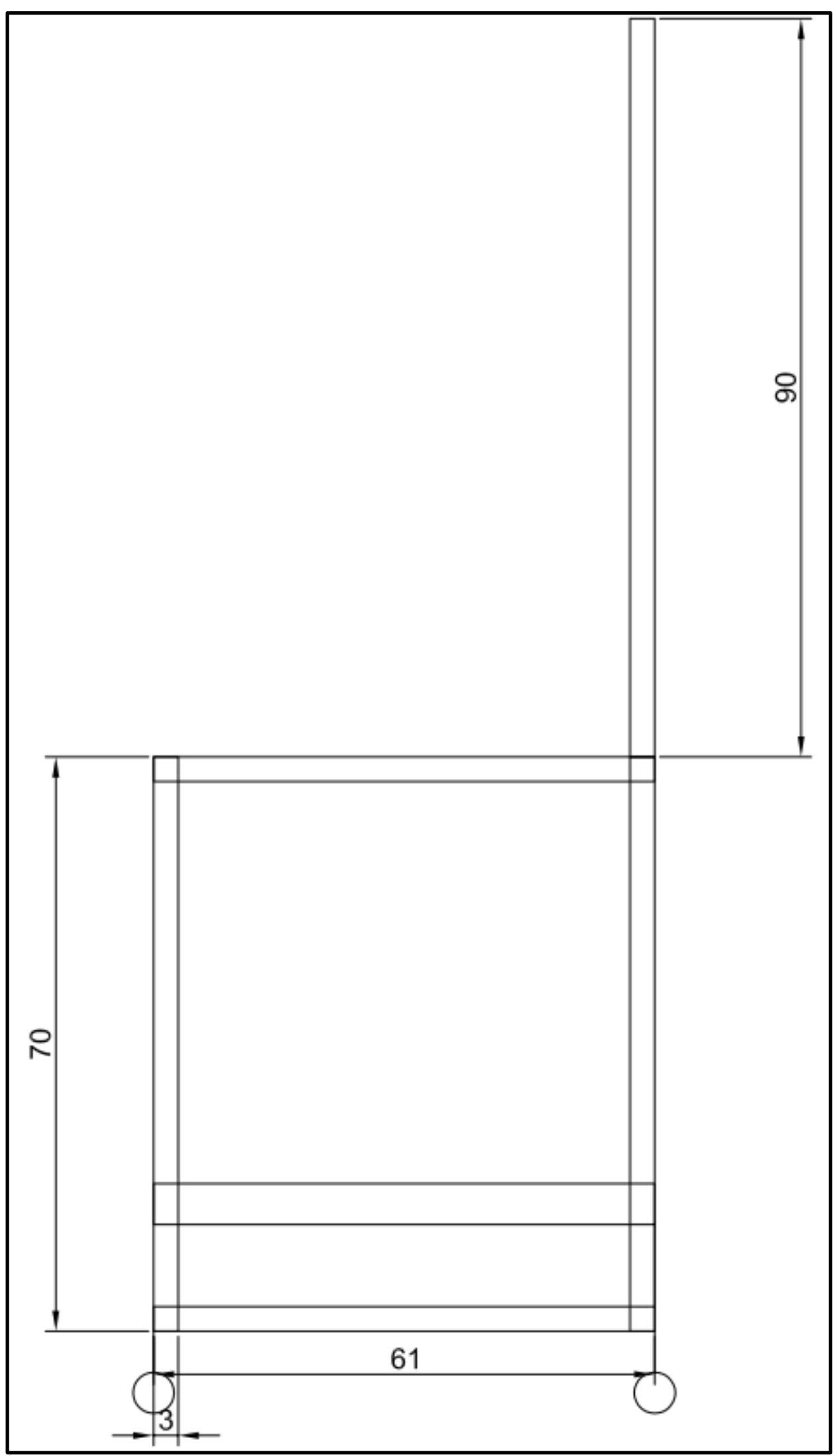


APENDICE C - PROJETO DO FLANGE DE ACOPLAMENTO

DISTANCIADOR

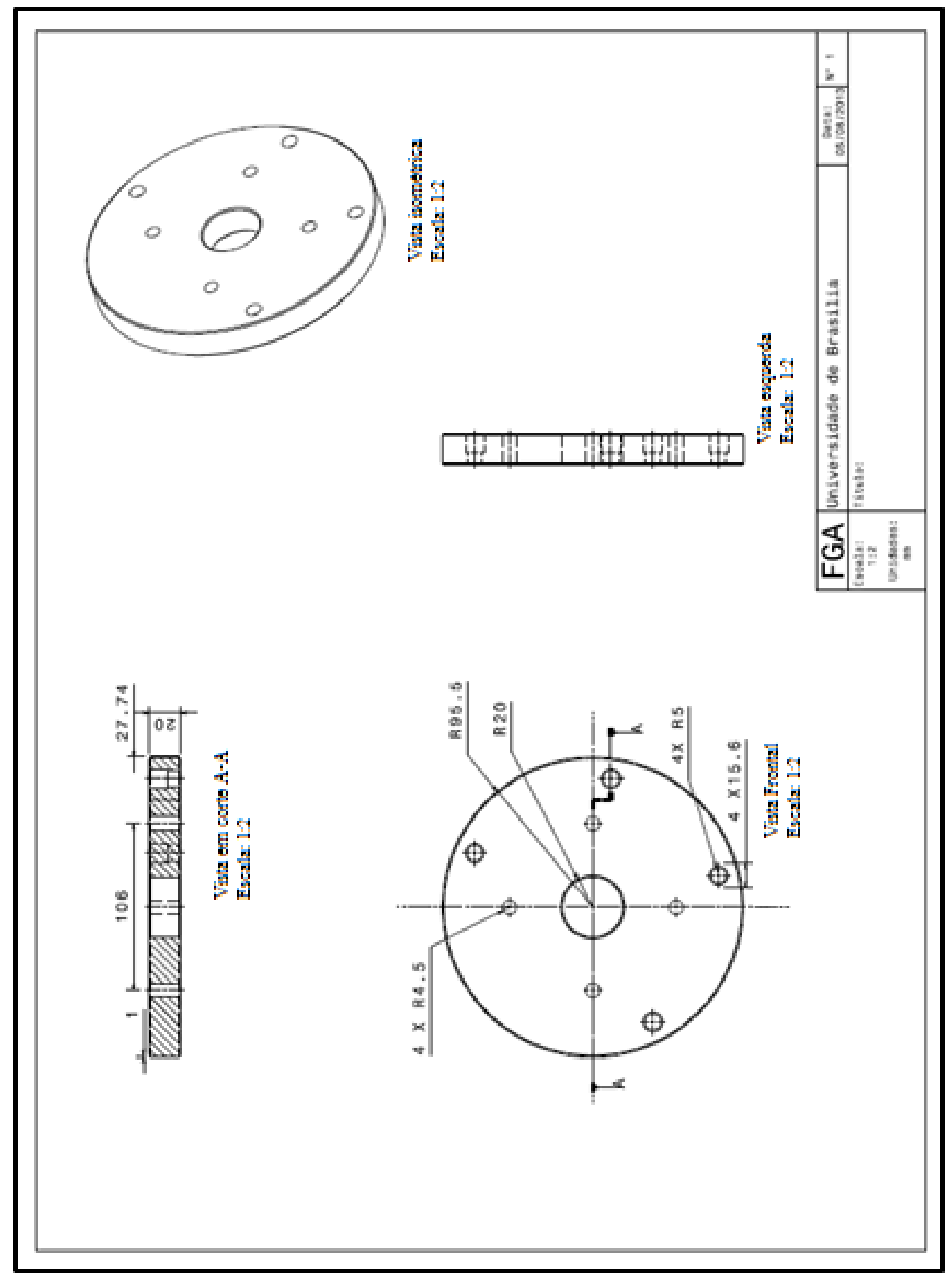


FLANGE

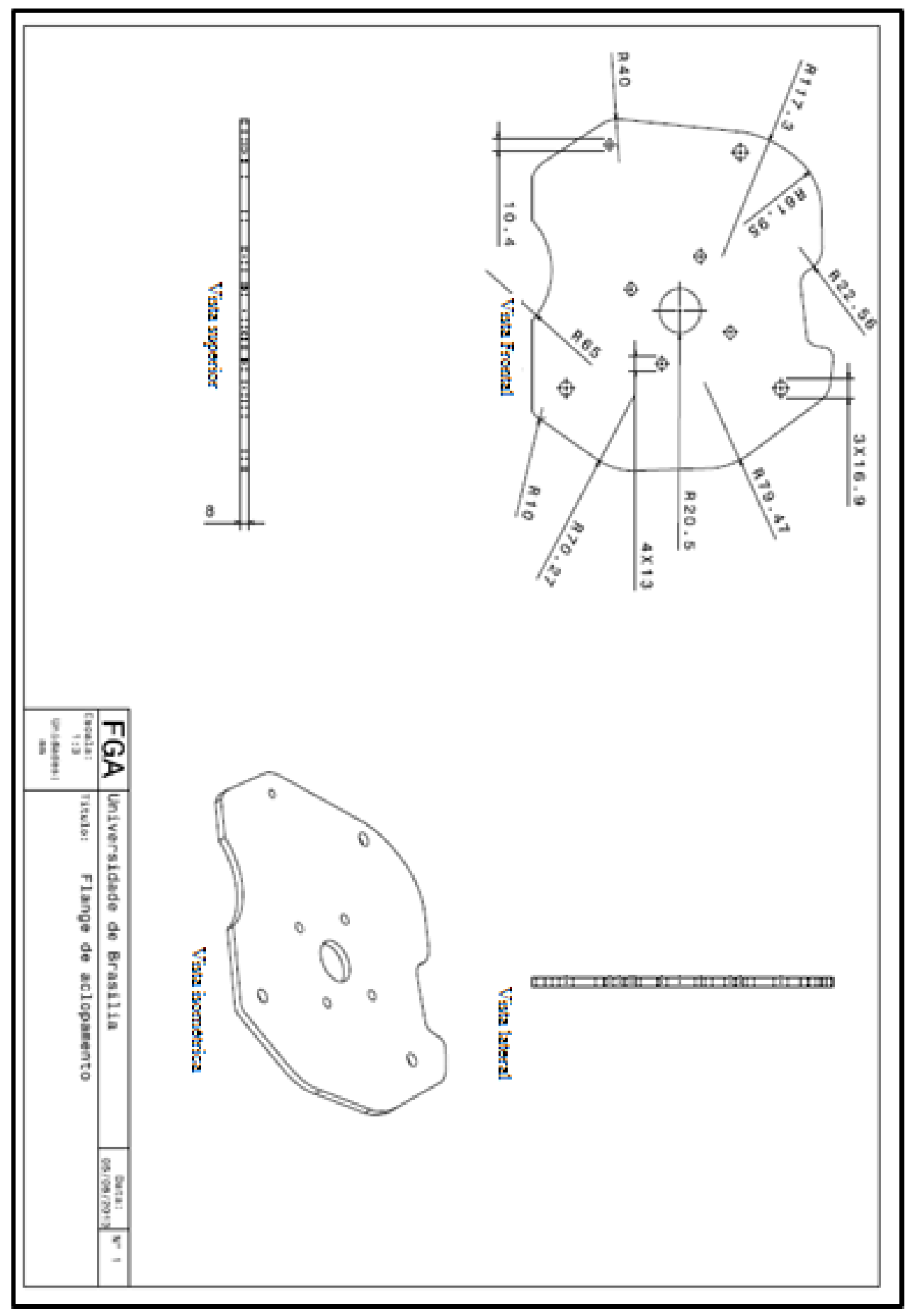


ACOPLAMENTO

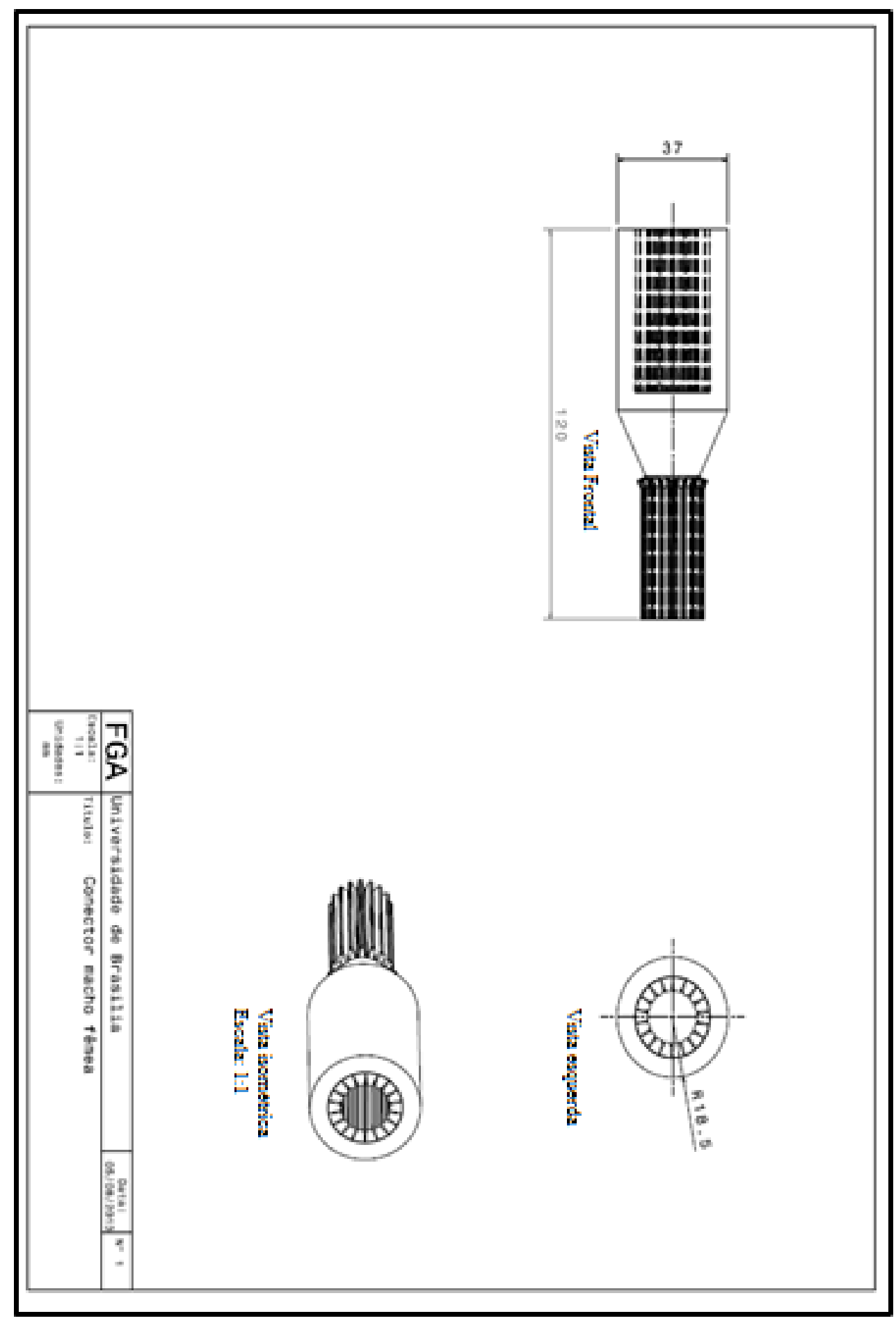

